\title{
Family-centered care for hospitalized children aged 0-12 years: a systematic review of qualitative studies
}

\author{
Robin Watts, AM, PhD, MHSc, BA, DipNEd, RN, FACN ${ }^{1}$ \\ Huaqiong Zhou, MCN, BSc, $\mathrm{RN}^{1}$ \\ Linda Shields, MD, PhD, FACN ${ }^{2}$ \\ Marjory Taylor, BAppSc, BA ${ }^{3}$ \\ Ailsa Munns, RN, RM, CHN (Cert), BSc (Nursing), M (Nursing), FACN ${ }^{4}$ \\ Irene Ngune, $\mathrm{MPH}, \mathrm{BScN}^{5}$
}

1. School of Nursing and Midwifery, Curtin University, Western Australia; West Australian Centre for Evidence Informed Healthcare Practice (WACEIHP): a Collaborating Centre of the Joanna Briggs Institute

2. Tropical Health Research Unit, School of Nursing and Nutrition, James Cook University, Townsville; and School of Medicine, The University of Queensland, Queensland

3. Library and Information Service, Child and Adolescent Health Service, Princess Margaret Hospital, Western Australia

4. School of Nursing and Midwifery, Curtin University, Western Australia

5. Department of National Drug Research Institute, Curtin Health Innovation Research Institute, Curtin University, Western Australia

Corresponding author:

Robin Watts

r.watts@curtin.edu.au

\section{Executive summary}

\section{Background}

The foundation for a family-centered approach to pediatric health care is the belief that a child's emotional and developmental needs, and overall family wellbeing are best achieved when the service system supports the ability of the family to meet the needs of their child by involving families in their child's care. There are a range of potential benefits and difficulties associated with the provision of family-centered care, e.g. role negotiation, parental expectations in regard to participation in their child's care, and issues relating to power and control. Currently, however, there is limited systematic information on how the principles of family-centered care are implemented in the delivery of care to the hospitalized child and their family, and the impact on the family and the health care providers.

Watts et al. Family-centered care for hospitalized children aged 0-12 years: a systematic review of qualitative 


\section{Objective}

To synthesize the existing qualitative evidence on family and/or health providers' experience of family-centered models of care for hospitalized children aged 0-12 years (excluding premature neonates).

\section{Inclusion criteria}

\section{Types of participants}

Hospitalized children aged 0-12 years (but excluding premature neonates), their family and/or health providers.

\section{Phenomenon of interest}

The phenomenon of interest for this review was family and/or health providers' experience of family-centered models of care for hospitalized children. Only studies that provided clear evidence that the family and/or child were actively involved in the planning and/or delivery of health care during the child's hospitalization were included.

\section{Types of studies}

Studies using qualitative methodologies, e.g. phenomenology, grounded theory, and descriptive qualitative designs, together with studies employing mixed methods (only qualitative data being extracted) were considered for the review.

\section{Types of outcomes}

The two outcomes of interest were the participants' experiences and their perceptions related to the care provided within a model of family-centered care. For each of these "umbrella" outcomes a number of specific outcomes were detailed, e.g. for "experience" - parental comfort with their degree of involvement in their child's care, and for "perceptions" - the extent of commitment of health providers to implementing this model of care.

\section{Search strategy}

The search strategy sought to identify both published and unpublished studies. There was no limitation by publication language and databases were searched from inception to 2013.

\section{Methodological quality}

Papers identified by the screening process as being potentially eligible for inclusion were assessed by two independent reviewers for methodological quality using standardized critical appraisal tools from the Joanna Briggs Institute Qualitative Assessment and Review Instrument (JBI-QARI).

\section{Data collection}

Data were independently extracted from the 14 included studies by two reviewers using the standardized data extraction tool from JBI-QARI. The data extracted included specific details about the populations, study methods and findings of significance to the review objective. 


\section{Data synthesis}

Study findings were pooled using JBI-QARI. Findings were rated according to their level of credibility and categorized based on similarity in meaning. These categories were then subjected to a meta-synthesis to produce a comprehensive set of synthesized findings.

\section{Results}

Fourteen studies were included in the review. Six synthesized findings from the experiences and perspectives of parents and three from those of health care providers were derived from a total of 29 categories and 84 findings. There were common themes in the synthesized findings from both groups, e.g. the value of parents being with their child and continuing the "mothering" role, recognition of the barriers to implementing family-centered care. However role negotiation around parents' participation could prove difficult or non-existent. Parents' experiences with staff in terms of interpersonal skills and communication were both positive and negative.

\section{Conclusions}

This review confirms that parents wish to participate in their hospitalized child's care. However the nature and extent of this involvement has to be negotiated on an individual family basis. Although it appears that nurses and other health care professionals have a reasonably good understanding of the elements that constitute family-centered care, incorporation of these into practice is not uniform. The difficulty is that the changes required challenge professional power.

\section{Keywords}

family-centered care; care of children in hospital; pediatric care

\section{Background}

(Some sections of the Background are adopted or adapted from the Cochrane systematic review of family-centered care in hospitalized children 0-12 years $(2007)^{1}$ and its update $(2012)^{2}$ and are published here with permission from Wiley. A more detailed discussion of the development of the concept of family-centered care is available in these publications.)

Family-centered care is defined as "a way of caring for children and their families within health services which ensures that care is planned around the whole family, not just the individual child/person, and in which all the family members are recognized as care recipients". ${ }^{3}\left({ }^{p .1318)}\right.$ A number of related terms have been used to describe the attributes of family-centered care; ${ }^{4}$ these include partnership-in-care, ${ }^{5}$ parental involvement, ${ }^{6}$ nurse-parent partnership, ${ }^{3}$ parental participation, ${ }^{7}$ and care-by-parent. ${ }^{8,9}$

Until at least the late 1950s, hospitals worldwide tended to be bleak places for children. It was believed that visits from parents would inhibit effective care ${ }^{10}$ and were detrimental to the child, who would become distressed when the parents left. ${ }^{11,12}$ Researchers began to suggest, however, that children whose parents did not visit them suffered acute emotional trauma which may have long-term psychological consequences in adolescence and adulthood. ${ }^{13,14}$ In 1956, the British government commissioned a report into the welfare of children in hospital. The resulting report, the Platt Report ${ }^{15}$, recommended that visiting be unrestricted, that mothers stay in hospital with their child, and that 
training of medical and nursing staff should promote understanding of the emotional needs of children. The process of change has resulted in a humanization of pediatrics ${ }^{16,17}$ although the movement from traditional approaches to health service delivery to the involvement of families in all aspects of the planning, delivery, and evaluation of health care has been slow. ${ }^{18,19}$ The foundation for a family-centered approach to pediatric health care is the belief that a child's emotional and developmental needs, and overall family wellbeing, are best achieved when the service system diligently supports the ability of the family to meet the needs of their child by involving families in the plan of care. , $20,21^{2}$

\section{Potential advantages and disadvantages of family-centered care}

There are a range of potential benefits and difficulties associated with the provision of family-centered care. One is the degree to which the family is seen as responsible for the child's care. In a number of cases family-centered care has been interpreted as care that is led by parents, who are regarded as expert in the care of their child, with the health professional acting as a consultant. ${ }^{6,7}$ However, in recent years research has indicated that parents feel that they are being made totally responsible for the care of their child and the expectations of them, at least initially, are too great. In Coyne and Cowley's words: "the pendulum has swung too far in the other direction" ${ }^{8(\mathrm{p} .893)}$ They are much more comfortable working in a truly collaborative way with health-care providers. ${ }^{9}$

The hospitalization of a child, whether planned or unplanned, is stressful for even the most wellorganized and functional family. ${ }^{22}$ The significant adjustments to both parent and health care provider roles when a child is hospitalized may result in understandable levels of stress. ${ }^{23} \mathrm{~A}$ number of studies report that the stress levels of parents are reduced by being more informed and involved in caring for their children while in hospital. ${ }^{24}$ However, on the other hand, involvement can lead, at least in the short term, to additional stress or anxiety for both the parents and child. Parents may feel that they are expected to provide input into the care of their child beyond their expectations or capabilities, or are given more information than either the child or the family is ready to hear.

Professional communication and the provision of information are key elements in the success or otherwise of family-centered care. In their study of parents' information needs in relation to their chronically ill children, Hummelinck and Pollock ${ }^{25}$ highlighted the double-edged nature of information in these situations: there is a delicate balance between the positive effects and the potentially negative impact, i.e. it can increase anxiety. Information was also a theme identified in Ygge's ${ }^{26}$ study of nurses' perceptions of parental involvement in hospital care. Not only did the nurses indicate that it was important to discuss with the parents what information was important to them at each stage, but that the information provided to them must be the same from all health personnel.

Family-centered care also requires specifically designed or adapted facilities. Verwey et al. ${ }^{27}$ found that attending to the parent's physical needs was an important component in reducing stress. Ensuring aspects such as comfortable sleeping arrangements, nutritious food and time to relax away from the ward made a family's experience a more positive one.

Researchers have also reported challenges when trying to implement changes which would result in meaningful family involvement in the care of their hospitalized child. Health care providers have reported a lack of adequate education in relation to understanding and implementing the concept of family-centered care in a practice situation, as well a lack of shared understanding of, and commitment to, family-centered care among all health professionals and families., ${ }^{9,18,28-30}$

Watts et al. Family-centered care for hospitalized children aged 0-12 years: a systematic review of qualitative studies (C) the authors 2014 doi:10.11124/jbisrir-2014-1683 
Darbyshire ${ }^{16}$ suggested that family-centered care was a wonderful idea, but difficult to implement effectively. A number of authors agree, questioning family-centered care as a model of care ${ }^{9,31}$ and the ethics of continuing a model which is becoming increasingly described as ineffective are under scrutiny. ${ }^{32}$

\section{Standard models of health care for children}

Family-centered care is regarded as different to the "standard" models of care used in pediatric health services. In the latter, often the health care provider plays a major role in assessing and formulating a plan of care, based upon the perceived needs of the child and/or family. In the medical or standard model of health care, the health care worker plans care around the child's illness and treatment needs, and the family is generally expected to comply with treatment recommendations. ${ }^{33}$

\section{Implementation of family-centered care}

It is expected that the development, implementation and outcomes of family-centered models of care may differ according to the population and setting in which the models are applied. For example, the needs and outcomes for families with a chronic condition who experience long hospital stays may differ from those of families of a previously healthy young child who is admitted for a treatment procedure. Also, older children may have a greater awareness and understanding of the reasons for their hospitalization. Therefore, models of care may reflect increased participation of the child in their hospital care. However, even if the processes of family-centered care are seen as making a difference and advantageous in their own right, reliable reassurance that they result in more good than harm should be sought. Currently there is limited systematic information on how these principles have underpinned changes in health care practice and service delivery when a child is hospitalized, and the effect of family-centered approaches on child and family outcomes and health service delivery. ${ }^{20}$

Several systematic reviews have been conducted on the effectiveness of family-centered care but very few studies have met the inclusion criteria. Consequently no conclusions could be drawn from these reviews. Shields, et al. ${ }^{1}$ conducted a Cochrane review of the effectiveness of family-centered care including randomized controlled trials (RCTs), before and after and cohort studies from 1960 to 2004. An update of the Cochrane review was also undertaken by Shields, et al. ${ }^{2}$ in 2012 which examined RCTs only from 2004 to December 2011. Furthermore, Shields et al. ${ }^{34}$ conducted a systematic review of quasi-experimental studies on the topic published between 2004 and December 2011.

A literature review by Shields ${ }^{3}$ on the topic examined qualitative studies published between 1990 and 2004. Eleven research articles were included in the review. Three main themes emerged: role negotiation, parental expectation of participation in their child's care, and issues relating to power and control. The findings revealed that family-centered models of care were influenced by negotiation between staff and families, and roles of both parents and staff within interactions that took place in hospital during a child's admission. Corlett and Twycross ${ }^{35}$ also reviewed evidence on the negation of parental roles within family-centered care. The results revealed that family participation in their child's care was hindered by nurses' lack of communication and limited negotiation. Nurses did not routinely negotiate with parents even though nurses had clear ideas on what nursing care parents could be involved in. In addition, Coyne ${ }^{36}$ conducted a review of both research and literature from 1993 to 2007 on children's participation at the health service level. It was found that children were rarely involved in the decision-making process and their views were rarely sought nor acknowledged.

Watts et al. Family-centered care for hospitalized children aged 0-12 years: a systematic review of qualitative studies (C) the authors 2014 doi:10.11124/jbisrir-2014-1683

Page 208 
To date, there has not been a formal systematic review published on the qualitative evidence of family-centered models of care.

This systematic review aims to examine any qualitative studies from 2004 to December 2012 that address the experiences and /or perceptions related to family-centered care by families and/or health care providers. The objectives, inclusion criteria and methods of analysis for this review were specified in advance and documented in a protocol. ${ }^{37}$

\section{Review question/objective}

The question which led to the review was: what are the experiences of families and health providers of family-centered models of care for hospitalized children?

The aim of the review was to synthesize the existing qualitative evidence on family and/or health providers' experiences of family-centered models of care for hospitalized children aged 0-12 years (excluding premature newborns).

The specific objectives were to identify the experience of family-centered models for hospitalized children aged 0-12 years (excluding premature neonates) from the perspective of:

- Families

- Health care providers.

\section{Inclusion criteria}

\section{Types of participants}

This review considered studies that include hospitalized children aged 0-12 years (but excluding premature neonates), their family and/or health providers.

Definitions:

- Child/children: throughout this review, the term "child" or "children" is used to include all newborn infants, babies and children up to the age of 12 years being cared for in hospital, and all parts of hospitals that provide a service to children. The definitions of childhood can vary, and age limits are arbitrary. For the purpose of this review the National Library of Medicine's medical subject headings were used to define the age cut-off of 12 years. However, neonates born prematurely and who are patients in a neonatal intensive or special care nursery have been excluded as their requirements for family-centered care, and the ethics and philosophies of care around this particular group are different to those in a ward/unit where full term infants and children are nursed. ${ }^{38}$ Studies about adolescents have also been excluded for similar reasons.

- Families: throughout the review the following definition of "family" was applied, i.e. a basic social unit having as its nucleus two or more persons, irrespective of age, in which each of the following conditions are present:

- the members are related by blood, marriage, adoption or by a contract which is either explicit or implied;

- the members communicate with each other in terms of defined social roles such as mother, father, wife, husband, daughter, son, brother, sister, grandfather, grandmother, uncle, aunt; and 
- they adopt or create and maintain common customs and traditions. This definition has been modified from Nixon's original definition ${ }^{39}$ to allow for inclusion of significant others who do not usually cohabit with the family.

Healthcare providers involved in caring for hospitalized children: for the purposes of the review, the term "health care provider" was used to describe any health professional involved in the care of hospitalized children.

\section{Phenomenon of interest}

The review considered studies that investigated family and/or health providers' experience of familycentered models of care for hospitalized children. Only studies that provide clear evidence that the family and/or child were actively involved in the planning and/or delivery of health care during the child's hospitalization were considered for inclusion. For the purposes of the review, the minimum criteria for active involvement included evidence of collaboration between health carers and the family and/or child in the planning and/or delivery of care as soon as possible after admission or during the preadmission period.

The elements of family-centered care can be grouped into three clusters as follows: ${ }^{5}$

- Family as a constant

- Culturally responsive

- Supporting family individuality.

"Family as a constant" can be evidenced by:

- Recognizing family strengths

- Parent/professional collaboration

- Needs-based family support

- Flexible provision of health care

- Sharing information with families.

Examples of how the family-centered care model can be "culturally responsive" include, but are not confined to, the family receiving culturally competent health care and respect being shown for family diversity.

"Supporting family individuality and need for different types of family support" can be demonstrated by:

- Respecting family coping methods

- Providing emotional support

- Family-to-family support

- Attending to developmental needs of the child and family. 


\section{Exclusions:}

Parent-to-parent support studies where there is no clear evidence of collaboration between the family and/or child and health care provider in the planning and/or delivery of care.

Parental presence only studies which include parents being present to support the child during health care procedures such as routine examinations, anesthetic induction, venipuncture and postanesthetic recovery or bereavement team/protocols. Parental presence on these occasions without any framework of ongoing collaboration, communication, etc. does not meet the holistic principles on which family-centered care is based.

\section{Types of outcomes}

This review considered studies that include but are not confined to the following outcome measures:

- Experience of family-centered care models of care from family and/or health providers:

- clarity of role expectations

- $\quad$ nature of relationships between family and health care providers

- parental comfort with their degree of involvement in the child's care

- content, consistency, timeliness, level of understanding and degree to which information provided meets parent's needs

- family members' stress and anxiety levels

- adequacy of facilities for family's needs

- health care providers' support for the collaborative model of care

- adequacy of health care providers' knowledge and skills, and availability of time to implement family-centered care.

- Perceptions of family-centered care models of care by family and/or health providers:

- $\quad$ how the experience is viewed

- degree to which expectations are being or have been met

- degree to which the model of care has been individualized to meet specific needs of families

- degree to which the model of care is implementable in actual operating contexts

- degree to which health care providers are committed to the model's implementation. 


\section{Types of studies}

The review considered qualitative research studies. Studies which adopted qualitative designs such as, but not limited to, phenomenology, grounded theory and qualitative approaches were initially only to be considered for inclusion. However, recognizing an increasing trend to conduct studies of mixed methods designs as well as the broader tradition in qualitative studies, studies with both a quantitative and qualitative focus were also included. It was intended that only the qualitative data from these mixed methods studies would be extracted.

\section{Search strategy}

The search strategy sought to identify both published and unpublished studies. There was no limitation by publication language and databases were searched from 2004 to 2013 . The year 2004 was selected as the starting point for the literature search in order to extend the search conducted by Shields ${ }^{3}$ for her prior literature review which covered qualitative studies on the topic conducted between 1990 and 2004.

A three-step search strategy was utilized in each component of this review. An initial limited search of MEDLINE and CINAHL was undertaken followed by analysis of the text words contained in the title and abstract, and of the index terms used to describe articles. A second search using all identified keywords and index terms was then undertaken across all included databases. Thirdly, the reference list of all identified reports and articles was searched for additional studies.

The databases searched included:

Medline

Embase

Psyclnfo

CINAHL

Sociological Abstracts.

The search for unpublished studies included:

Trove (Libraries Australia) for Australian Theses

Web of Science Conference Proceedings

Mednar.

Initial keywords used were: child/children, parent/s, health services, family-centered care/familycentered care. The search strategies are detailed in Appendix I.

\section{Methods of the review}

Articles identified with the search strategy were first assessed by reading the title and abstract. For abstracts written in languages other than English, health professional colleagues fluent in these languages translated and assessed the content of the abstract in conjunction with a reviewer. Full text articles were obtained for the studies deemed relevant in order to assess the degree of familycenteredness (Appendix II) and other inclusion criteria (Appendix III) by two independent reviewers. 
It was agreed that any disagreements between the reviewers that arose on this assessment would be resolved through discussion or, if necessary, by a third reviewer. As there was disagreement on some studies in respect to the rating of family centeredness a third reviewer was required.

\section{Assessment of family-centeredness}

The degree of family-centeredness was determined by a modified rating scale based on that developed by Trivette ${ }^{5}$ (Appendix II). These authors used the nine elements of family-centered care, as described by the Association for the Care of Children's Health, to develop 13 evaluation items that describe the features of family-centered care. These items are further grouped into three cluster groups (Cluster 1: family as a constant; Cluster 2: culturally responsive; Cluster 3: supporting family individuality) derived from an original cluster analysis by Trivette. ${ }^{5}$ The clusters were designed to be used to help describe the model of family-centered care for individual research studies.

A rating of 0 to 4 was applied to each of the 13 items of family-centered care, as follows:

0 . Article includes no evidence that the intervention either implicitly or explicitly was based on the element of family-centered care.

1. Article includes a minimal amount of implicit evidence that the intervention was based on the element of family-centered care.

2. Article includes numerous instances of implicit evidence that the intervention was based on the element of family-centered care.

3. Article includes a minimal amount of explicit evidence that the intervention was based on the element of family-centered care.

4. Article includes numerous instances of explicit evidence that the intervention was based on the element of family-centered care.

The maximum possible score is 52 . Two reviewers independently scored the study against the Family Centeredness Score Form (Appendix II). The scores from the two reviewers were averaged as the final score for the study.

One of three "degrees of family-centeredness" was assigned to each study assessed:

- A study with a score of 42 or more from a possible total of $52(80 \%)$ was considered as having a "high degree of family-centeredness",

- Those studies scoring between $50 \%$ and $80 \%$ were classified as having a "moderate degree of family-centeredness",

- Those studies scoring below $50 \%$ were classified as having a "low degree of familycenteredness".

Those studies with a family-centeredness score of less than $50 \%$ were excluded from the study.

\section{Assessment of quality}

Those studies that were classified as having either a high or moderate degree of "familycenteredness" and met the other screening criteria were then assessed by two independent reviewers for methodological validity prior to inclusion in the review using standardized critical appraisal instruments from the Joanna Briggs Institute Qualitative Assessment and Review Instrument (JBI-

Watts et al. Family-centered care for hospitalized children aged 0-12 years: a systematic review of qualitative studies (C) the authors 2014 doi:10.11124/jbisrir-2014-1683 
QARI) (Appendix IVa). ${ }^{40}$ The third reviewer was not required as differences were settled through discussion.

To facilitate inter-rater reliability, those involved in critically appraising the studies came to agreement on aspects of the wording of the appraisal criteria requiring clarification or interpretation. In respect to Question 1 it was agreed that if a study employed a generic qualitative approach, rather than a formal philosophically based qualitative methodology, the former would receive a 'Not applicable' rating.

For the second criterion it was agreed that the term 'methodology' would encompass study design congruent with the interpretive paradigm. The two questions ( $Q 7$ and $Q 9)$ addressing two related components of a criterion were the only other criteria which required discussion. If only one component was addressed in a study it was agreed that this would be noted on the standardized form. For the two mixed methods studies the assessment was confined to the qualitative aspect of the study.

\section{Data extraction}

Data were independently extracted from the 14 included studies by two reviewers using the standardized data extraction tool from JBI-QARI (Appendix IVb). ${ }^{40}$ The data extracted included specific details about the populations, study methods and findings of significance to the review question and specific objectives. The third reviewer was not required as there were no disagreements between the reviewers.

\section{Data synthesis}

Meta-synthesis of the qualitative findings was undertaken. This involved aggregation or synthesis of the findings to generate a set of statements that represented that aggregation. Each finding was assigned a level of credibility (JBI-QARI) (Appendix VI) and the findings assembled (Level 1 findings). They were then categorized based on similarity in meaning (Level 2 findings). These categories were then subjected to a meta-synthesis to produce a comprehensive set of synthesized findings (Level 3 findings) to be used as a basis for evidence-based practice.

Themes and subthemes constituted 'findings'. These were drawn from the results section of the studies. Only those findings that were supported by illustrations from participants' data were included.

The two primary reviewers, working together, examined all the extracted findings and grouped these into draft categories. The draft categories and their associated findings were then re-examined, discussed and refined two weeks later. The grouping of findings into categories was based on relatedness in terms of meaning. The synthesized findings were drafted by the primary author then discussed with the second reviewer for validation.

\section{Review results}

\section{Description of studies}

The initial literature search produced 18,528 records. After removal of 5,845 duplicates, a total of 12,682 papers with potential relevance to this review remained. From this total, 12,643 were excluded by reviewing the title and abstract, to leave 39 studies for detailed assessment against the eligibility criteria (Appendices II and III). This process excluded a further 24, leaving 14 studies for assessment of methodological quality against the JBI Critical Appraisal Checklist (Appendix IVa).$^{40}$ Only two of the 
full text articles retrieved for assessment for eligibility were in a language other than English (Spanish and Portuguese) and for which translation resources were available.

Of the 25 excluded studies 22 failed to meet the cut-off inclusion score for family-centered care. Five of these studies also failed to meet another inclusion criterion. Of the remaining three, one was excluded as the study was conducted in a neonatal intensive care unit and two included children over the age limit for the study (Appendix V).

(The reporting of two studies ${ }^{42,43 ; 44,45}$ involved two publications. These have been treated as one study but required two references each in Endnote.)

The 14 included studies (Appendix VI) were published over a 21-year period (1991-2013). Two were conducted in the 1990s and eight between 2003 and 2006.

Nine countries were represented in the review:

- United Kingdom ${ }^{16,41-46}$

- $\quad$ Australia ${ }^{30,44,45,47,48}$

- Canada $^{9,49}$

- Indonesia ${ }^{44} 45$

- $\operatorname{Iran}^{50}$

- South Africa ${ }^{27}$

- Sweden $^{26}$

- Thailand ${ }^{44,45}$

- $\operatorname{Spain}^{51}$

The study by Shields and King ${ }^{44,45}$ was an international study conducted in four countries. The only other study to report collecting data from different cultural groups was Teare and Smith ${ }^{46}$ whose participants were Caucasian and South Asian. In the latter case both groups were using the same health care system while the health care systems in Shields and King's study ${ }^{44,45}$ differed.

In respect to the phenomenon of interest all but one study addressed a number of aspects of the topic, although the emphasis on particular aspects varied. Callery and Smith ${ }^{41}$, however, confined their study to the exploration of role negotiation between parents and nurses. Of the 14 studies included in the review only two studies ${ }^{16,48}$ were rated as having a "high degree of family centeredness", scoring above 42/52. Four scored in the 34-36/52 range $\mathrm{e}^{9,30,44-46}$ while the remaining eight studies ${ }^{26,27,41-43,47,49-51}$ either just reached the cut-off score or were at the low end of "moderate degree of family-centeredness".

The three clusters of the rating tool ${ }^{5}$ varied in respect to the inclusion of their elements in the studies. Cluster 1 Family as a constant had the highest score compared to the other two clusters; in particular, two out of the six elements in this cluster "Family as a constant in child's life" and "Recognizing family strengths" were scored most frequently. In contrast, Cluster 2 Culturally responsive had the lowest score out of the three clusters, with the element 'Providing financial support' being the least frequently included element in the studies. This suggests that this element is not regarded as one that is feasible to implement. In Cluster 3 Supporting family individuality and need for different types of family support the most commonly included element was "Attending to the developmental needs of children and families". The remaining three elements featured minimally. 
PRISMA flow diagram

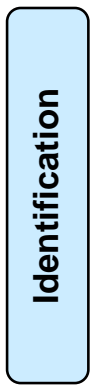

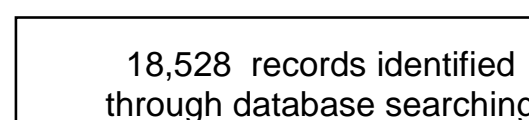
through database searching

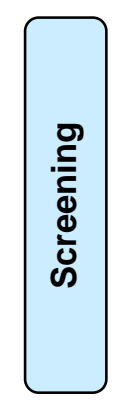

12,682 records after duplicates removed
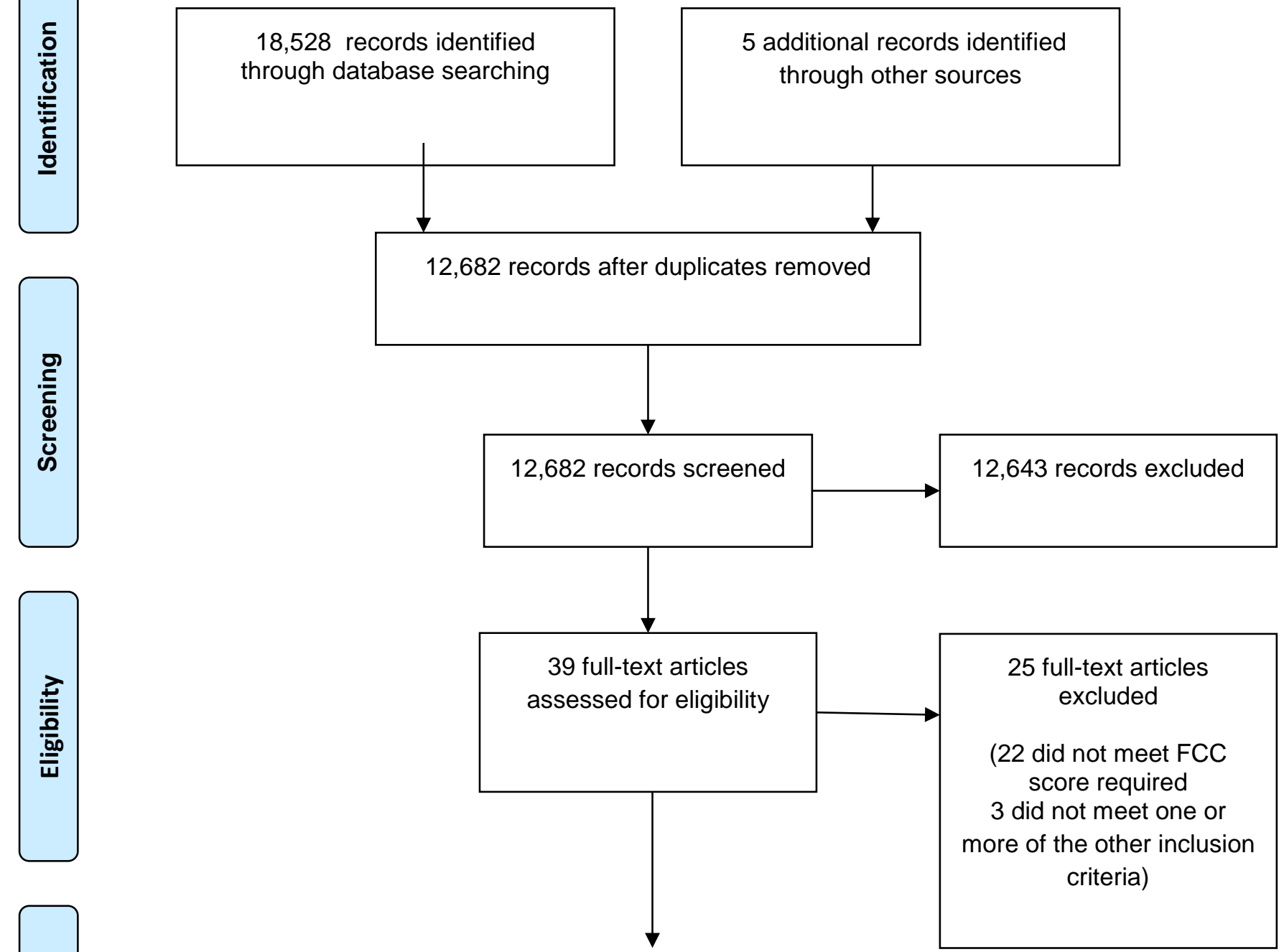

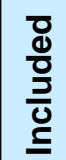

14 studies included in qualitative synthesis

Table 1: Number of studies found and retrieved

\begin{tabular}{|c|c|}
\hline Number of studies found & Number of studies selected for retrieval \\
\hline 39 & 14 \\
\hline
\end{tabular}

Only three studies specified the qualitative methodology and underlining philosophy being employed grounded theory ${ }^{9}$, grounded theory plus phenomenology ${ }^{16}$, phenomenology ${ }^{27}$ - while another reported using grounded theory "techniques". ${ }^{30}$ The majority of studies used qualitative designs 
and/or methods which were titled variously as "qualitative approach", "descriptive qualitative" or "exploratory qualitative" studies. One study ${ }^{41}$ referred only to the qualitative method employed critical incident technique. There were two mixed methods studies ${ }^{48,51}$ using surveys, either combined with interviews or the collection of qualitative comments to enhance the quantitative data.

In terms of participants, six ${ }^{9,16,30,44,45,48,50}$ studies included both parents and health care professionals, five $e^{27,42,43,46,49,51}$ parents only and three $e^{26,41,47}$ health care professionals only. In those studies that provided data on the relationship of the participating parent to the child, the child's mother was the parent most frequently participating in the research, although a small number of fathers also contributed. Only one study ${ }^{30}$ reported involving carers other than a parent. In respect to health care professionals, of the nine studies that included this category, all but one indicated that nurses were recruited. One also included doctors and allied health staff. ${ }^{44,45}$ The remaining study ${ }^{9}$ referred to "frontline health care providers in developmental services" but did not specify professions. Sample sizes varied from eight to 351 , although the latter sample came from one ${ }^{48}$ of the mixed methods studies. If this "outlier" is removed, the range becomes eight to $179^{44,45}$, the latter sample being from the study undertaken in four countries. The largest sample for a study conducted in one location was 57.

\section{Methodological quality}

Of the 14 studies that met the screening criteria for consideration for inclusion in the review, all were assessed as being of sufficient quality to be included in the review. (See Appendix VII for details.)

Table 2: Number of studies included and excluded on quality

\begin{tabular}{|c|c|}
\hline Number of studies included & Number of studies excluded \\
\hline 14 & 0 \\
\hline
\end{tabular}

All included studies met six of the criteria: congruence between methodology and research question or objectives (criterion 2), methodology and methods (criterion 3), methodology and data analysis (criterion 4), methodology and interpretation of results (criterion 5), participants and their voices adequately represented (criterion 8) and conclusions flow from analysis or interpretation of results (criterion 10). All the studies were assessed as ethical but four did not report receiving ethical approval from an appropriate body. For the earliest study included $(1991)^{41}$ this may not have been a requirement at that time for qualitative studies; for the remaining three it was possibly a reporting omission. Only two studies ${ }^{16,27}$ met all the criteria - these studies employed sophisticated qualitative methodology.

The weakest areas were criteria 6 and 7. Only four studies ${ }^{16,27,41,50}$ were assessed as meeting criterion 6 (researcher located culturally or theoretically). Three studies ${ }^{9,16,27}$ met criterion 7 (influence of researcher on the research, or vice- versa) fully and another four ${ }^{30,44,45,49,50}$ addressed the first component of the criterion. 


\section{Data synthesis}

The accompanying illustrations for each finding are provided in Appendix VIII.

\section{Meta-synthesis of parent findings}

Meta-synthesis of parent findings included in the review generated six synthesized findings. These were derived from 43 study findings that were subsequently aggregated into 16 categories.

\section{Synthesized finding 1}

In general, parents of a hospitalized child wish to be involved in the care of their child but want to determine the extent and nature of their participation on an individual basis. A number of factors may facilitate parents' engagement in assisting with their child's care, including health care professionals raising the topic in a non-threatening manner, allowing choice, and providing support and consistent advice to the parents.

Table 3: Synthesized finding 1

\begin{tabular}{|c|c|c|}
\hline Findings & Category & Synthesized finding \\
\hline $\begin{array}{l}\text { Ways in which nurses broached the subject of } \\
\text { parents' participation were important - informal, } \\
\text { non-threatening, given choice. }(U)\end{array}$ & \multirow{3}{*}{ Becoming involved } & \multirow{12}{*}{$\begin{array}{l}\text { In general, parents of a } \\
\text { hospitalized child wish to } \\
\text { be involved in the care of } \\
\text { their child but want to } \\
\text { determine the extent and } \\
\text { nature of their participation } \\
\text { on an individual basis. A } \\
\text { number of factors may } \\
\text { facilitate parents' } \\
\text { engagement in assisting } \\
\text { with their child's care, } \\
\text { including health care } \\
\text { professionals raising the } \\
\text { topic in a non-threatening } \\
\text { manner, allowing choice, } \\
\text { and providing support and } \\
\text { consistent advice to the } \\
\text { parents. }\end{array}$} \\
\hline $\begin{array}{l}\text { Parental lack of knowledge about the nature and } \\
\text { possible extent of participation. }(U)\end{array}$ & & \\
\hline Parent participation an unspoken assumption. (U) & & \\
\hline $\begin{array}{l}\text { Most parents willing to do the "mothering" but } \\
\text { reluctant to perform nursing care. }(U)\end{array}$ & \multirow{5}{*}{$\begin{array}{l}\text { Nature and extent } \\
\text { of participation }\end{array}$} & \\
\hline $\begin{array}{l}\text { Nature of participation was determined by } \\
\text { severity of child's illness or injury. (U) }\end{array}$ & & \\
\hline $\begin{array}{l}\text { Some parents wish to be involved in planning the } \\
\text { child's nursing care. }(U)\end{array}$ & & \\
\hline $\begin{array}{l}\text { Parents want to negotiate and have some control } \\
\text { over the extent of their participation. }(U)\end{array}$ & & \\
\hline $\begin{array}{l}\text { Delegation of nursing care to parent can lead to } \\
\text { overloading the parent and inconsistency in care. } \\
(\mathrm{U})\end{array}$ & & \\
\hline Feeling powerless in caring for their child. (U) & Feeling powerless & \\
\hline $\begin{array}{l}\text { Need for training from staff prior to care being } \\
\text { delegated to parents. }(U)\end{array}$ & \multirow[t]{2}{*}{$\begin{array}{l}\text { Need for parental } \\
\text { training }\end{array}$} & \\
\hline Need for consistency in instruction. (U) & & \\
\hline $\begin{array}{l}\text { The need for assistance with advocacy in a } \\
\text { complex, fragmented system for a child with } \\
\text { longer term needs. (U) }\end{array}$ & $\begin{array}{l}\text { Need for assistance } \\
\text { with advocacy for } \\
\text { child }\end{array}$ & \\
\hline
\end{tabular}

Watts et al. Family-centered care for hospitalized children aged 0-12 years: a systematic review of qualitative 
This synthesized finding was derived from five categories and 12 findings (Table 3).

Parents' experiences relating to being introduced to participating in the care of their child vary. For some the nurse broaches the subject in an informal, non-threatening manner and allows the parent to make the decision. In contrast, parental participation is in some cases an unspoken assumption; there is no choice, parents are just expected to become involved. Parents may be unaware that they can participate, and what the nature and extent of that participation may be.

In general, parents wish to confine the nature and extent of their participation to what they normally do for their child. Most parents are willing to do the "mothering" but are reluctant to provide nursing care. They want to negotiate and have some control over the extent of their participation, for example some wish to be involved in the planning of their child's care. The severity of the child's condition will govern the extent and nature of parental involvement, as can other family and personal demands on the parent. Often parents feel powerless in caring for their child. They experience a loss of control: they are not involved in the decisions, large or small, being made in respect to their child's care; health care professionals do not ask parents for information or take any notice of what parents tell them about the child.

For many parents "on-the-job" instruction facilitates their participation. Both parent-to-parent and staffto-parent teaching occur. Parents want this training, including staff assessing them as competent, prior to care being delegated to them. A major problem encountered by parents is that the instructions received from staff are often inconsistent. For those parents with children with longer term care needs, assistance with advocacy is needed; navigating through a complex, fragmented system to obtain appropriate help for a child is emotionally and physically exhausting.

\section{Synthesized finding 2}

Parents themselves may also need care and should be included in the plan of care. A number of aspects of care should be assessed and addressed if required, including the physical and psychosocial needs of parents.

Table 4: Synthesized finding 2

\begin{tabular}{|l|c|c|}
\hline \multicolumn{1}{|c|}{ Findings } & Category & Synthesized finding \\
\hline Caring for the parent(s). (U) & \multirow{2}{*}{$\begin{array}{c}\text { Need to care for } \\
\text { the parent carer }\end{array}$} & $\begin{array}{c}\text { Parents themselves may } \\
\text { also need care and should } \\
\text { be included in the plan of } \\
\text { care. A number of aspects } \\
\text { of care should be } \\
\text { assessed and addressed if } \\
\text { required, including the } \\
\text { physical and psychosocial } \\
\text { needs of parents. }\end{array}$ \\
\cline { 1 - 1 } Sources of support - other parents. (U) & Sources of \\
The unknown. (U) & parental stress & \\
\hline Waiting for admission. (U) & & \\
\hline Their child's distress. (U) & & \\
\hline
\end{tabular}

Watts et al. Family-centered care for hospitalized children aged 0-12 years: a systematic review of qualitative studies (C) the authors 2014 doi:10.11124/jbisrir-2014-1683 
In this synthesized finding the focus is on caring for the parent(s) who is caring for the child. Six findings contributed to two categories (Table 4).

Parents perceive a range of behaviors as being caring: allowing the parent to get some sleep at night, ensuring they have time to attend to their own needs, nurse taking time to sit with them, not treating them as another pair of hands to help with the nurses' work; enquiring as to the parent's wellbeing, offering options. One suggestion was for the parents to have a care plan. On a practical note, advising parents on admission of the facilities available to them is very helpful. Just knowing there is a shower, tea and coffee, etc. available makes the parents feel that they are being cared for. Introducing them to other parents in the ward can also assist as a source of support.

Parents are often stressed and this stress can arise through a number of factors. Not knowing what is going to happen is a major source of stress for the parents. Linked to that is waiting for admission: the length of time it can take, waiting for the specialist to attend, worrying about the rest of the family at home. A third major source of stress identified by parents is seeing their child in distress, e.g. from pain.

\section{Synthesized finding 3}

Parents regard positive interpersonal skills and effective communication by health care professionals as an essential component of the care of both the child and themselves. Of high importance to parents is that health care professionals acknowledge that the parents "know" their child, and that their concerns and their observations should be accorded due attention. 
Table 5: Synthesized finding 3

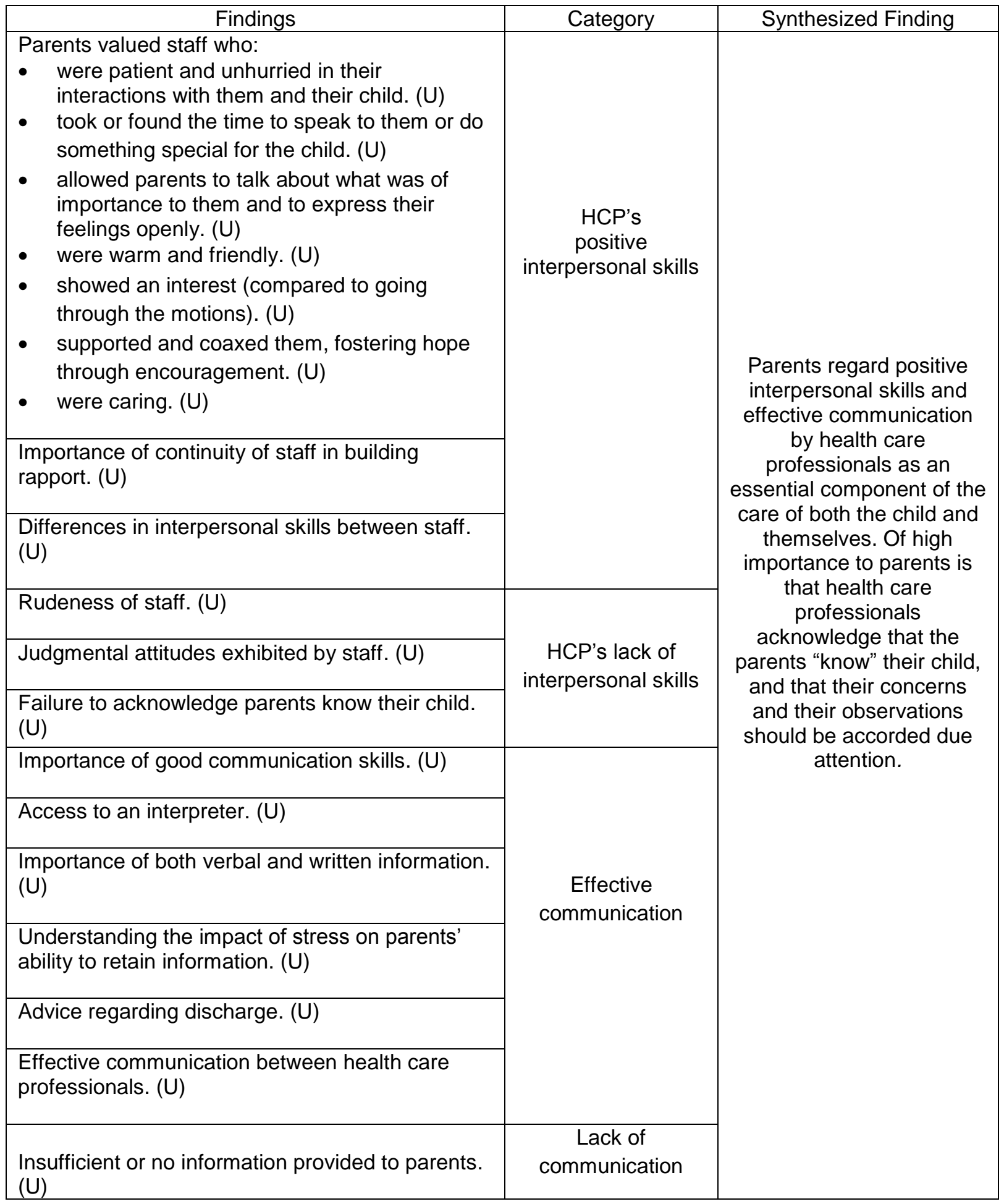

Nineteen findings were grouped into four categories from which the synthesized finding was derived (Table 5).

Parents value staff in terms of their interpersonal skills, for example: patient and unhurried in their interactions, find time to speak to them, allow them to express their feelings openly, show an interest

Watts et al. Family-centered care for hospitalized children aged 0-12 years: a systematic review of qualitative studies (C) the authors 2014 doi:10.11124/jbisrir-2014-1683 
in them and their child, are warm and friendly, support and coax them keeping their spirits up. Continuity of staff caring for the child and family is important in building rapport. Parents notice differences between staff in terms of interpersonal skills, with nurses seen as being better than doctors in this respect.

In contrast, the second category focuses on health care professionals' lack of interpersonal skills. Parents regard staff who are rude or who exhibit judgmental attitudes towards them as having poor interpersonal skills. Also of major concern are staff who do not listen to parents who are trying to tell them something is not right with their child, based on what the parents know to be normal for that child.

Parents stress the importance of being kept aware of what is happening or likely to happen with their child so they can prepare themselves, including advice as to when the child is likely to be discharged. Having an assigned nurse for the child makes it easier for the parents to ask questions or express concerns and seek reassurance as the nurse knows the child and the family knows the nurse. Having access to both written and verbal information is very useful to parents, particularly as stress impacts on their ability to retain information. Parents also value effective communication between health professionals to facilitate, for example, admission to hospital and consistent care. Access to interpreters is also important.

Problems arise when there is a lack of communication with the parents or between health care professionals involved in the child's care. A frequent complaint from parents is that they have been given insufficient or no information as to what is wrong with their child or why certain tests or treatments are being done. In these situations some parents will ask, others feel too intimidated to do so. A lack of communication and co-operation between health care professionals can also lead to confusion for the parents and a lack of trust on their part.

\section{Synthesized finding 4}

A child's admission to hospital may have a negative impact on the family. Assessment of the family should include negative effects on the family as a whole or on individual members, and appropriate action implemented. 
Table 6: Synthesized finding 4

\begin{tabular}{|c|c|c|}
\hline Findings & Category & Synthesized Finding \\
\hline Caring for other members of the family. (U) & $\begin{array}{l}\text { Concern for other } \\
\text { members of the } \\
\text { family }\end{array}$ & $\begin{array}{l}\text { A child's admission to } \\
\text { hospital may have a } \\
\text { negative impact on the } \\
\text { family. Assessment of the } \\
\text { family should include }\end{array}$ \\
\hline Impact on employment. (U) & Financial concerns & $\begin{array}{l}\text { family as a whole or on } \\
\text { individual members, and } \\
\text { appropriate action } \\
\text { implemented. }\end{array}$ \\
\hline
\end{tabular}

This synthesis is based on two findings contributing to two categories (Table 6).

Concern about how the rest of the family is going to be cared for is a major source of stress for the parent caring for the hospitalized child, particularly if there is not another family member available to step into this role. Not realizing the impact that a child's hospitalization can have on their siblings can also be a problem. Continuation of employment and the related family income is also a major concern for some parents.

\section{Synthesized finding 5}

Barriers may exist to the implementation of the principles of family-centered care which need to be identified and solutions sought. These barriers include nurses' workloads that do not allow time for supporting and educating parent carers, inflexible and inappropriate hospital policies and routines, and physical facilities that are not child- and family-friendly.

Table 7: Synthesized finding 5

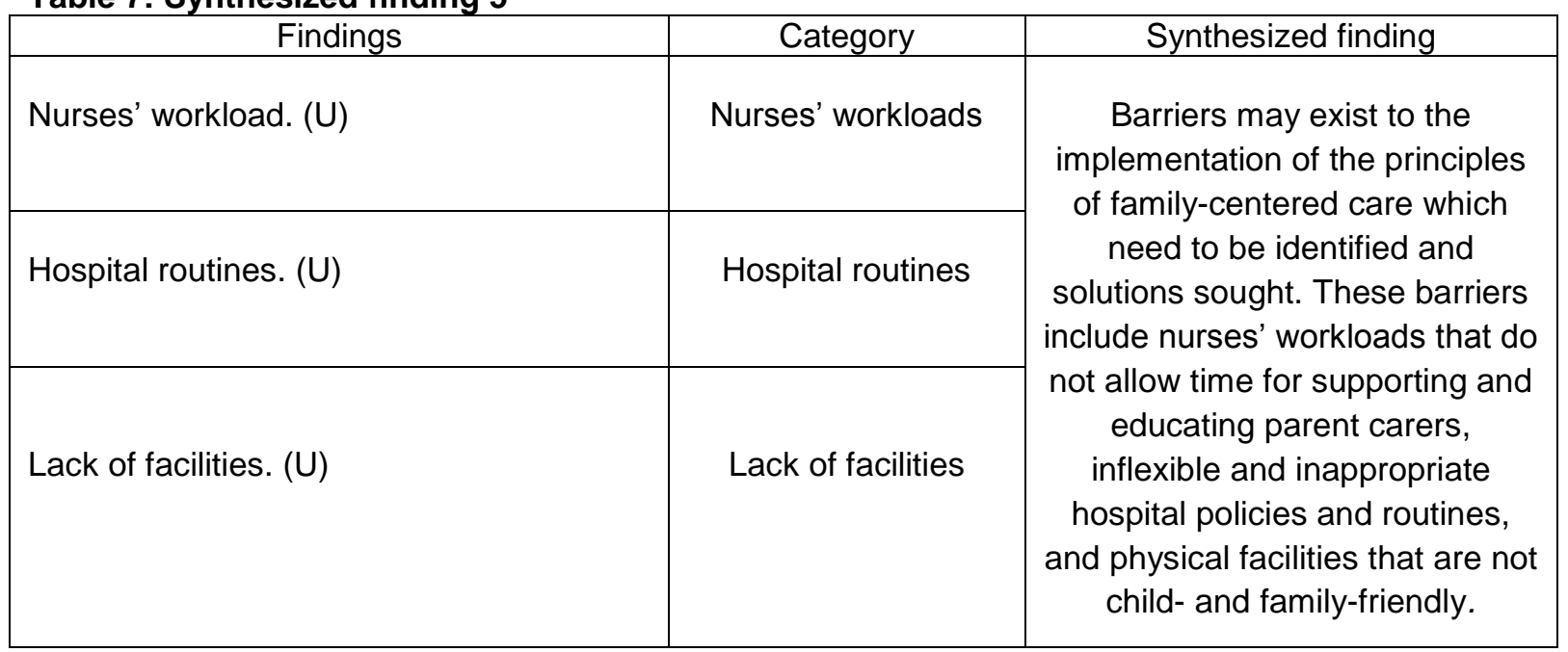

Three findings grouped into three categories contributed to this synthesis (Table 7).

Watts et al. Family-centered care for hospitalized children aged 0-12 years: a systematic review of qualitative 
Parents are reluctant to ask questions or request assistance because nurses always seem busy and seem to have more important priorities to attend to than talk to them. These priorities include hospital routines which take precedence over the needs of children and families. Thirdly is the lack of facilities: the case of children having to be placed in an adult ward, and for parents a lack of waiting areas that provide some privacy, comfortable sleeping arrangements, no access to a phone.

\section{Synthesized finding 6}

In addition to prompt and competent care of their child, parents have a number of other expectations related to the provision of care. Among these expectations are health care professionals who have time for the family, a need to experience a sense of safety, and, where possible, the maintenance of the child's daily routine. Caring for the child and family provides nurses with an opportunity to demonstrate the complexity of their role, and their comprehensive pediatric knowledge and skills.

Table 8: Synthesized finding 6

\begin{tabular}{|c|c|c|}
\hline Findings & Category & Synthesized finding \\
\hline Immediate, prioritized attention. (U) & \multirow{6}{*}{$\begin{array}{l}\text { Parental assessment } \\
\text { of child's care }\end{array}$} & \multirow{7}{*}{$\begin{array}{l}\text { In addition to prompt and } \\
\text { competent care of their child, } \\
\text { parents have a number of } \\
\text { other expectations related to } \\
\text { the provision of care. Among } \\
\text { these expectations are health } \\
\text { care professionals who have } \\
\text { time for the family, a need to } \\
\text { experience a sense of safety, } \\
\text { and, where possible, the } \\
\text { maintenance of the child's } \\
\text { daily routine. Caring for the } \\
\text { child and family provides } \\
\text { nurses with an opportunity to } \\
\text { demonstrate the complexity of } \\
\text { their role, and their } \\
\text { comprehensive pediatric } \\
\text { knowledge and skills. }\end{array}$} \\
\hline A feeling of safety. $(U)$ & & \\
\hline Time for family. (U) & & \\
\hline Care environment. (U) & & \\
\hline Lack of care. $(\mathrm{U})$ & & \\
\hline $\begin{array}{l}\text { Nurses should help maintain child's normal } \\
\text { routines. }(U)\end{array}$ & & \\
\hline The nurses' role. $(U)$ & $\begin{array}{l}\text { Parents' perceptions } \\
\text { of the nurse's role }\end{array}$ & \\
\hline
\end{tabular}

Seven findings and two categories contributed to the final synthesized finding from the parents' perspective on the provision of care (Table 8).

The first category is the parents' assessment of the child's care. Five of the findings reflect parents' satisfaction with the care received or care exceeding expectations. What parents value is a feeling of safety - feeling that their child is in safe hands and if anything goes wrong help is immediately available. They also value their child receiving immediate attention on admission rather than the priority being filling in forms; time made available by staff for the family; and a neat, clean environment. On the other hand dissatisfaction with care can encompass a variety of aspects of care ranging from failure to attend to the child's basic hygiene needs, not maintaining the child's daily routine and omitting to advise the parents that a sibling's admission to hospital can be very distressing for the remaining siblings. 
The second category relates to parents' perceptions of the role of the nurse. This role may be seen as very basic and task oriented, and not very skilled or stimulating.

Benefits of being there

Another significant theme arising from the parents' findings related to their views on the benefits of being able to stay with their child. As the findings only formed one category, a synthesized finding could not be generated. However the findings have been included here for completeness of reporting.

In terms of benefits to the child, parental presence provides emotional security, safety and assurance that the child receives the care they require. Parents are also the source of information as to what constitutes "normal" for their child - they "know" their child. When parents are with their child their anxiety is reduced as they have first-hand knowledge of what is being done for their child. Nurses also benefit from the parents' presence as they help lessen the nurses' workload by caring for their child.

Meta-synthesis of health care professionals' findings

Meta-synthesis of health care professionals' findings included in the review generated three synthesized findings. These were derived from 41 study findings that were subsequently aggregated into 13 categories.

\section{Synthesized finding 7}

Although health care professionals may be aware of the principles of family-centered care and the benefits of the parents being with the child, their implementation of these principles may be secondary to the maintenance of professional control.

A total of 16 findings were grouped into three categories and then further derived into a synthesized statement (Table 9). . 
Table 9: Synthesized finding 7

\begin{tabular}{|c|c|c|}
\hline Findings & Category & $\begin{array}{l}\text { Synthesized } \\
\text { finding }\end{array}$ \\
\hline $\begin{array}{l}\text { Nurses acknowledged the importance of assuming responsibility for } \\
\text { care and protection of families, not just the individual child. }(U)\end{array}$ & \multirow{5}{*}{$\begin{array}{l}\text { Important } \\
\text { elements of } \\
\text { family- } \\
\text { centered } \\
\text { care }\end{array}$} & \multirow{16}{*}{$\begin{array}{c}\text { Although health } \\
\text { care } \\
\text { professionals } \\
\text { may be aware of } \\
\text { the principles of } \\
\text { family-centered } \\
\text { care and the } \\
\text { benefits of the } \\
\text { parents being } \\
\text { with the child, } \\
\text { their } \\
\text { implementation } \\
\text { of these } \\
\text { principles may } \\
\text { be secondary to } \\
\text { the maintenance } \\
\text { of professional } \\
\text { control. }\end{array}$} \\
\hline $\begin{array}{l}\text { Health care practitioners believed the service should be driven by } \\
\text { family needs. }(U)\end{array}$ & & \\
\hline Importance of knowing the family and involving them. $(U)$ & & \\
\hline $\begin{array}{l}\text { Nurses felt more support for parents meant more support given to } \\
\text { the child. (C) }\end{array}$ & & \\
\hline $\begin{array}{l}\text { Some HCPs identified the role parents were able to play would vary } \\
\text { between families and working with families was a collaboration } \\
\text { process. }(U)\end{array}$ & & \\
\hline $\begin{array}{l}\text { Most of the nurses stated that a parental presence meets the } \\
\text { needs of the child, reduces the child's emotional stress, increases } \\
\text { the child's security and cooperativeness, and decreases } \\
\text { behavioral issues. }(U)\end{array}$ & \multirow{11}{*}{$\begin{array}{l}\text { Benefits of } \\
\text { parental } \\
\text { presence } \\
\text { and } \\
\text { participation }\end{array}$} & \\
\hline $\begin{array}{l}\text { Parental presence valued as reduced nurses' workload - help with } \\
\text { basic care and relieving distress. }(U)\end{array}$ & & \\
\hline Nurses recognized parents know their child best. (U) & & \\
\hline Nurse manager viewed parents as informal evaluators of care. $(U)$ & & \\
\hline $\begin{array}{l}\text { The general consensus among nurses was that basic mothering } \\
\text { tasks were the province of parents and more technical tasks, that of } \\
\text { nurses. }(U)\end{array}$ & & \\
\hline $\begin{array}{l}\text { Nurses felt parents willing to do basic care but some were reluctant } \\
\text { to perform nursing care. }(U)\end{array}$ & & \\
\hline $\begin{array}{l}\text { The clear demarcation between parental and nursing roles was } \\
\text { blurred in longer stay and chronic illness. }(U)\end{array}$ & & \\
\hline $\begin{array}{l}\text { Some nurses do not support parental presence during painful } \\
\text { procedures as they believe the child and parent will get more } \\
\text { distressed. }(U)\end{array}$ & & \\
\hline $\begin{array}{l}\text { Nurses stressed importance of nurses performing nursing roles and } \\
\text { tasks and retaining their professional role; they expressed concerns } \\
\text { regarding role erosion. }(U)\end{array}$ & & \\
\hline $\begin{array}{l}\text { Nurse the "knowledge experts" in providing nursing care for sick } \\
\text { children. }(U)\end{array}$ & & \\
\hline Nurses' accountability for care an issue. (U) & & \\
\hline
\end{tabular}

Watts et al. Family-centered care for hospitalized children aged 0-12 years: a systematic review of qualitative studies (C) the authors 2014 doi:10.11124/jbisrir-2014-1683 
Health care professionals identified a number of the elements of FCC. These elements include the importance of assuming responsibility for the care and protection of the family, not just the child, and that the services provided to the family should be driven by the family's needs. Support for the parents means support for the child. Collaboration is the key to working with families. Health care professionals acknowledge that the role(s) parents are able to take on in caring for their child varies with individual families.

They also acknowledged the benefits of parental presence and participation. In respect to the child, this assists in meeting the child's needs by increasing their feeling of security, reducing their stress and decreasing behavioral issues. Parents' knowledge and understanding of their child enables them to identify changes in their condition and/or their behavior quickly and communicate these to the staff.

Benefits from parental presence and participation in care also accrue to the nursing staff, for example relieving staff of some of the physical and emotional care of the child. On occasion parents are also identified by managers as useful sources of information on the quality of the care provided by staff.

However these benefits were countered by staff concerns over the erosion of their role and their accountability for care if the parents' role extends beyond "mothering" tasks. The general consensus of nurses on the extent and type of parental participation is that the care the child would receive at home remains the domain of the parents in a hospital setting, while the technical care is the nurses' responsibility. Several reasons have been cited for this division of roles: the nurses' accountability for the care delivered and that they are the "knowledge experts" in the provision of nursing care to sick children. In general nurses feel that, while most parents are willing to continue providing the usual care they give the child, some, for various reasons, are reluctant to be involved in care they regard as the nurses' responsibility. However the clear demarcation between roles becomes blurred in cases of longer stay and chronic illness as the parent becomes more confident and/or will need to carry out this care at home after discharge. Some nurses do not support the presence of parents during painful procedures as, from their experience, this can result in increased stress for all concerned, including the nurse.

\section{Synthesized finding 8}

The process of engaging parents in their child's care is facilitated by health care professionals establishing a trusting relationship with the parents and demonstrating an understanding of appropriate cultural considerations. Based on this relationship, care roles can be negotiated, two-way information-sharing can occur in a timely manner and appropriate support offered. 
Table 10: Synthesized finding 8

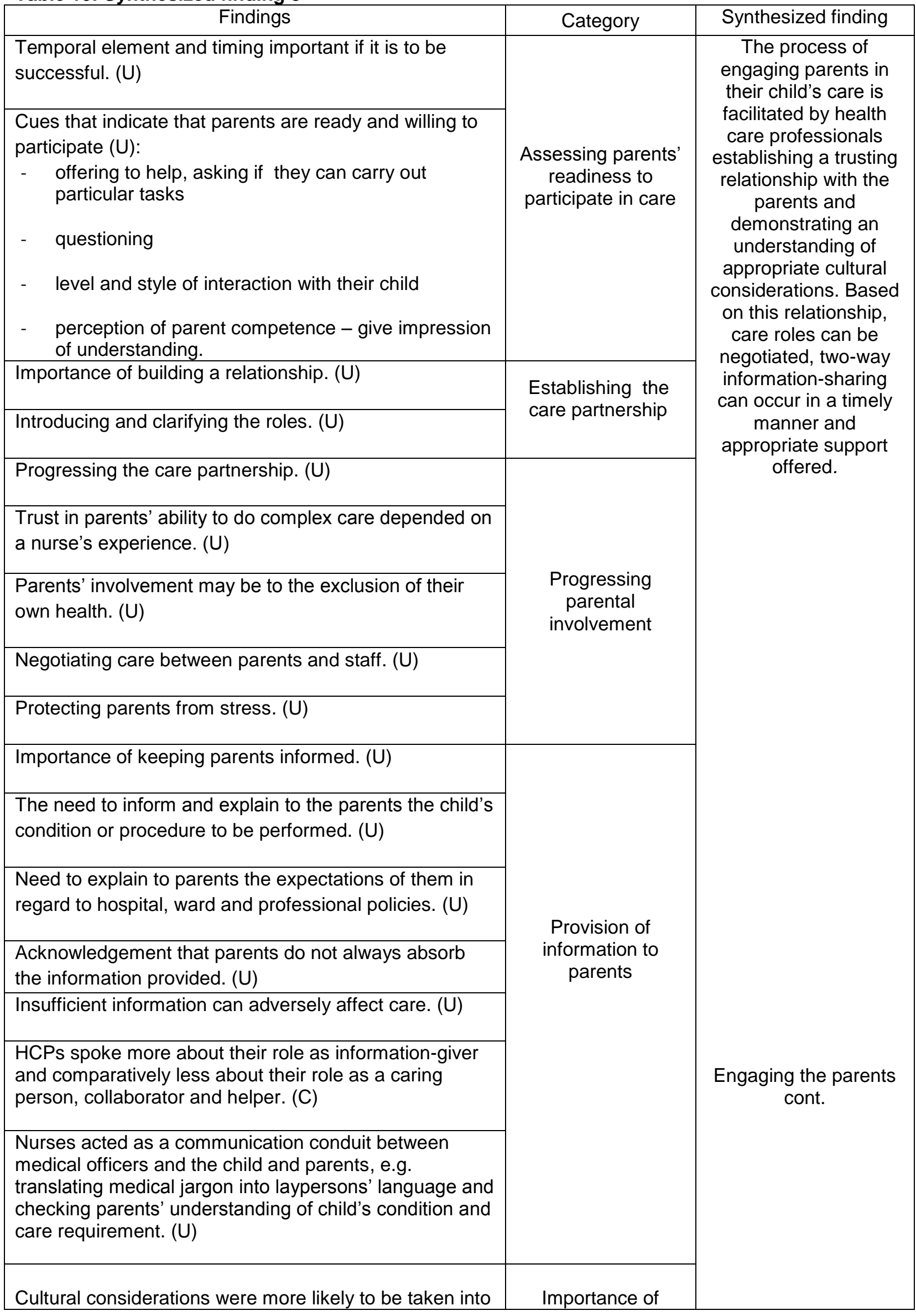

Watts et al. Family-centered care for hospitalized children aged 0-12 years: a systematic review of qualitative studies (C) the authors 2014 doi:10.11124/jbisrir-2014-1683 
account in some countries than others; this may have been influenced by the prevailing culture of dominance of the medical profession in the latter countries. (U)

HCPs spoke of their admiration for the persistence of parents of children with long term conditions in dealing with "the system". (U) cultural considerations

Resilience of parents

This synthesized statement was derived from six categories with 18 findings (Table 10).

The initial phase in engaging the parents is assessing the parents' readiness to participate in the child's care. Identifying whether it is the appropriate time to suggest to parents that they become involved in caring for their child is important; they need time to process what is happening to the child and to understand and accept this. Parents exhibit cues that they are ready and willing to participate in their child's care. These include directly offering or asking to be involved, starting to take an interest in what the staff are doing, e.g. asking questions about what the staff are doing; the amount and style of interaction they have with their child; and demonstrating understanding and competence. Once parents are assessed as ready to be involved, the focus moves to establishing the partnership of care between parents and staff. This stage consists of introducing and clarifying the roles of parents and staff. How this is achieved needs to be individualized for each family. Parents need explanations of the importance of parents being with the child. They also need encouragement, support and reassurance to become involved in care, starting with basic care such as feeding or washing the child. Advising them of the facilities available to them, e.g. the kitchen, is also important.

The care partnership needs to be constantly reviewed based on the child's condition and the parents' wishes. When parents wish to be involved in more technical tasks, negotiation is required to obtain the agreement of staff. Nurses stress that the need to assess the parents' competency is essential; experience has taught some nurses that a parent's claim that they have a particular skill should not just be accepted. Another concern is that parents can become involved in their child's care to the exclusion of their own health and need to be encouraged to take time out to take care of themselves.

Informing and explaining the child's condition to the parents is regarded as very important, as is the need to explain the HCP's expectations of the parents in regard to hospital, ward and professional practices. It is acknowledged by HCPs that, for various reasons such as stress or being overwhelmed by the amount of information provided, parents do not always absorb the information shared with them. In some cases HCPs see their role as information-giver being more important than other roles in a partnership with families, e.g. caring person, collaborator or helper. One of the identified nurses' roles in the provision of information is to act as a conduit between medical officers and the family translating medical terminology into terms that the family can comprehend, and ensuring parents understand the child's condition and the treatment required.

It is important that cultural considerations are taken into account when engaging parents in the care partnership. In addition to those considerations that apply to all health care, there are some that require particular attention in the context of FCC. These include the cultural definitions of "family" which may extend beyond that of the "nuclear" family, how decisions are made regarding the child and who in the family makes those decisions, the cultural position of the medical profession vis-a-vis that of other staff, and how familiar the parents are with the health care system and the type of facilities to which their child has been admitted and in which the parents now have to function. 
The final category contributing to this synthesis is the resilience of parents of children with long term conditions in dealing with the complexities of the care system. Parents expend considerable time and energy in dealing with the numerous professionals and disparate sources of potential support required for their child, and persistence in trying to obtain that support and care.

\section{Synthesized finding 9}

Health care professionals may encounter barriers to their efforts to implement family-centered care. They need organizational support, workloads that acknowledge the need to spend time with families, and the knowledge and skills necessary to effectively communicate with and support parents.

Table 11: Synthesized finding 9

\begin{tabular}{|c|c|c|}
\hline Findings & Category & $\begin{array}{l}\text { Synthesized } \\
\text { finding }\end{array}$ \\
\hline $\begin{array}{l}\text { Time constraints, staff shortages, heavy workloads impacted } \\
\text { on nurses' ability to give sufficient time to each family. }(U)\end{array}$ & \multirow{2}{*}{$\begin{array}{l}\text { Insufficient time } \\
\text { to spend with } \\
\text { parents }\end{array}$} & \multirow{7}{*}{$\begin{array}{l}\text { Health care } \\
\text { professionals } \\
\text { may encounter } \\
\text { barriers to their } \\
\text { efforts to } \\
\text { implement } \\
\text { family-centered } \\
\text { care. They need } \\
\text { organizational } \\
\text { support, } \\
\text { workloads that } \\
\text { acknowledge } \\
\text { the need to } \\
\text { spend time with } \\
\text { families, and the } \\
\text { knowledge and } \\
\text { skills necessary } \\
\text { to effectively } \\
\text { communicate } \\
\text { with and support } \\
\text { parents }\end{array}$} \\
\hline $\begin{array}{l}\text { Nurses believed they were too busy to assist parents with } \\
\text { aspects not directly related to the child's care. (U) }\end{array}$ & & \\
\hline $\begin{array}{l}\text { The "unspoken arrangement" - nurses shared parents' } \\
\text { perception that participation was rarely discussed at the } \\
\text { outset. (U) }\end{array}$ & \multirow{2}{*}{$\begin{array}{l}\text { Lack of } \\
\text { communication } \\
\text { with parents }\end{array}$} & \\
\hline $\begin{array}{l}\text { Most of the nurses stated that they left the parents to get on } \\
\text { with it and to learn about expectations over time. (U) }\end{array}$ & & \\
\hline Lack of organizational support and infrastructure. (U) & $\begin{array}{l}\text { Lack of } \\
\text { organizational } \\
\text { support }\end{array}$ & \\
\hline $\begin{array}{l}\text { Individual nurses reported a lack of knowledge, education and } \\
\text { experience. }(U)\end{array}$ & \multirow{2}{*}{$\begin{array}{l}\text { Lack of relevant } \\
\text { knowledge, } \\
\text { skills and } \\
\text { experience }\end{array}$} & \\
\hline $\begin{array}{l}\text { Differences were identified between experienced and less } \\
\text { experienced nurses in relating to parents. Role insecurity } \\
\text { prevented competent addressing of parent questions, } \\
\text { education and anxiety. (U) }\end{array}$ & & \\
\hline
\end{tabular}

Watts et al. Family-centered care for hospitalized children aged 0-12 years: a systematic review of qualitative 
Four categories containing six findings contribute to this synthesized statement (Table 11).

The first category relates to the inability of nurses to spend sufficient time with parents in order to provide information and instruction. This results from staff shortages, heavy workloads and administrative tasks. However, even with time available, communication from nurses to parents does not necessarily occur - the second category. Participation, for example, although expected of the parents, is often not discussed with them at the outset; this was referred to as the "unspoken arrangement". Parents are left to their own devices and left to learn about expectations on their own.

The third category focuses on the lack of organizational support for the concept of FCC. Specific concerns are the lack of separate and appropriate facilities for both children and parents, and adequate staffing to provide the care required.

The final category concerns lack of relevant knowledge and skills in individual nurses. Reasons for this include failure to provide ongoing education in pediatric nursing and FCC in particular. Experience is also a factor, with differences being noted between experienced and inexperienced nurses in their ability to relate to parents, e.g. being able to competently address parents' questions, anxiety and education needs' or maintain a professional relationship with parents rather than a personal one.

\section{Impact of FCC on nursing}

There were also several findings that related to the impact of family-centered care on nursing in terms of the effect it is perceived to have had on nurses' roles. As only one theme emerged from these findings, a synthesized finding could not be generated, but the findings have been included here to complete the reporting of the extracted data. With the implementation of FCC and mothers providing care for their child, concern is expressed that nurses are moving away from their core responsibilities and that mothers are becoming "trainee nurses". A related concern is that when there are staff shortages, nurses have no option but to delegate what are perceived as nursing tasks to the parents, despite this being contrary to hospital policy.

\section{Discussion}

This review was conducted to synthesize the evidence on the experiences and /or perceptions related to family-centered care by families and health care providers for hospitalized children aged 0-12 years (excluding premature neonates). Fourteen qualitative studies were included following the literature search and critical appraisal processes.

Six synthesized findings from parents' perspectives and three from health care providers were derived from the data synthesis process. The following discussion will compare the synthesized findings from the two groups and also the findings with previous systematic reviews focusing on the effectiveness of family-centered care. ${ }^{2,34}$

\section{Commonalities and differences between the respondent groups}

Both parents and health care providers recognized the value of parents being with their hospitalized child. These benefits included providing children emotional security and safety, reducing both the child's and parents' stress and anxiety, recognizing changes in children, advocating for the child as they know what is "normal', and helping with nurses' workload by caring for the child. Nurses acknowledged that parental presence not only reduces their physical workload but also in providing the psychosocial care the child needs. However, in discussing workload, nurses raised the issue of

Watts et al. Family-centered care for hospitalized children aged 0-12 years: a systematic review of qualitative studies (C) the authors 2014 doi:10.11124/jbisrir-2014-1683

Page 231 
demarcation of roles between nurse and parent. This is discussed in more detail later in respect to role negotiation.

In general, both groups felt parents are willing to continue to "mothering" their child by providing usual care, but, with some exceptions, were reluctant to provide nurses' technical care. There was also agreement that the nature and stage of the illness govern the extent of parental engagement in the delivery of care. However, parents would still like to be fully informed and involved in planning the care for their child at all stages of the child's illness, although what parents actually meant by the term "planning care" was not clarified. It could well have a different meaning to that held by HCPs. However, the clear demarcation between the roles of parent and nurse becomes blurred with extended hospitalization and chronic illness, particularly when parents need to continue care at home post-discharge. Parents of children with long term needs emphasized the assistance they need to navigate the complex support systems involved and the advocacy skills that this requires - a need often not recognized by HCPs.

In terms of the introduction of parents to the concept of participation in their child's care there was acknowledgement by nurses of parents' needs and the degree of readiness on the parents' part to become involved. However there were also examples provided where this was not the case. The timing and the way staff introduced the topic was very important to parents. Recognition that parents need to adjust to the initial shock of the child's condition and hospitalization before introducing the topic and then doing this in an informal, non-threatening manner plus offering the parent choices was identified by both groups as important. For some parents being able to contribute to caring for their child is not something they thought would be allowed. This initial approach also contributes to the process of building a relationship between staff and parents. Both groups acknowledged the need for supporting and training parents in and for their involvement. However, in other cases there is an unspoken assumption on the part of staff that parents will assume this role with no discussion, that is, they are given no choice in the matter.

Integral to the concept of family-centered care is the negotiation of roles between staff and parents, in keeping with the concept of an effective partnership. This role negotiation is not a one-off discussion post-admission but should continue throughout the child's stay in hospital. However, little evidence of the importance of negotiation was found in the data from HCPs. Although some reference was made to negotiating roles on an ongoing basis and ensuring parents continued to be involved in decision making, nurses' responses focused primarily on concerns about role erosion. A number of reasons were given to support their position on this matter, including nurses having the required knowledge and expertise and their accountability for the nursing care given to a child. Most parents on the other hand, although not wishing to be responsible for the nursing care, made it very clear that they wanted to negotiate and have some control over the nature and extent of their participation. A number of examples were provided of parents feeling powerless, no longer having any control in their child's care. They were not kept informed, consulted or involved in decision-making. The power still resided with the staff.

The interpersonal and communication skills of staff were a major focus for parents. Parents experienced both positive and negative interactions with staff together with good and poor communication. Parents were very clear on what they valued in interactions with staff and what was important to communicate to them as parents. They were equally clear on certain attitudes and behaviors that they did not appreciate in their dealings with staff. The HCPs focused on the provision of information to parents and its importance. Authors of one of the included studies concluded that

Watts et al. Family-centered care for hospitalized children aged 0-12 years: a systematic review of qualitative studies (C) the authors 2014 doi:10.11124/jbisrir-2014-1683

Page 232 
HCPs "spoke more about their role as information-giver and comparatively less about their role as a caring person, collaborator and helper". ${ }^{9(p .78)}$

Each group came from a markedly different perspective when discussing the provision of care. The parents, understandably, evaluated both the care their child received and how they felt, e.g. their degree of confidence in the staff and time given to them by staff. In general, parents were satisfied or more than satisfied with the care provided, although a few exceptions were recorded. One study explored parent's perceptions of the nurses' role - a role that was not seen as being particularly skilled or challenging. Nurses were concerned about the impact of the FCC model on the role of nurses, an impact that was of concern in that they were moving away from their core responsibilities and delegating these to the mothers. Ironically, this is a role most parents do not wish to assume.

Both groups identified several common themes, albeit from their particular perspectives, in relation to barriers to implementation of a FCC model of care. The primary barrier related to staff shortages and the consequent heavy workloads that resulted from this. This left nurses having insufficient time to spend with parents, while parents were reluctant to interrupt nurses. This linked to the priority of hospital routines over individualized care. The third theme was the lack of facilities to provide an appropriate care environment for both children and parents. An aspect that only the nurses commented on related to some nurses' lack of relevant knowledge, skills and experience as an impediment to implementing FCC.

Two of the synthesized findings were derived from parental data only, with little or no specific mention being made of these aspects of care by HCPs. This may have resulted from the type of questions asked in the collection of data, or possibly not an aspect of care that came readily to mind for HCPs. These findings related to the importance of caring for the parent carer and the impact of the child's admission to hospital on the family. Both of these findings are integral to the concept of familycentered care, i.e. planning of care around the whole family; ${ }^{3}$ lack of HCP data on these aspects could indicate a significant gap in the implementation of the model.

\section{Relationship of findings of other reviews on topic}

In discussing the relationship of the findings of this review to those of other reviews (literature and systematic) related to various aspects of this topic, the question that arises is: did the studies that contributed to this review actually study the model of family-centered care as a whole or did they only examine the implementation of selected elements of the model? Given that the scores of the Trivette ${ }^{5}$ scale achieved by the majority of the included studies clustered around the low end of acceptability for inclusion, the conclusion can be drawn that the findings from these studies cannot lead to a conclusion about the meaningfulness or feasibility of the FCC model itself. However, conclusions can be drawn in relation to the meaningfulness ${ }^{52}$ of specific features of the family-centered care model.

As this systematic review is of qualitative studies, no conclusions can be made about the question raised by Shields ${ }^{32}$ in regards to the effectiveness or otherwise of the model. However there is no evidence to support the ethical concern that implementation of any of the features of the model might be harmful in some way. ${ }^{20}$ In contrast, implementation of the features in the manner envisaged by the concept of family-centered care was welcomed by the parents as being supportive of their child, themselves and the family in number of ways. However, failure to implement these features did generate problems, e.g. failure to negotiate the nature and extent of parental participation on an individual family basis in an appropriate and timely manner increases parents' stress.

Watts et al. Family-centered care for hospitalized children aged 0-12 years: a systematic review of qualitative studies (C) the authors 2014 doi:10.11124/jbisrir-2014-1683 
The same themes identified by Shields ${ }^{3}$ in her literature review of qualitative studies on FCC published in 2006 - role negotiation, parental expectations of participation in their child's care, and issues relating to power and control - were replicated in this review despite two thirds of the studies included in this latest review being published after Shield's review was conducted. The same problems still exist, albeit perhaps to a lesser extent.

In respect to the findings of the review by Corlett and Twycross ${ }^{35}$ that family participation in their child's care was hindered by nurses' lack of communication and limited negotiation, there was some evidence in this latest review to support this. However there were a number of examples to suggest that nurses were communicating about participation and determining the extent to which parents wished to be involved. In this review the major barrier to participation beyond the "mothering" role was nurses' protection of their professional role, although few if any parents wanted the total responsibility.

As children were not included as participants in any of the studies included in this review, no comparisons can be made to the review by Coyne ${ }^{36}$ in regards to children's views on or participation in decision-making related to their care.

\section{Limitations}

Most of the included studies identified limitations to the individual studies. The most common limitation mentioned was that the results were not generalizable given the context dependent methodology. A number of authors ${ }^{30,43,49}$ also nominated small sample sizes as limitations. Recruitment of planned numbers was a problem in several cases, either of parents ${ }^{46}$ or nurses. ${ }^{43,45}$ Contextual factors also played a part in Shields et.al.'s ${ }^{45}$ study - data collection in Thailand occurred during an economic crisis and severe pay cuts had resulted in disgruntled staff unwilling to participate in the study. Several authors indicated that if more resources had been available they would have been able to generate richer data either through second interviews ${ }^{43}$ (Neill) or tapping additional sources of data. ${ }^{47}$ While Dicastillo and Cheng ${ }^{51}$ noted that their survey tool was piloted but not validated, their assessment was that the tool was fit for purpose and collected useful data. Callery and Smith ${ }^{41}$ experienced some inter-rater reliability when studying the concept of negotiation in the context of family-centered care. However, the general consensus of the authors was that, despite these limitations, the data reported provided a clear indication of the participants' views.

There are also several limitations to the review itself. Only two studies ${ }^{44,50}$ included data from developing countries. Also there were limitations in respect to the type of participants included in the studies. Studies involving parents of premature neonates and adolescents were not include, nor, as far as can be determined, did any of the included studies involve parents with dying children. In terms of health professionals, most of the studies focused on nurses with only two involving allied health and medical staff. ${ }^{9,44}$

\section{Conclusion}

This review confirms that parents wish to participate in their hospitalized child's care. However the nature and extent of this involvement has to be negotiated on an individual family basis. Although it appears that nurses and other health care professionals have a reasonably good understanding of the elements that constitute family-centered care, parents did not perceive that this understanding was in many cases being put into practice. The difficulty is that the changes required challenge professional power.

Watts et al. Family-centered care for hospitalized children aged 0-12 years: a systematic review of qualitative studies (C) the authors 2014 doi:10.11124/jbisrir-2014-1683

Page 234 
In relation to the question that has been raised in regard to the current usefulness of the FCC model, it is difficult to imagine that parents, from their perspective, would accept that any or all of the elements of the model be discarded. In developed countries at least, this review indicates that parents now expect these elements to be part of the care of a hospitalized child. This expectation is reflected in the policies of many specialized pediatric hospitals.

As only two studies included data from developing countries, no definitive conclusions can be drawn for these countries as there are different drivers operating, e.g. a marked lack of financial resources affecting the ratio of nurses to patients means it is essential that a family member is with the child at all times to ensure that basic care is provided.

\section{Implications for practice}

When caring for pediatric patients in developed countries, the features of family-centered care (i.e. care includes the family in a meaningful way at all times, is culturally responsive, and supports family individuality by recognizing the need for different types of family support) and the associated elements should be implemented (Grade A recommendation). ${ }^{52}$

At a hospital organizational level in developed countries, the elements of family-centered care could be incorporated into parent satisfaction surveys and the findings used to indicate areas of weakness in its delivery, e.g. communication with parents. Where staff performance is involved, intervention programs could then be designed and implemented to improve performance in the identified area. If changes in hospital policy or provision of facilities are indicated, the appropriate processes to consider these changes would then be initiated (Grade B recommendation). ${ }^{52}$

Currently there is insufficient evidence on which to base recommendations for practice in developing countries.

\section{Implications for research}

On the basis that a large number of qualitative studies have been conducted on family-centered care in developed countries, research on this topic should now shift its focus.

The following recommendations are made for further research:

- More research studies be conducted in developing countries on the meaning and applicability of the elements of family-centered care.

- Program evaluation studies be conducted of intervention programs designed to improve the quality of the provision of specific elements of family-centered care.

- The experiences and perceptions of parents and adolescents of family-centered care be explored.

- Given the increasing use of day-care procedures and home-based care, the feasibility and application of the elements family-centered care in community settings be investigated.

\section{Conflicts of interest}

There are no conflicts of interest to report.

\section{Acknowledgements}

No sources of external funding were accessed. The authors would like to thank the Cochrane Communication and Consumers Review Group, and John Wiley \& Sons Ltd, for permission to publish 
sections of the Cochrane Systematic Review on Family-centered Care for Hospitalized Children aged $0-12$ years. ${ }^{1}$ 


\section{References}

1. Shields L, Pratt J, L.M. D, Hunter J. Family-centred care for children in hospital. Cochrane Database Syst Rv. 2007;1.

2. Shields L, Zhou H, Pratt J, Taylor M, Hunter J, Pascoe E. Family-centred care for hospitalised children aged 0-12 years. Cochrane Database Syst Rv. 2012;10.

3. Shields L, Pratt J, Hunter J. Family centred care: A review of qualitative studies. Journal of Clinical Nursing. 2006;15:1317-23.

4. Costello A, Chapman J. Mothers' perceptions of the care-by-parent program prior to hospital discharge of their preterm infants. Neonatal Network: Journal of Neonatal Nursing. 1998;17(7):37-42.

5. Trivette CM, Dunst C, Allen S, Wall L. Family-centeredness of Children's Health Care Journal. Child Health Care. 1993;22(4):241-56.

6. P.D. W, Johnson BH. Developing family-centered vision, mission, and philosophy of care statements: Bethesda, Maryland: Insitute of Family-Centered Care; 1999.

7. Irlam LK, Bruce JC. Family-centred care in paediatric and neonatal nursing: A literature review. South Africa Nursing Journal. 2002;25(3):28-34.

8. Coyne I, Cowley S. Challenging the philosophy of partnership with parents: A grounded theory study. International Journal of Nursing Studies. 2007;44:893-904.

9. MacKean GL, Thurston WE, Scott CM. Bridging the divide between families and health professionals' perspectives on family-centred care. Health Expectations. 2005;8:74-85.

10. Nethercott S. A concept for all the family-centred care, a concept analysis. Professional Nurse. 1993;8(12):794-497.

11. Shields L. A comparative study of the care of hospitalised children in developed and developing countries: Brisbane:Department of Paediatrics and Child Health, Unversity of Queensland; 1998.

12. Johnson B. The changing role of families in health care. Child Health Care. 1990;19:234-41.

13. Bowlby J. Attachment and loss: Harmondsworth, UK: Penguin; 1971.

14. Bowlby J. Separation: Anxiety and anger. Harmondsworth, UK: Penguin; 1973.

15. Platt $\mathrm{H}$. The welfare of children in hospital. London: Ministry of Health, Central Health Services Council; 1959.

16. Darbyshire $\mathrm{P}$, editor. Living with a sick child in hospital: The experiences of parents and nurses. London: Chapman \& Hall; 1994.

17. Jolley J, Shields L. The evolution of family-centred care. Journal of Pediatric Nursing. 2009;24(2):164-70.

18. Coyne I. Disruption of parent participation: Nurses' strategies to manage parents on children's wards. Journal of Clinical Nursing. 2007;12(23):3150-8.

19. Palmer S. Care of sick children by parents: A meaningful role. Journal of Advanced Nursing. 1993;18(2):185-91. 
20. Allen RI. Rethinking family-centered practice. The American Journal of Orthopsychiarty. 1998;68(1):4-15.

21. Neff JM, Eichner JM, Hardy DR, Klein M. American Academy of Pediatrics Committee on Hospital Care, Institute for Family-Centered Care policy statement: family-centered care and the pediatrician's role. Pediatrics. 2003;112(3):691.

22. Melnyk BM. Intervention studies involving parents of hospitalized young children: An analysis of the past and future recommendations. Journal of Pediatric Nursing. 2000;15(1):4-13.

23. Callery P. Caring for parents of hospitalized children: A hidden area of nursing work. Journal of Advanced Nursing. 1997;26:992-8.

24. Melnyk BM, Alpert-Gillis L, Feinstein N, Crean H, Johnson J, Fairbanks E, et al. Creating opportunities for parent empowerment: program effects on the mental health/coping outcomes of critically ill young children and their mothers. Paediatrics. 2004;113:e597-e607.

25. Hummelinck A, Pollock K. Parents' information needs about the treatment of their chronically ill child: A qualitative study. Patient Education and Counseling. 2006;62:228-34.

26. Ygge BM. Nurses' perceptions of parental involvement in hospital care. Paediatric Nursing. 2007;19(5):38-40.

27. Verwey M, Jooste K, Arries E. Experiences of parents during the hospitalisation of their child in a private paediatric unit. Curationis. 2008;31(2):30-42.

28. Bruce B, Ritchie J. Nurses' practices and perceptions of family-centered care. Journal of Pediatric Nursing. 1997;12(4):214-22.

29. Bruce B, Letorneau N, Ritchie J, Larocque S, Dennis C, Elliott MR. A multisite study of health professionals' perceptions and practice of family-centered care. Journal of Family Nursing. 2002;8(4):408-29.

30. Roden J. The involvement of parents and nurses in the care of acutely-ill children in a nonspecialitst paediatric setting. Journal of Child Health Care. 2005;9(3):222-40.

31. Sarajarvi A, Haapamäki ML, Paavilainen E. Emotional and informational support for families during their child's illness. International Nursing Review. 2006;53(3):205-10.

32. Shields L. Questioning family-centred care. Journal of Clinical Nursing. 2010;19:2629-38.

33. Ahmann E, Johnson B. Family matters: new guidance materials promote family-centered change in health care institutions. Paediatric Nursing. 2001;27(2):173-5.

34. Shields L, Zhou H, Taylor M, Hunter J, Munns A, Watts R. Family-centred care for hospitalised children aged 0-12 years: A systematic review of quasi-experimental studies. JBI Library of Systematic Reviews. 2012;10(39):2559-92.

35. Corlett J, Twycross A. Negotiation of parental roles within family-centred care: A review of the research. Journal of Clinical Nursing. 2006;15:1308-16.

36. Coyne I. Children's participation in consultations and decision-making at health service level: A review of the literature. International Journal of Nursing Studies. 2008;45:1682-9. 
37. Zhou H, Shields L, Watts R, Taylor M, Munns A, Ngune I. Family-centred care for hospitalized children aged 0-12 Years: A systematic review protocol of qualitative studies. The JBI Database of Systematic Reviews and Implementation Reports. 2012;10(57):3917-35.

38. Brophy M, Barrow C. Health problems of the neonate. In: Glasper EA, Richardson J, editors. A Textbook of Children's and Young People's Nursing. 1st ed: Edinburgh: Churchill Livingstone Elsevier 2006. p. 623-36.

39. Nixon JW. Family cohesion in families with an impaired child. Brisbane: Department of Social and Preventive Medicine, University of Queensland; 1988.

40. The Joanna Briggs Institute. The Joanna Briggs Institute Reviewers Manual 2014 Edition: Adelaide: The Joanna Briggs Institute; 2014.

41. Callery P, Smith L. A study of role negotiation between nurses and the parents of hospitalized children. Journal of Advanced Nursing. 1991;16:772-81.

42. Neill S. Parent participation 1: Literature review and methodology. British Journal of Nursing. 1996;5:34-40.

43. Neill S. Parent participation 2: Findings and their implications for practice. British Journal of Nursing. 1996;5:110-7.

44. Shields L, King S. Qualitative analysis of the care of children in hospital in four countries: Part 1. Journal of Pediatric Nursing. 2001;16:137-45.

45. Shields L, King S. Qualitative analysis of the care of children in hospital in four countries: Part 2. Journal of Pediatric Nursing. 2001;16:206-13.

46. Teare J, Smith J. Using focus groups to explore the views of parents whose children are in hospital. Paediatric Nursing. 2004;16(5):30-4.

47. Paliadelis $\mathrm{P}$, Cruickshank $\mathrm{M}$, Wainohu $\mathrm{D}$, Winskill R, Stevens $\mathrm{H}$. Impementing family-centred care: An exploration of the beliefs and practices of paediatirc nurses. Australian Journal of Advanced Nursing. 2005;23(1):31-6.

48. Wilson SB. Family centred care: A descriptive study of the situation in rural Western Australia. Perth: Curtin University; 2004.

49. Espezel H, Canam C. Parent-nurse interactions: Care of hospitalized children. Journal of Advanced Nursing. 2003;44:34-41.

50. Aein F, Alhani F, Mohammadi E, Kazemnejad A. Parental participation and mismanagement: A qualitative study of child care in Iran. Nursing and Health Sciences. 2009;11:221-7.

51. Dicastillo OL, Cheung YP. Pediatric nursing and family-centered care. Enfermeria Clinica. 2004;14(2):83-92.

52. The Joanna Briggs Institute Level of Evidence and Grades of Recommendation Working Party. Supporting Document for the Joanna Briggs Institute Levels of Evidence and Grades of Recommendation. The Joanna Briggs Institute; 2014.

53. Watts R. Study Screening tool. Perth: WACEBNM, 2000. 


\section{Appendix I: Search strategy}

Databases searched:

Medline

Embase

Psyclnfo

CINAHL

Sociological Abstracts

Other sources:

Trove (Libraries Australia) for Australian Theses

Web of Science Conference Proceedings

Mednar

Search Strategies

MEDLINE (Ovid)

Searched on $15 / 11 / 12$

Results $=6609$

1. exp child/ or exp infant/ or child*.tw.

2. exp pediatrics/ or exp pediatric nursing/ or p?ediatric ${ }^{*}$.tw.

3. perinat $^{\star}$ or neonat ${ }^{\star}$ or newborn* or infant $^{\star}$ or baby or babies or toddler $\left.{ }^{\star}\right)$.tw.

4. (preterm or prematur* or (school age or schoolage)).tw.

5. or/1-4

6. exp hospitalization/ or exp hospitals/ or hospital units/

7. hospital ${ }^{\star} . t w$.

8. child, hospitalized.sh.

9. 6 or 7

10. (9 and 5$)$ or 8

11. patient-centered care.sh.

12. (family cent?red or patient cent?red or (famil ${ }^{\star}$ adj support $\left.{ }^{\star}\right)$ ).tw.

13. (famil* $^{\star}$ adj2 support $\left.{ }^{\star}\right) \cdot$.tw.

14. ((child* or famil $\left.{ }^{*}\right)$ adj focus $\left.{ }^{*}\right)$.tw.

15. (shar* adj2 care).tw.

Watts et al. Family-centered care for hospitalized children aged 0-12 years: a systematic review of qualitative studies (C) the authors 2014 doi:10.11124/jbisrir-2014-1683 
16. ((care or cared or caring) adj2 (parent ${ }^{*}$ or mother $^{*}$ or father ${ }^{\star}$ or famil $\left.\left.^{\star}\right)\right) . t w$.

17. ((famil ${ }^{\star}$ or parent ${ }^{\star}$ or mother ${ }^{\star}$ or father ${ }^{\star}$ or care ${ }^{\star}$ or mutual) adj2 (partner ${ }^{\star}$ or participat ${ }^{\star}$ or presence or involv ${ }^{*}$ or decision* or communicat* or negotiat $^{\star}$ or collaborat $^{\star}$ or visit* $\left.)\right)$.tw.

18. professional-family relations/ or social support/ or family nursing/ or exp maternal child nursing/

19. or/11-18

20. 10 and 19

\section{EMBASE (Ovid)}

tTo November 212012 Results $=643$

1. exp child/ or exp pediatrics/

2. (child* or p?ediatric $\left.{ }^{\star}\right) . t i, a b, k w$.

3. perinat $^{\star}$ or neonat* or newborn $^{\star}$ or infant $^{*}$ or baby or babies or toddler $\left.{ }^{\star}\right) . \mathrm{ti}, \mathrm{ab}, \mathrm{kw}$.

4. (pre term or preterm or prematur $\left.{ }^{\star}\right) . t i, a b, k w$.

5. (school age or schoolage).ti,ab,kw.

6. or/1-5

7. exp hospital/ or hospitalization/

8. hospital ${ }^{\star} . t i, a b, k w$.

9. child hospitalization/ or hospitalized child/ or hospitalized infant/

10. 6 and (7 or 8$)$

11.9 or 10

12. family-centered care/

13. (family-centered or family-centered).ti,ab,kw.

14. patient cent?red.ti,ab,kw.

15. (patient centered or patient centered).ti,ab,kw.

16. caregiver/ or caregiver*.ti,ab,kw.

17. (famil ${ }^{\star}$ adj support*).ti,ab,kw.

18. social support/

19. (share* adj2 care).ti,ab,kw.

20. ((care or cared or caring) adj2 (parent ${ }^{\star}$ or mother ${ }^{*}$ or father ${ }^{\star}$ or famil $\left.\left.{ }^{\star}\right)\right) . t i, a b, k w$.

21. ((famil ${ }^{\star}$ or parent ${ }^{\star}$ or mother ${ }^{*}$ or father* or care $^{*}$ or mutual) adj2 (partner ${ }^{*}$ or participat ${ }^{\star}$ or presence or involv* or decision* or communicat* ${ }^{\star}$ r negotiat* or collaborat ${ }^{\star}$ or visit*)).ti,ab,kw.

22. or $/ 12-21$

23. 11 and 22

Watts et al. Family-centered care for hospitalized children aged 0-12 years: a systematic review of qualitative studies (C) the authors 2014 doi:10.11124/jbisrir-2014-1683

Page 241 
24. limit 23 to exclude medline journals

\section{PsycINFO (Ovid)}

To week 1, November 2012, searched on 14/11/12

References retrieved 4449

1. (child* or infant*).ti,ab,hw,id.

2. p?ediatric*.ti,ab,hw,id.

3. (perinat* or neonat $^{\star}$ or newborn* or infant $^{\star}$ or baby or babies or toddler $\left.{ }^{\star}\right)$.ti,ab,hw,id.

4. (preterm or prematur $\left.{ }^{\star}\right) . t i, a b, h w, i d$.

5. (school age or schoolage).ti,ab,hw,id.

6. or/1-5

7. (hospitals or hospitalization or hospitalized patients or hospital admission).sh.

8. hospital ${ }^{*} . t i, a b, i d$.

9. 6 and (7 or 8$)$

10. patient cent?ered.ti,ab,id.

11. family cent?ered.ti,ab,id.

12. ((child* or famil $\left.{ }^{\star}\right)$ adj focus $\left.{ }^{\star}\right) \cdot$ ti,ab,id.

13. (famil ${ }^{*}$ adj support*).ti,ab,id.

14. caregivers/ or (mother child relations or father child relations or parent child relations).sh.

15. parental involvement/ or exp parents/ or exp family/ or family members/

16. (shar* adj3 care).ti,ab,id.

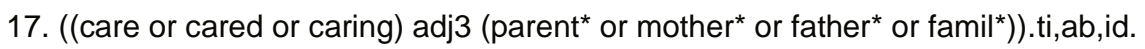

18. ((famil ${ }^{*}$ or parent ${ }^{*}$ or mother* or father $^{*}$ or care* or mutual) adj4 (partner* or participat* or presence or involv* or decision* or communicat ${ }^{\star}$ or negotiat* or collaborat* or visit $\left.\left.^{\star}\right)\right)$.ti,ab,id.

19. or/10-18

20. 9 and 19

21. limit 20 to human

CINAHL

Searched 22/11/12 Results $=6001$

S1. $\mathrm{MH}$ child+

S2. AB child* or TI child*

Watts et al. Family-centered care for hospitalized children aged 0-12 years: a systematic review of qualitative studies (C) the authors 2014 doi:10.11124/jbisrir-2014-1683 
S3. $\mathrm{MH}$ pediatrics+ or $\mathrm{MH}$ pediatric nursing + or $\mathrm{MH}$ perinatal nursing

S4. TI (pediatric* or paediatric ${ }^{*}$ ) or AB (pediatric* or paediatric $\left.{ }^{*}\right)$

S5. TI (perinat ${ }^{\star}$ or neonat* or newborn* or infant ${ }^{\star}$ or baby or babies or toddler ${ }^{\star}$ ) or AB (perinat ${ }^{\star}$ or neonat $^{\star}$ or $^{*}$ newborn* or infant* or baby or babies or toddler*)

S6. TI (preterm or prematur $\left.{ }^{\star}\right)$ or $A B\left(\right.$ preterm or prematur $\left.{ }^{\star}\right)$

S7. $\mathrm{TI}$ (school age or schoolage) or AB (school age or schoolage)

S8. S1 or S2 or S3 or S4 or S5 or S6 or S7

S9. $\mathrm{MH}$ hospitalization+ or $\mathrm{MH}$ hospitals+ or $\mathrm{MH}$ hospital units+

S10. TI hospital* or AB hospital ${ }^{*}$

S11. MH child, hospitalized or MH adolescent, hospitalized or MH infant, hospitalized

S12. S8 and (S9 or S10)

S.13. $\mathrm{S} 12$ or $\mathrm{S} 11$

S.14. MH patient centered care or $\mathrm{MH}$ family-centered care+

S15. TI (family-centered or family-centered) or AB (family-centered or family-centered)

S16. TI (patient-centered or patient-centered) or AB (patient-centered or patient-centered)

S17. famil* N2 support

S18. $\mathrm{MH}$ professional-family relations or $\mathrm{MH}$ family health or $\mathrm{MH}$ maternal behavior or $\mathrm{MH}$ paternal behavior or $\mathrm{MH}$ parent-child relations+ or $\mathrm{MH}$ caregivers

S19. (child N2 focus ${ }^{\star}$ ) or (famil* N2 focus*)

S20. shar $^{*}$ N2 care

S21. (famil ${ }^{*} \mathrm{~N} 2$ presence) or (mother ${ }^{*} \mathrm{~N} 2$ presence) or (father ${ }^{*} \mathrm{~N} 2$ presence) or (parent ${ }^{*} \mathrm{~N} 2$ presence) or (care* N2 presence)

S22. (famil* N2 collaborat* ${ }^{\star}$ ) or (mother* N2 collaborat ${ }^{\star}$ ) or (father ${ }^{\star}$ N2 collaborat ${ }^{\star}$ ) or (parent ${ }^{\star}$ N2 collaborat $^{\star}$ ) or (care* $\mathrm{N} 2$ collaborat $^{\star}$ )

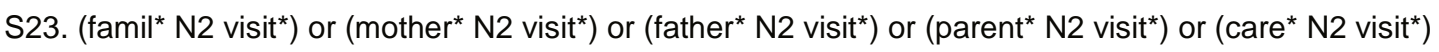

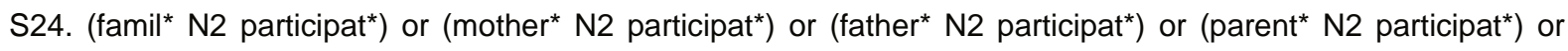
(care* N2 participat*)

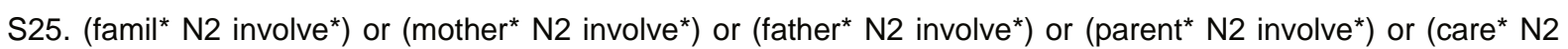
involve*)

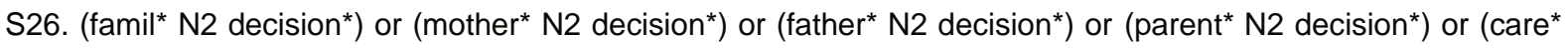
N2 decision*)

S27. (famil ${ }^{*} \mathrm{~N} 2$ communicat $^{*}$ ) or (mother* N2 communicat $^{\star}$ ) or (father* N2 communicat ${ }^{*}$ ) or (parent* N2 communicat $^{\star}$ ) or (care* $\mathrm{N} 2$ communicat $\left.^{\star}\right)$

S28. (care* N2 parent $\left.{ }^{\star}\right)$ or (care* N2 mother $\left.{ }^{\star}\right)$ or (care* N2 father $\left.{ }^{\star}\right)$ or (care* N2 famil ${ }^{\star}$ )

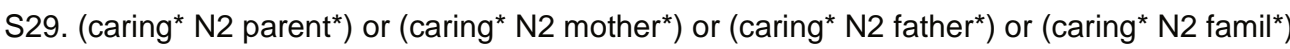

Watts et al. Family-centered care for hospitalized children aged 0-12 years: a systematic review of qualitative studies (C) the authors 2014 doi:10.11124/jbisrir-2014-1683 
S30. S14 or S15 or S16 or S17 or S18 or S19 or S20 or S21 or S22 or S23 or S24 or S25 or S26 or S27 or S28 or $\mathrm{S} 29$

S31. S13 and S30

Sociological Abstracts (ProQuest)

Searched $27 / 11 / 12$ Results $=826$

S1 SU.EXACT.EXPLODE("Preschool Children") OR SU.EXACT("Children") OR SU.EXACT.EXPLODE("Infants" OR "Premature Infants")

S2 $\mathrm{TI}, \mathrm{AB}, \mathrm{IF}\left(\right.$ child $^{\star}$ or neonat ${ }^{*}$ or infant* or newborn* or baby or babies or toddler* or preterm or prematur* or $p^{*}$ ediatric ${ }^{\star}$ )

S3 TI,AB,IF(schoolage) or TI,AB,IF.EXACT("school age")

S4 (SU.EXACT.EXPLODE("Preschool Children") OR SU.EXACT("Children") OR SU.EXACT.EXPLODE("Infants" OR "Premature Infants")) OR TI,AB,IF(child* OR neonat* OR infant* OR newborn* OR baby OR babies OR toddler* OR preterm OR prematur* OR p*ediatric*) OR (TI,AB,IF(schoolage) OR TI,AB,IF.EXACT("school age"))

S5 SU.EXACT("Hospitals")OR SU.EXACT("Hospitalization")

S6 $\mathrm{TI}, \mathrm{AB}, \mathrm{IF}\left(\right.$ hospital $\left.^{\star}\right)$

S7 ((SU.EXACT.EXPLODE("Preschool Children") OR SU.EXACT("Children") OR SU.EXACT.EXPLODE("Infants" OR "Premature Infants")) OR TI,AB,IF(child* OR neonat* OR infant* OR newborn* OR baby OR babies OR toddler* OR preterm OR prematur* OR p*ediatric*) OR (TI,AB,IF(schoolage) OR TI,AB,IF.EXACT("school age"))) AND ((SU.EXACT("Hospitals")OR SU.EXACT("Hospitalization")) OR $\mathrm{TI}, \mathrm{AB}, \mathrm{IF}\left(\right.$ hospital $\left.\left.^{\star}\right)\right)$

S8 TI,AB,IF("patient cent*ed") or TI,AB,IF("patient cent*ed")

S9 SU(family)OR SU.EXACT.EXPLODE("Adolescent Fathers" OR "Adolescent Mothers" OR "Adolescent Parents" OR "Adoptive Parents" OR "Fathers" OR "Grandparents" OR "Homosexual Parents" OR "Mothers" OR "Parents" OR "Single Fathers" OR "Single Mothers" OR "Surrogate Parents" OR "Working Mothers")OR SU(caregivers)

S10 TI,AB,IF((child or famil*) N/2 focus*)

$\mathrm{S} 11 \mathrm{TI}, \mathrm{AB}, \mathrm{IF}\left(\right.$ shar $^{*} \mathrm{~N} / 2$ care $)$

S12 TI,AB,IF(famil* N/2 support)

S13 TI,AB,IF((care or cared or caring) N/2 (parent* or mother ${ }^{\star}$ or father ${ }^{\star}$ or famil $\left.{ }^{\star}\right)$ )

S14 TI,AB,IF((parent* or mother ${ }^{\star}$ or father ${ }^{\star}$ or famil ${ }^{\star}$ or care $\left.{ }^{\star}\right) \mathrm{N} / 2$ (partner ${ }^{\star}$ or participat ${ }^{\star}$ or presence or decision or communicat ${ }^{\star}$ or negotiat* or collaborat $^{*}$ or visit $\left.^{\star}\right)$ )

S15 (TI,AB,IF("patient cent*ed") OR TI,AB,IF("patient $\quad$ cent $^{*}$ ed")) OR $\quad$ (SU(family) OR SU.EXACT.EXPLODE("Adolescent Fathers" OR "Adolescent Mothers" OR "Adolescent Parents" OR "Adoptive Parents" OR "Fathers" OR "Grandparents" OR "Homosexual Parents" OR "Mothers" OR "Parents" OR "Single Fathers" OR "Single Mothers" OR "Surrogate Parents" OR "Working Mothers") OR SU(caregivers)) OR

Watts et al. Family-centered care for hospitalized children aged 0-12 years: a systematic review of qualitative studies (C) the authors 2014 doi:10.11124/jbisrir-2014-1683

Page 244 
TI,AB,IF((child OR famil*) NEAR/2 focus*) OR TI,AB,IF(shar* NEAR/2 care) OR TI,AB,IF(famil* NEAR/2 support) OR TI,AB,IF((care OR cared OR caring) NEAR/2 (parent* OR mother* OR father* OR famil*)) OR $\mathrm{TI}, \mathrm{AB}, \mathrm{IF}\left(\left(\right.\right.$ parent* OR mother* OR father* OR famil* OR care $\left.{ }^{\star}\right)$ NEAR/2 (partner* OR participat* OR presence OR decision OR communicat* OR negotiat* OR collaborat* OR visit*))

S16 ((SU.EXACT.EXPLODE("Preschool Children") OR SU.EXACT("Children") OR SU.EXACT.EXPLODE("Infants" OR "Premature Infants")) OR TI,AB,IF(child* OR neonat* OR infant* OR newborn* OR baby OR babies OR toddler* OR preterm OR prematur* OR p*ediatric*) OR (TI,AB,IF(schoolage) OR TI,AB,IF.EXACT("school age"))) AND ((SU.EXACT("Hospitals")OR SU.EXACT("Hospitalization")) OR TI,AB,IF(hospital $\left.\left.{ }^{*}\right)\right)$ ) AND ((TI,AB,IF("patient cent*ed") OR TI,AB,IF("patient cent $\left.\left.{ }^{*} e d "\right)\right)$ OR (SU(family) OR SU.EXACT.EXPLODE("Adolescent Fathers" OR "Adolescent Mothers" OR "Adolescent Parents" OR "Adoptive Parents" OR "Fathers" OR "Grandparents" OR "Homosexual Parents" OR "Mothers" OR "Parents" OR "Single Fathers" OR "Single Mothers" OR "Surrogate Parents" OR "Working Mothers") OR SU(caregivers)) OR TI,AB,IF((child OR famil*) NEAR/2 focus*) OR TI,AB,IF(shar* NEAR/2 care) OR TI,AB,IF(famil* NEAR/2 support) OR TI,AB,IF((care OR cared OR caring) NEAR/2 (parent* OR mother* OR father* OR famil*)) OR TI,AB,IF ((parent* OR mother* OR father* OR famil* OR care $\left.{ }^{\star}\right)$ NEAR/2 (partner* OR participat* OR presence OR decision OR communicat* OR negotiat* OR collaborat* OR visit*))) 


\section{Appendix II: Family-centeredness score form ${ }^{5}$}

Study ID (Author Surname Year):

Name of review author completing this form:

Date form completed:

Q1

Does this study focus on family-centered care?

YES NO

Q2

Does the model of family-centered care in this study score $\geq 26$ based on criteria below?

NO

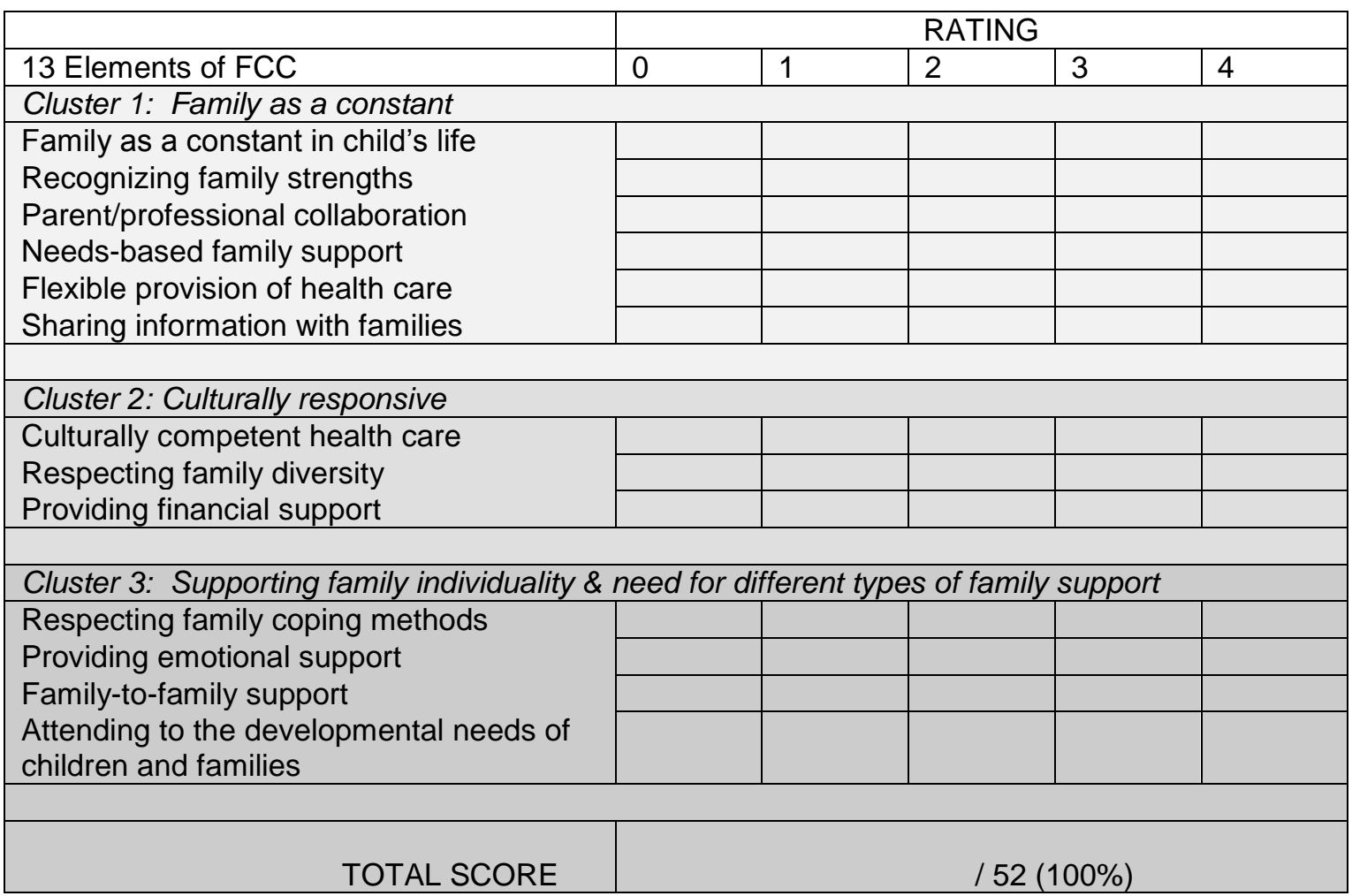

Watts et al. Family-centered care for hospitalized children aged 0-12 years: a systematic review of qualitative 
Instructions for applying the form

Q1:

Include any study that explores the experiences of parents, children's and/or health professionals in relation to the elements of family-centered care during a child's hospitalisation identified above.

\section{Q2: Scoring criteria for family-centeredness}

0 Article includes no evidence that the study's framework and/or findings either implicitly or explicitly addressed or included the specific element of FCC being assessed.

1 Article includes a minimal amount of implicit evidence that the study's framework and/or findings addressed or included the specific element of FCC being assessed.

2 Article includes numerous instances of implicit evidence that the study's framework and/or findings addressed or included the specific element of FCC being assessed.

3 Article includes a minimal amount of explicit evidence that the study's framework and/or findings addressed or included the specific element of FCC being assessed.

4 Article includes numerous instances of explicit evidence that the study's framework and/or findings addressed or included the specific element of FCC being addressed.

Explicit evidence $=$ an element was clearly stated and distinctly expressed

Implicit evidence =if it could be inferred that the author(s) statements, descriptions, discussion, etc. were consistent with the intent of the specific element of FCC. 


\section{APPENDIX III: Study screening tool ${ }^{53}$}

Title:

Author(s):

Year:

\begin{tabular}{|c|c|c|}
\hline Criteria & Satisfied & Comments \\
\hline Type of studies & & \\
\hline $\begin{array}{l}\text { Studies using qualitative methodologies, e.g. } \\
\text { phenomenology, grounded theory, and } \\
\text { descriptive qualitative designs, together with } \\
\text { studies employing mixed methods (only } \\
\text { qualitative data to be considered) being } \\
\text { extracted) }\end{array}$ & & \\
\hline Type of participants & & \\
\hline $\begin{array}{l}\text { Hospitalized children aged } 0-12 \text { years (but } \\
\text { excluding premature neonates), their family } \\
\text { and/or health providers }\end{array}$ & & \\
\hline Phenomenon of interest & & \\
\hline $\begin{array}{l}\text { Family and/or health providers' experience of } \\
\text { family-centered models of care for hospitalized } \\
\text { children. } \\
\text { Only studies that provide clear evidence that the } \\
\text { family and/or child are actively involved in the } \\
\text { planning and/or delivery of health care during the } \\
\text { child's hospitalization are to be included. }\end{array}$ & & \\
\hline Type of outcome measures & & \\
\hline $\begin{array}{l}\text { Experience of family-centered care models of } \\
\text { care from family and/or health providers } \\
\text { (for example: nature of relationships between } \\
\text { family and health care providers, parental comfort } \\
\text { with their degree of involvement in child's care, } \\
\text { family members' stress and anxiety levels ) } \\
\\
\text { Perceptions of family-centered care models of } \\
\text { care by family and/or health providers } \\
\text { (for example: how the experience is viewed, } \\
\text { degree to which expectations are being or have } \\
\text { been met, degree to which the model of care has } \\
\text { been individualized to meet specific needs of } \\
\text { families, degree to which the model of care is } \\
\text { implementable in actual operating contexts, } \\
\text { degree to which health care providers are } \\
\text { committed to the model's implementation) }\end{array}$ & & \\
\hline
\end{tabular}




\section{Appendix IVa: JBI critical appraisal checklist for interpretive and critical research}

\section{JBI QARI Critical Appraisal Checklist for Interpretive \& Critical Research}

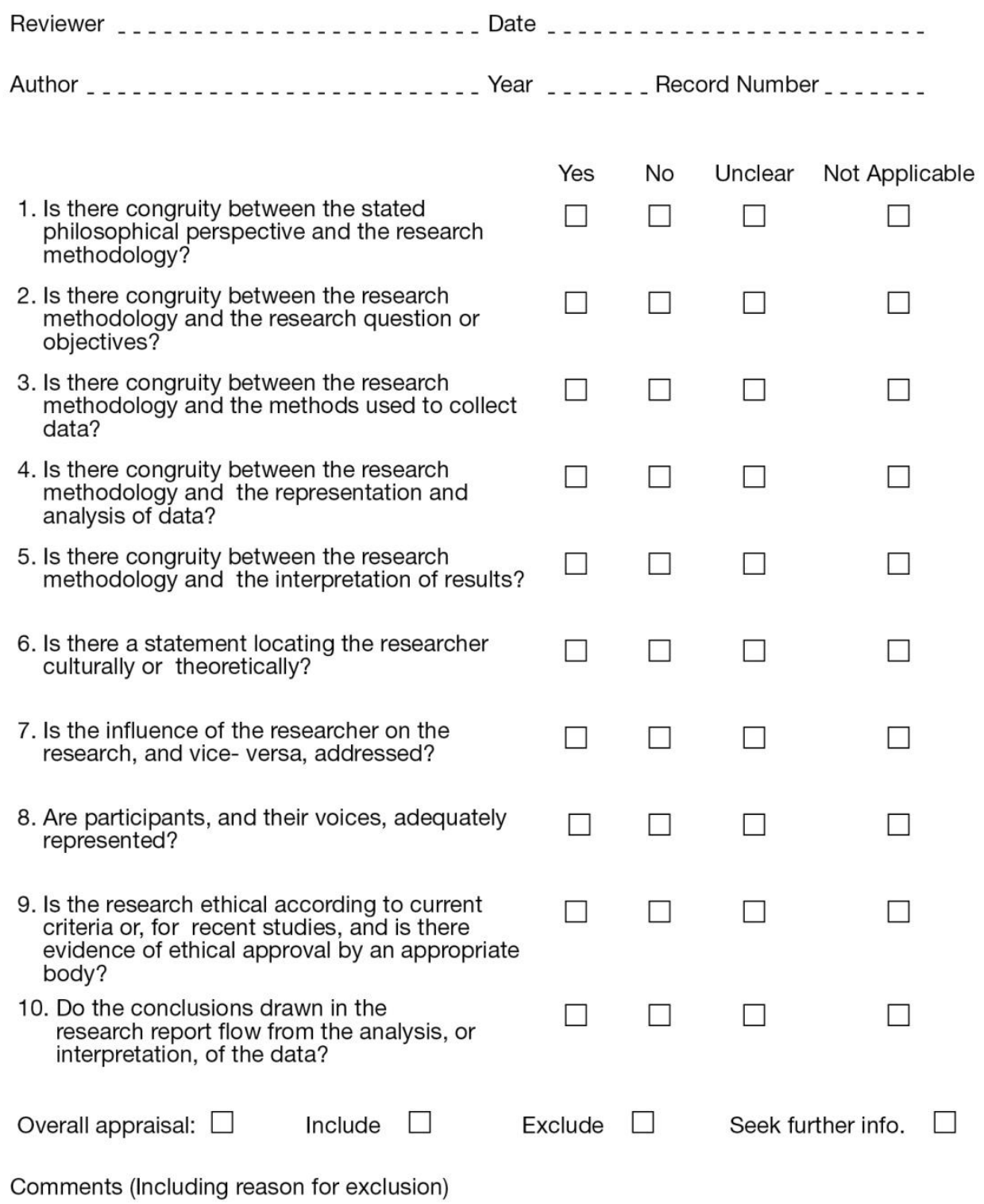

Watts et al. Family-centered care for hospitalized children aged 0-12 years: a systematic review of qualitative 


\section{Appendix IVb: Data extraction form for qualitative studies}

\section{JBI QARI Data Extraction Form for Interpretive \& Critical Research}

Reviewer Date

Author Year

Journal Record Number -

\section{Study Description}

Methodology

Method

Phenomena of interest

Setting

Geographical

Cultural

Participants

Data analysis

Authors Conclusions

Comments

Complete

Yes $\square$

No $\square$

Watts et al. Family-centered care for hospitalized children aged 0-12 years: a systematic review of qualitative 


\begin{tabular}{|l|l|l|l|l|}
\hline \multirow{2}{*}{ Findings } & \multirow{2}{*}{$\begin{array}{c}\text { Illustration from } \\
\text { Publication } \\
\text { (page number) }\end{array}$} & \multicolumn{3}{|c|}{ Evidence } \\
\cline { 3 - 5 } & & & & \\
\hline & & & & \\
\hline & & & & \\
\hline & & & & \\
\hline & & & & \\
\hline & & & & \\
\hline & & & & \\
\hline & & & & \\
\hline & & & & \\
\hline & & & & \\
\hline & & & & \\
\hline
\end{tabular}

Extraction of findings complete $\quad$ Yes $\square \quad$ No $\square$ 


\section{Appendix V: List of excluded studies}

All studies that were subjected to critical appraisal were included in the review. The following studies were excluded on the basis of not meeting the inclusion criteria.

Al-Akour N, Gharaibeh M, Al-Sallal R. Perception of Jordanian mothers of nursing support during their hospitalisation. Journal of Clinical Nursing. 2013; 22 (1-2): 233-9.

Reason for exclusion: Low degree of family-centeredness

Bsiri-Moghaddam K, Bsiri-Moghaddam M, Sadeghmoghaddam L, Ahmadi F. The concept of hospitalization of children from the view point of parents and children. Iranian Journal of Pediatrics. 2011; 21(2): 201-8.

Reason for exclusion: Low degree of family-centeredness

Callery P, Luker K. The use of qualitative methods in the study of parents' experiences of care on a children's surgical ward. Journal of Advanced Nursing. 1996; 23:338-45.

Reason for exclusion: Low degree of family-centeredness

Callery P. Paying to participate: Financial, social and personal costs to parents of involvement in their children's care in hospital. Journal of Advanced Nursing.1997; 25: 746-52.

Reason for exclusion: Low degree of family-centeredness

Coyne I. Children's experiences of hospitalization. Journal of Child Health Care. 2006; 10(4): 326-36.

Reason for exclusion: Low degree of family-centeredness

Coyne I, Cowley S. Challenging the philosophy of partnership with parents: A grounded theory study. International Journal of Nursing Studies. 2007;44: 893-904.

Reason for exclusion: Low degree of family-centeredness

de Lima R, Rocha S, Scochi C, Callery P. Involvement and fragmentation: A study of parental care of hospitalized children in Brazil. Pediatric Nursing. 2001; 27(6): 559-80.

Reason for exclusion: Low degree of family-centeredness

Elander G, Kristensson-Hallstrom. Parents' experience of hospitalization: Different strategies for feeling secure. Pediatric Nursing. 1997; 23(4):361-7.

Reason for exclusion: Low degree of family-centeredness

Evans A. An investigation into the feasibility of parental participation in the nursing care of their children. Journal of Advanced Nursing. 1994; 20: 477-82.

Reason for exclusion: Low degree of family-centeredness and single procedures

Harbaugh B, Tomlinson P, Kirschbaum M. Parents' perceptions of nurses' caregiving behaviors in the pediatric intensive care unit. Issues in Comprehensive Pediatric Nursing. 2004; 27:163-78.

Reason for exclusion: Pediatric Intensive Care Unit setting and low degree of familycenteredness

Hummelinck A, Pollock K. Parents' information needs about the treatment of their chronically ill child: A qualitative study. Patient Education and Counseling. 2006;62:228-34.

Reason for exclusion: Low degree of family-centeredness

Jackson A, Stewart H, O'Toole M, Tokatlian N, Enderby K, Miller J, Ashley D. Pediatric brain tumor patients: Their parents' perception of the hospital experience. Journal of Pediatric Oncology Nursing. 2007; 24(2):95-105. 
Reason for exclusion: Low degree of family-centeredness

Kawik L. Nurses' and parents' perceptions of participation and partnership in caring for a hospitalized child. British Journal of Nursing. 1996; 5(7): 430-7.

Reason for exclusion: Low degree of family-centeredness

Klock P, Erdmann A. Caring for newborns in a NICU: Dealing with the fragility of living/surviving in the light of complexity. Rev Esc Enferm USP. 2012; 46(1):43-9.

Reason for exclusion: Not focused on family-centered care and Neonatal Intensive care Unit setting

Higham S, Davies R. Protecting, providing, and participating: Fathers' roles during their child's unplanned hospital stay, an ethnographic study. Journal of Advanced Nursing. 2012; 69(6): $1390-9$.

Reason for exclusion: Low degree of family-centeredness

Lam L, Chang A, Morrissey J. Parents' experiences of participation in the care of hospitalized children: A qualitative study. International Journal of Nursing Studies. 2006; 43:535-45.

Reason for exclusion: Low degree of family-centeredness

Lee R, Lau V. An interpretive phenomenological study of Chinese mothers' experiences of constant vigilance in caring for a hospitalized sick child. Journal of Advanced Nursing. 2013;69(8): 1808-18.

Reason for exclusion: Low degree of family-centeredness

Macdonald M, Liben S, Carnevale F, Cohen R. An office or a bedroom? Challenges for familycentered care in the pediatric intensive care unit. Journal of Child Health Care. 2012; 16(3): 237-249.

Reason for exclusion: Pediatric Intensive Care Unit setting and three children were over 12 years old

Madrigal V, Carroll K, Hexem K, Faerber J, Morrison W, Feudtner C. Parental decision -making preferences in the pediatric intensive care unit. Critical Care Medicine. 2012; 40(10): 287682.

Reason for exclusion: Pediatric Intensive Care Unit setting and low degree of familyCenteredness

Pinto JP, Ribeiro CA, Vieira de Silva C. Trying to maintain the equilibrium to serve their demands and take care of hospitalized children: the family experience. Revista Latino- Americana de Enfermagem. 2005; 13(6):974-81.

Reason for exclusion: Low degree of family-centeredness

Stratton K. Parents experiences of their child's care during hospitalization. Journal of Cultural Diversity. 2004; 11(1): 4-11.

Reason for exclusion: Children aged one month to 18 years

Traijkoski S, Schmied V, Vickers M, Jackson D. Neonatal nurses' perspectives of family-centered care: A qualitative study. Journal of Clinical Nursing. 2012; 21:2477-87.

Reason for exclusion: Neonatal Intensive Care Unit setting

Watt L, Dix D, Sung J, Klaassen R, Shaw N, Klassen A. Family-centered care: A qualitative study of Chinese and South Asian immigrant parents' expereinces of care in paediatric oncology.

Watts et al. Family-centered care for hospitalized children aged 0-12 years: a systematic review of qualitative studies (C) the authors 2014 doi:10.11124/jbisrir-2014-1683 
Child: care, health and development. 2013; 39(2): 185-93. doi: 10.1111/j.13652214.2011.01342.x. Epub 2011 Nov 9.

Reason for exclusion: Children aged 18 or younger

Wray J, Lee K, Dearmun N, Franck L. Parental anxiety and stress during children's hospitalisation: The StayClose study. Journal of Child Health Care. 2011; 15(3): 163-74.

Reason for exclusion: Low degree of family-centeredness

Wiroonpanich W. Getting back to normal: Parents' perception of hospitalized children undergoing painful abdominal surgery. Songkla Medical Journal. 2006; 24(3): 191-203.

Reason for exclusion: Not focused on family-centered care 


\section{Appendix VI: Summary of included studies}

\begin{tabular}{|c|c|c|c|c|c|}
\hline $\begin{array}{l}\text { Authors/ } \\
\text { year/ } \\
\text { country }\end{array}$ & $\begin{array}{c}\text { Aims/purpose } \\
\text { Research } \\
\text { question }\end{array}$ & Sample & $\begin{array}{l}\text { Design and } \\
\text { methods }\end{array}$ & $\begin{array}{c}\text { Phenomena of } \\
\text { interest }\end{array}$ & Conclusions \\
\hline $\begin{array}{l}\text { Aein, Alhani, } \\
\text { Mohammadi } \\
\& \\
\text { Kazemnejad } \\
50 \\
(2009) \\
\text { Iran }\end{array}$ & $\begin{array}{l}\text { To explore } \\
\text { parents' and } \\
\text { nurses' } \\
\text { experiences of } \\
\text { parental } \\
\text { participation in } \\
\text { child care in } \\
\text { hospitals in Iran }\end{array}$ & $\begin{array}{l}14 \text { parents \& } 11 \\
\text { nurses }\end{array}$ & $\begin{array}{l}\text { A qualitative } \\
\text { approach using } \\
\text { thematic } \\
\text { analysis }\end{array}$ & $\begin{array}{l}\text { Individual } \\
\text { experiences and } \\
\text { perceptions of } \\
\text { participation in } \\
\text { care }\end{array}$ & $\begin{array}{l}\text { The nurses' reliance on the parents in the delivery of care } \\
\text { indicates that parental participation in our sample is about } \\
\text { organizational constraints, not parental empowerment. } \\
\text {...using parents as unpaid care-providers might lead to } \\
\text { parental resentment, jeopardize the child's safety, and } \\
\text { challenge parent-nurse partnership ideology... } \\
\text { Nurses need to make an accurate assessment of the } \\
\text { parents' wishes for participation and negotiate care with a } \\
\text { view to empower the parents to engage and participate. } \\
\text { (p. 226) }\end{array}$ \\
\hline $\begin{array}{l}\text { Callery \& } \\
\text { Smith } 41 \\
(1991)\end{array}$ & $\begin{array}{l}\text { Elicit nurses' } \\
\text { responses to their } \\
\text { perception that a } \\
\text { parent wanted to } \\
\text { increase or } \\
\text { decrease her or } \\
\text { his involvement in } \\
\text { her or his child's } \\
\text { care. }\end{array}$ & $\begin{array}{l}64 \text { nurses } \\
\text { ('sisters', staff } \\
\text { nurses, enrolled } \\
\text { nurses - } \\
\text { numbers in sub- } \\
\text { groups not } \\
\text { reported) } \\
4 \text { returned both } \\
\text { forms blank \& } \\
8 \text { others with } \\
\text { incomplete data }\end{array}$ & $\begin{array}{l}\text { Critical incident } \\
\text { technique } \\
\text { (Flanagan, 1954) } \\
\text { Participants asked } \\
\text { to describe } 2 \\
\text { episodes of } \\
\text { negotiation with } \\
\text { parents, one } \\
\text { where parents } \\
\text { wanted more } \\
\text { involvement and } \\
\text { one where they } \\
\text { wanted less. }\end{array}$ & $\begin{array}{l}\text { Role negotiation } \\
\text { between nurses } \\
\text { and the parents } \\
\text { of hospitalized } \\
\text { children }\end{array}$ & $\begin{array}{l}\text { Pattern of responses related to grade of nurse. ENs } \\
\text { tended to describe themselves as responding to parents } \\
\text { with encouragement, staff nurses described giving } \\
\text { explanations and advice, while sisters were more likely to } \\
\text { describe negotiating with parents. } \\
\text { Suggestion that differences in grades of staff influence the } \\
\text { way nurses relate to parents about their involvement with } \\
\text { their admitted child. (p.779-80) }\end{array}$ \\
\hline $\begin{array}{l}\text { Darbyshire }^{16} \\
\text { (1996) }\end{array}$ & $\begin{array}{l}\text { To explore } \\
\text { parents' lived } \\
\text { experience of } \\
\text { staying in hospital } \\
\text { with their child } \\
\text { and pediatric } \\
\text { nurses' }\end{array}$ & $\begin{array}{l}30 \text { parents }-26 \\
\text { families }(26 \\
\text { mothers, } 4 \\
\text { fathers) } \\
-16 \text { in } 4 \text { focus } \\
\text { groups, }\end{array}$ & $\begin{array}{l}\text { Grounded } \\
\text { theory and } \\
\text { phenomenology }\end{array}$ & $\begin{array}{l}\text { Parents' lived } \\
\text { experience of } \\
\text { staying in } \\
\text { hospital with } \\
\text { their child } \\
\text { Pediatric nurses' } \\
\text { understanding }\end{array}$ & $\begin{array}{l}\text { 1. The nature of being a live-in parent in hospital } \\
\text { 1.1 The ontological sense of being a live-in parent } \\
\text { Nurses need to see being a parent as an ontological } \\
\text { relationship, as a particular way of being-in-the-world with } \\
\text { a child. The parents' child was not simply the object of } \\
\text { their parental work, attention, care and concern. Their }\end{array}$ \\
\hline
\end{tabular}

Watts et al. Family-centered care for hospitalized children aged 0-12 years: a systematic review of qualitative studies @ the authors 2014 doi:10.11124/jbisrir-2014-1683 


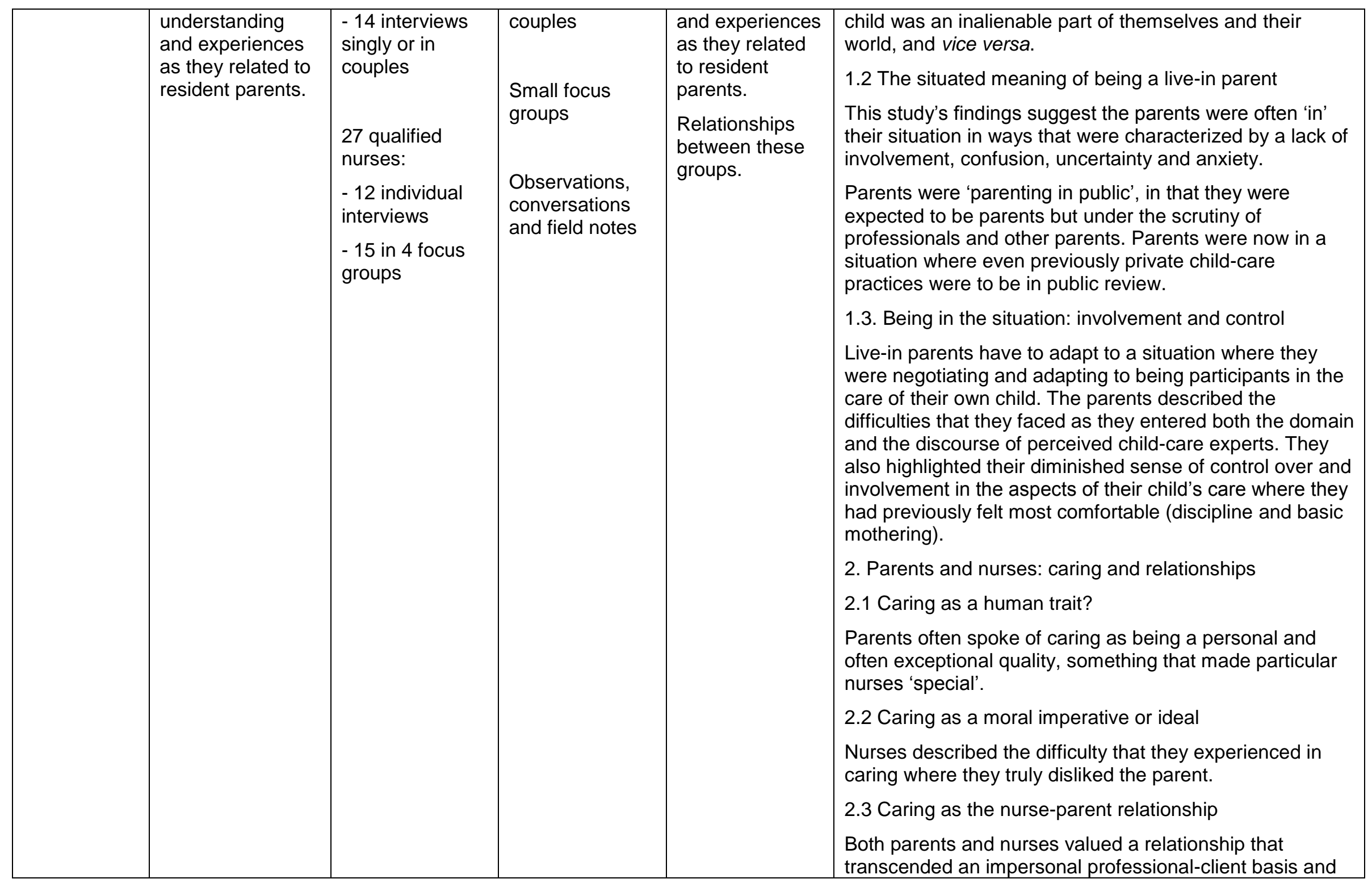

Watts et al. Family-centered care for hospitalized children aged 0-12 years: a systematic review of qualitative studies (C) the authors 2014 doi:10.11124/jbisrir-2014-1683 


\begin{tabular}{|c|c|c|c|c|c|}
\hline & & & & & $\begin{array}{l}\text { developed into more of a friendship. } \\
\text { 3. Caring as a fusion of concerns } \\
\text { This study supports an alternative conceptualization of } \\
\text { caring which stresses not dualism but unity, not } \\
\text { fragmentation but connectedness, not opposition but } \\
\text { relation. } \\
\text { 4. Implications } \\
\text { It was suggested that the involvement and commitment } \\
\text { required by nurses to make FCC the meaningful advance } \\
\text { that it promised to be, far exceeds the demands of giving } \\
\text { purely technical or task-centered pediatric nursing care } \\
\text { Should focus on developing nurses' understanding of } \\
\text { resident parents and of their own nursing practices from } \\
\text { more phenomenological and ontological perspective } \\
\text { Service manager and practitioners to create comfortable } \\
\text { spaces and places for a continuing open dialogue with } \\
\text { those concerned (parents and nurse). }\end{array}$ \\
\hline $\begin{array}{l}\begin{array}{l}\text { Dicastillo \& } \\
\text { Cheung }^{51}\end{array} \\
\text { (2004) } \\
\text { Spain }\end{array}$ & $\begin{array}{l}\text { To explore } \\
\text { experiences of } \\
\text { families with a } \\
\text { child admitted to } \\
\text { hospital in relation } \\
\text { to the facilities } \\
\text { and support, } \\
\text { involvement in the } \\
\text { child's care, care } \\
\text { of the family and } \\
\text { relationships with } \\
\text { health } \\
\text { professionals } \\
\text { caring for their } \\
\text { child }\end{array}$ & $\begin{array}{l}88 / 132 \text { returned } \\
\text { surveys, } 55 \\
\text { families met the } \\
\text { study's inclusion } \\
\text { criteria of having } \\
\text { had a child } \\
\text { hospitalized } \\
\text { Semi-structured } \\
\text { interviews: } 10 \\
\text { mothers - 30\% } \\
\text { were } \\
\text { housewives i.e. } \\
\text { did not work } \\
\text { outside the } \\
\text { home and none } \\
\text { were } \\
\text { unemployed, }\end{array}$ & $\begin{array}{l}\text { Mixed methods } \\
\text { Survey and } \\
\text { semi-structured } \\
\text { interviews } \\
\text { Survey - some } \\
\text { open ended } \\
\text { questions. }\end{array}$ & $\begin{array}{l}\text { Experiences of } \\
\text { families with a } \\
\text { child admitted to } \\
\text { hospital in } \\
\text { relation to the } \\
\text { facilities and } \\
\text { support, } \\
\text { involvement in } \\
\text { the child's care, } \\
\text { care of the } \\
\text { family and } \\
\text { relationships } \\
\text { with health } \\
\text { professionals } \\
\text { caring for their } \\
\text { child }\end{array}$ & $\begin{array}{l}\text { In general terms the families wished to participate in the } \\
\text { care of their child but this participation always had to be } \\
\text { voluntary and individualized. } \\
\text { Health professionals cannot always assume that the } \\
\text { parents are prepared to undertake certain types of care, } \\
\text { nor that all parents will wish to undertake the same type of } \\
\text { care. } \\
\text { To achieve family-centered care changes are required in } \\
\text { the way hospitals function and in the attitudes of health } \\
\text { professionals who work there. }\end{array}$ \\
\hline
\end{tabular}

Watts et al. Family-centered care for hospitalized children aged 0-12 years: a systematic review of qualitative studies () the authors 2014 doi:10.11124/jbisrir-2014-1683 


\begin{tabular}{|c|c|c|c|c|c|}
\hline & & $\begin{array}{l}\text { compared to } \\
15 \% \\
\text { housewives and } \\
11 \% \\
\text { unemployed in } \\
\text { the survey } \\
\text { group - } \\
\text { otherwise socio- } \\
\text { economically } \\
\text { comparable }\end{array}$ & & & \\
\hline $\begin{array}{l}\begin{array}{l}\text { Espezel \& } \\
\text { Canam }^{49}\end{array} \\
(2003) \\
\text { Canada }\end{array}$ & $\begin{array}{l}\text { To examine the } \\
\text { experiences of } \\
\text { parents who } \\
\text { interacted with } \\
\text { nurses in a } \\
\text { hospital setting } \\
\text { regarding the care } \\
\text { of their children }\end{array}$ & $\begin{array}{l}8 \text { parents } \\
\text { representing } 7 \\
\text { families - } \\
\text { repeated } \\
\text { experiences } \\
\text { interacting with } \\
\text { nurses (children } \\
18 / 12+\text { at time } \\
\text { of interview with } \\
\text { medical } \\
\text { conditions } \\
\text { requiring long } \\
\text { term follow-up } \\
\text { and treatment) }\end{array}$ & $\begin{array}{l}\text { Qualitative } \\
\text { approach } \\
\text { In depth } \\
\text { interviews - } \\
\text { open ended } \\
\text { questions. } \\
\text { External to } \\
\text { hospital clinics } \\
\text { Researcher - } \\
\text { field notes, } \\
\text { reflective journal }\end{array}$ & $\begin{array}{l}\text { Experiences of } \\
\text { parents who } \\
\text { interacted with } \\
\text { nurses in } \\
\text { hospital setting } \\
\text { about the care } \\
\text { of their children }\end{array}$ & $\begin{array}{l}\text { Parents who participated in this study reported generally } \\
\text { positive interactions with nurses caring for their children, } \\
\text { but did not characterize these interactions as collaborative } \\
\text { relationships. Parents and nurses were very often able } \\
\text { to establish rapport and share children's care. } \\
\text { However, the degree and ease with which this occurred } \\
\text { was greatly influenced by parental expectations of the } \\
\text { nurse and changes in the child's condition. Parents were } \\
\text { more likely to perceive their interactions with nurses as } \\
\text { positive when the nurse knew the child and acted as a } \\
\text { mediator between doctor and parent. Better } \\
\text { understanding of the elements involved in parent-nurse } \\
\text { interaction in the context of the current health care climate } \\
\text { gives rise to constructive direction for administrative policy } \\
\text { and nursing practice in the pursuit of improving pediatric } \\
\text { health care. (p.40) }\end{array}$ \\
\hline $\begin{array}{l}\text { Mackean, } \\
\text { Thurston \& } \\
\text { Scott }^{9} \\
(2005) \\
\text { Canada }\end{array}$ & $\begin{array}{l}\text { To develop a } \\
\text { conceptualization } \\
\text { of FCC grounded } \\
\text { in the experiences } \\
\text { of families and } \\
\text { direct health-care } \\
\text { providers }\end{array}$ & \begin{tabular}{|l}
37 parents \\
(children- 19 \\
autism \\
spectrum, 12 \\
Down's \\
syndrome, 6 pre \\
- schoolers with \\
developmental \\
delay) \\
16 front line
\end{tabular} & $\begin{array}{l}\text { Qualitative - } \\
\text { Grounded } \\
\text { Theory } \\
5 \text { focus groups - } \\
31 \text { parents ( } 7 \\
\text { groups); } 15 \\
\text { health care } \\
\text { providers }\end{array}$ & $\begin{array}{l}\text { The experiences } \\
\text { of families and } \\
\text { HCPs in relation } \\
\text { to FCC }\end{array}$ & $\begin{array}{l}\text { Based on key findings from the research reported here, } \\
\text { we argue for a re-examination of where we are going with } \\
\text { respect to family-centered care, and advocate strongly for } \\
\text { moving beyond conceptualizing and operationalizing } \\
\text { family-centered care as the training of parents to assume } \\
\text { more responsibility. } \\
\text { The results of the research do not support the primary } \\
\text { focus of family-centered care being to shift } \\
\text { responsibility of caring for children with illnesses and/or } \\
\text { disabilities from the health-care system to families. }\end{array}$ \\
\hline
\end{tabular}

Watts et al. Family-centered care for hospitalized children aged 0-12 years: a systematic review of qualitative studies (C) the authors 2014 doi:10.11124/jbisrir-2014-1683 


\begin{tabular}{|c|c|c|c|c|c|}
\hline & & $\begin{array}{l}\text { health care } \\
\text { providers } \\
\text { working in } \\
\text { developmental } \\
\text { services }\end{array}$ & $\begin{array}{l}\text { (HCPs) } \\
\text { Face to face } \\
\text { semi structured } \\
\text { interviews - } 7 \text { (6 } \\
\text { parents, } 1 \mathrm{HCP})\end{array}$ & & $\begin{array}{l}\text { Rather, they support the importance of the development of } \\
\text { collaborative relationships between families and health- } \\
\text { care providers, where the respective roles are jointly } \\
\text { determined rather than dictated by health care providers. } \\
\text { To advance family-centered care research and practice, } \\
\text { collaborative processes at multiple levels involving } \\
\text { children, families, front-line health care providers, } \\
\text { managers, and policy-makers is the way forward. } \\
\text { This will require building on what is known about } \\
\text { collaboration, effective client health-care provider relation- } \\
\text { ships, individual change, organizational change, and } \\
\text { public participation in policy and decision-making. } \\
\text { Future research needs to be planned so as to begin to } \\
\text { bridge the current disconnect between the perspectives of } \\
\text { family-centered care 'experts' and families themselves. } \\
\text { (p.83) }\end{array}$ \\
\hline $\begin{array}{l}\text { Neill }^{42,43} \\
\text { (1996a \& } \\
\text { 1996b) }\end{array}$ & $\begin{array}{l}\text { To explore } \\
\text { parents' views } \\
\text { and experiences } \\
\text { of participating in } \\
\text { their hospitalized } \\
\text { child's care and to } \\
\text { identify factors } \\
\text { that inhibit or } \\
\text { facilitate } \\
\text { participation }\end{array}$ & $\begin{array}{l}16 \text { parents of } \\
\text { children } 2-5 \\
\text { years with } \\
\text { various medical } \\
\text { conditions, } \\
\text { differing lengths } \\
\text { of stay and from } \\
0-10 \text { previous } \\
\text { hospital } \\
\text { admissions }\end{array}$ & $\begin{array}{l}\text { Descriptive } \\
\text { qualitative } \\
\text { Semi-structured } \\
\text { interviews within } \\
2 \text { months of } \\
\text { child's discharge } \\
\text { (1-8 weeks) } \\
\text { One participant } \\
\text { interviewed at } \\
\text { work, others at } \\
\text { Opportunity for } \\
\text { families to } \\
\text { review transcript } \\
\text { - none took up } \\
\text { option. }\end{array}$ & $\begin{array}{l}\text { Parents' } \\
\text { experience of } \\
\text { participating in } \\
\text { their } \\
\text { hospitalized } \\
\text { child's care }\end{array}$ & $\begin{array}{l}\text { The findings suggest that parents do want to participate in } \\
\text { the care of their child in hospital, but at a level of their own } \\
\text { choosing. } \\
\text { Parents believed that participation is beneficial to both the } \\
\text { child and themselves and implied that pediatric nurses } \\
\text { need to consider how best to facilitate this process. } \\
\text { Nurses need to understand and avoid inhibitory factors } \\
\text { and to use facilitative factors to implement these findings } \\
\text { in the practice setting. } \\
\text { The inhibitory factors identified all stem from one common } \\
\text { problem: lack of adequate communication. In this study } \\
\text { this resulted in: } \\
\text { - Parents' lack of information } \\
\text { - Nursing and medical staff who were seen as } \\
\text { unapproachable } \\
\text { - Parents' perceptions of professionals as paternalistic } \\
\text { - Misunderstanding of the nurse's role } \\
\text { - Lack of parental involvement in the use of the nursing } \\
\text { process. }\end{array}$ \\
\hline
\end{tabular}

Watts et al. Family-centered care for hospitalized children aged 0-12 years: a systematic review of qualitative studies @ the authors 2014 doi:10.11124/jbisrir-2014-1683 


\begin{tabular}{|c|c|c|c|c|c|}
\hline & & & & & $\begin{array}{l}\text { The facilitative factors identified included the following } \\
\text { aspects of communication: } \\
\text { - Negotiation between parents and nursing staff } \\
\text { - Positive professional attitudes, such as being } \\
\text { approachable; volunteering information; and providing for } \\
\text { continuity of parental role } \\
\text { - Information giving, both verbal and written } \\
\text { - The development of trusting relationships. } \\
\text { All of these factors should be used to inform practice and } \\
\text { so enhance participation. } \\
\text { Overall it is clear from the findings that parents were not } \\
\text { participating in the care of their children in hospital in this } \\
\text { research setting at the time of the study. However, the } \\
\text { facilitative factors identified demonstrate that parent } \\
\text { participation is a practical possibility. A particular difficulty } \\
\text { remains, however, for parents of first admission short-stay } \\
\text { children. Further research is needed in this area. (p.116) }\end{array}$ \\
\hline $\begin{array}{l}\text { Paliadelis, } \\
\text { Cruickshank, } \\
\text { Wainohu, } \\
\text { Winskill \& } \\
\text { Stevens }^{47} \\
\text { (2005) } \\
\text { Australia }\end{array}$ & $\begin{array}{l}\text { To explore how } \\
\text { pediatric nursing } \\
\text { staff included and } \\
\text { involved family } \\
\text { members in the } \\
\text { care of the } \\
\text { hospitalized child }\end{array}$ & $\begin{array}{l}\text { Pediatric nurses } \\
\text { who care for } \\
\text { hospitalized } \\
\text { children in the } \\
\text { pediatric wards } \\
\text { of two hospitals } \\
\text { in regional NSW } \\
\text { Nurses with a } \\
\text { diverse range of } \\
\text { pediatric } \\
\text { experience }\end{array}$ & $\begin{array}{l}\text { Qualitative } \\
\text { approach }\end{array}$ & $\begin{array}{l}\text { Beliefs, } \\
\text { perceptions and } \\
\text { experiences of } \\
\text { how pediatric } \\
\text { nursing staff } \\
\text { included and } \\
\text { involved family } \\
\text { members in the } \\
\text { care of the } \\
\text { hospitalized } \\
\text { child }\end{array}$ & $\begin{array}{l}\text { The findings of this study showed that the pediatric nurses } \\
\text { who participated all believed strongly in the 'family- } \\
\text { centered care' concept, yet they found the application in } \\
\text { practice to be somewhat challenging. } \\
\text { Challenges described by the participants were linked to } \\
\text { the nurses' beliefs about their own professional role, their } \\
\text { desire to see themselves as the 'experts' in the care of } \\
\text { hospitalized children. } \\
\text { Participants described their role as involving not only } \\
\text { providing nursing care for the patient and family but also } \\
\text { protecting family members from painful or unpleasant } \\
\text { experiences. } \\
\text { This study provided significant insight into nurses' } \\
\text { assumptions, beliefs and experiences of implementing } \\
\text { family-centered care. (p. 36) }\end{array}$ \\
\hline
\end{tabular}

Watts et al. Family-centered care for hospitalized children aged 0-12 years: a systematic review of qualitative studies () the authors 2014 doi:10.11124/jisisri-2014-1683 


\begin{tabular}{|c|c|c|c|c|c|}
\hline $\begin{array}{l}\text { Roden }^{30} \\
\text { (2005) } \\
\text { Australia }\end{array}$ & $\begin{array}{l}\text { To explore, in } \\
\text { community } \\
\text { hospitals: } \\
\text { a) parents' } \\
\text { perceptions of } \\
\text { participation } \\
\text { b) factors } \\
\text { influencing } \\
\text { parents' } \\
\text { participation } \\
\text { c) attitudes of } \\
\text { pediatric nurses } \\
\text { to parent } \\
\text { participation } \\
\text { d) factors } \\
\text { influencing } \\
\text { nurses' } \\
\text { perceptions of } \\
\text { parental } \\
\text { participation }\end{array}$ & $\begin{array}{l}\text { Parents: } 2 \\
\text { couples } \\
\text { (presume } \\
\text { mother and } \\
\text { father in each); } \\
9 \text { mothers, } 1 \\
\text { father, } 2 \text { female } \\
\text { carers } \\
\text { Nurses: 1st } \\
\text { focus group - } 7 \\
\text { (5-RN, 1- NM, } \\
\text { 1-EN), 2nd FG - } \\
5 \text { (3-RN, 1- NM, } \\
\text { 1-EN) }\end{array}$ & $\begin{array}{l}\text { Qualitative } \\
\text { grounded theory } \\
\text { techniques } \\
\text { Focus group } \\
\text { interviews, } \\
\text { parents' and } \\
\text { nurses' groups } \\
\text { separately } \\
\text { then, nurse } \\
\text { group were } \\
\text { asked to review } \\
\text { the parents' } \\
\text { interviews and } \\
\text { then discuss, in } \\
\text { further focus } \\
\text { groups, what } \\
\text { was contained } \\
\text { in the parents' } \\
\text { interviews, this } \\
\text { providing more } \\
\text { data which was } \\
\text { analyzed. }\end{array}$ & $\begin{array}{l}\text { Parents' and } \\
\text { nurses' } \\
\text { perceptions of } \\
\text { parental } \\
\text { participation in a } \\
\text { child's care } \\
\text { while in hospital } \\
\text { and influencing } \\
\text { factors }\end{array}$ & $\begin{array}{l}\text { Communication problems were the central issue - both } \\
\text { parents and nurses saw real communication problems in } \\
\text { their relationship. } \\
\text { The four main themes arose from parental factors: control, } \\
\text { expectation, support and emotion: communication; } \\
\text { importance of being with your child; mothers do the } \\
\text { mothering and nurses do the nursing. (p.222) } \\
\text { Implications for practice and research were identified. }\end{array}$ \\
\hline $\begin{array}{l}\text { Shields \& } \\
\text { King } 44,45 \\
\text { (2001a \& } \\
2001 b) \\
\text { Australia } \\
\text { Britain }\end{array}$ & $\begin{array}{l}\text { To explore the } \\
\text { attitudes of } \\
\text { parents and staff } \\
\text { about the care of } \\
\text { children in } \\
\text { hospital and the } \\
\text { cultural influences } \\
\text { on their } \\
\text { relationships }\end{array}$ & $\begin{array}{l}\text { Total of } 23 \\
\text { hospitals - } \\
\text { general pediatric } \\
\text { wards - } \\
\text { Australia, } \\
\text { Britain, } \\
\text { Indonesia, and } \\
\text { Thailand } \\
150 \text { single }\end{array}$ & $\begin{array}{l}\text { Qualitative } \\
\text { approach } \\
\text { In depth } \\
\text { individual } \\
\text { Interviews } \\
\text { Two vignettes }\end{array}$ & $\begin{array}{l}\text { The attitudes of } \\
\text { parents and } \\
\text { staff about the } \\
\text { care of children } \\
\text { in hospital and } \\
\text { the cultural } \\
\text { influences on } \\
\text { their } \\
\text { relationships }\end{array}$ & $\begin{array}{l}\text { Cultural constructions have large influences on } \\
\text { the delivery of care to children and families in } \\
\text { hospital, and parents' expectations of that care. This } \\
\text { qualitative research project has highlighted the importance } \\
\text { of communication in the pediatric hospital, regardless of } \\
\text { the culture. Parents have strong expectations that their } \\
\text { child will receive treatment for its condition and needs } \\
\text { including support for other family members and, in } \\
\text { Indonesia and Thailand in particular consideration about } \\
\text { how they are going to care for their child and maintain }\end{array}$ \\
\hline
\end{tabular}

Watts et al. Family-centered care for hospitalized children aged 0-12 years: a systematic review of qualitative studies () the authors 2014 doi:10.11124/jbisrir-2014-1683 


\begin{tabular}{|c|c|c|c|c|c|}
\hline $\begin{array}{l}\text { Indonesia } \\
\text { Thailand }\end{array}$ & & $\begin{array}{l}\text { interviews } \\
179 \text { Australia - } \\
91 \text {; Britain- 49; } \\
\text { Indonesia - } 28 ; \\
\text { Thailand - } 11 \\
46 \text { focus group } \\
\text { interviews with } \\
\text { up to } 8 \text { per } \\
\text { group } \\
76 \text { parents, } 94 \\
\text { nurses, } 22 \\
\text { doctors, and } 53 \\
\text { allied health }\end{array}$ & $\begin{array}{l}\text { with one } \\
\text { question to } \\
\text { invoke } \\
\text { discussion }\end{array}$ & & $\begin{array}{l}\text { employment. } \\
\text { Communication skills should be a part of any medical, } \\
\text { nursing or allied health curriculum, and in-service } \\
\text { programs in health facilities. The need for improvement in } \\
\text { communication between parents and staff has proved to } \\
\text { be one of the major findings of this project. All health staff } \\
\text { working with children and parents need to learn a wide } \\
\text { range of communication skills. } \\
\text { Culture has proved to be largely influential on the way } \\
\text { care is delivered and parents 'expectations of that care, } \\
\text { irrespective of their country or cultural background. There } \\
\text { is little research about the influence of culture on hospital } \\
\text { care in developing countries, and little awareness of the } \\
\text { effect of cultural constructions such as class, religion, and } \\
\text { gender on the care of children in hospital. These effects } \\
\text { need to be identified, investigated, and taught. (p.213) }\end{array}$ \\
\hline $\begin{array}{l}\text { Teare \& } \\
\text { Smith } 46 \\
(2004) \\
\text { UK }\end{array}$ & $\begin{array}{l}\text { To inform an } \\
\text { action plan to } \\
\text { identify good } \\
\text { practice and } \\
\text { improve aspects } \\
\text { of service delivery } \\
\text { identified as of } \\
\text { concern to } \\
\text { parents }\end{array}$ & $\begin{array}{l}4 \text { focus groups } \\
\text { - } 15 \text { parents, of } \\
\text { which } 13 \text { were } \\
\text { mothers \& } 2 \\
\text { were fathers } \\
\text { - } 11 \text { Caucasian } \\
\text { participants - } 4 \\
\text { South Asian } \\
\text { participants } \\
\text {-13 were } \\
\text { resident parents } \\
\text {-7 parents } \\
\text { attended the } \\
\text { group with a } \\
\text { child/ baby }\end{array}$ & $\begin{array}{l}\text { Descriptive } \\
\text { qualitative } \\
\text { Focus groups }\end{array}$ & $\begin{array}{l}\text { Experiences of } \\
\text { parents whose } \\
\text { child has been } \\
\text { hospitalized }\end{array}$ & $\begin{array}{l}\text { The findings from this study have given a substantial } \\
\text { insight into what parents experience while in our care, } \\
\text { some of which should reassure staff that their efforts in } \\
\text { providing quality care do not go unnoticed and do have a } \\
\text { positive effect on parents. } \\
\text { Other findings clearly indicate a need for physical actions, } \\
\text { such as provision of parent information, and staff to care } \\
\text { for parents waiting with their child; as well as action to } \\
\text { address the invisible aspects of caring for children and } \\
\text { their parents. These include how we communicate } \\
\text { verbally, with body language and written communication. } \\
\text { Our attitudes and communication skills often create the } \\
\text { basis of parent/ practitioner relationship for the entirety of } \\
\text { a hospital stay and, as these parents confirmed, remain } \\
\text { as dominant memories in their experiences of hospital } \\
\text { care. } \\
\text { Parents in these focus groups appreciated an opportunity } \\
\text { to tell their story and we would recommend strongly that }\end{array}$ \\
\hline
\end{tabular}

Watts et al. Family-centered care for hospitalized children aged 0-12 years: a systematic review of qualitative studies () the authors 2014 doi:10.11124/jbisrir-2014-1683 


\begin{tabular}{|c|c|c|c|c|c|}
\hline & & & & & $\begin{array}{l}\text { focus groups are continued in the future to obtain users' } \\
\text { views of our services (p.34) }\end{array}$ \\
\hline $\begin{array}{l}\text { Verwey, } \\
\text { Jooste \& } \\
\text { Arries }^{27} \\
\text { (2008) } \\
\text { South Africa }\end{array}$ & $\begin{array}{l}\text { To describe } \\
\text { recommendations } \\
\text { to support parents } \\
\text { with the } \\
\text { hospitalization of } \\
\text { their child }\end{array}$ & $\begin{array}{l}\text { Parents: } \\
\text { biological, } \\
\text { adoptive, single/ } \\
\text { two parents, } \\
\text { step parents } \\
\text { Numbers not } \\
\text { specified }\end{array}$ & $\begin{array}{l}\text { Qualitative } \\
\text { Interpretive- } \\
\text { phenomenology } \\
\\
\text { Unstructured } \\
\text { individual } \\
\text { interviews, } \\
\text { narrative diaries, } \\
\text { field notes }\end{array}$ & $\begin{array}{l}\text { Role of the } \\
\text { family in a } \\
\text { child's illness } \\
\text { and support } \\
\text { given to them }\end{array}$ & $\begin{array}{l}\text { There is demand for parental participation at various } \\
\text { levels during hospitalization of child. Some parents } \\
\text { embrace this positively while others show resistance. } \\
\text { Further study in South Africa re parent participation is } \\
\text { needed. (p.41) }\end{array}$ \\
\hline $\begin{array}{l}\text { Wilson }^{48} \\
\text { (2004) } \\
\text { Australia }\end{array}$ & $\begin{array}{l}\text { To identify to what } \\
\text { extent family- } \\
\text { centered care } \\
\text { was being } \\
\text { practiced in rural } \\
\text { areas } \\
\text { To explore in } \\
\text { parents' and } \\
\text { nurses' } \\
\text { perceptions of the } \\
\text { concept of family } \\
\text { centered care }\end{array}$ & $\begin{array}{l}\text { Parents - } 243 \\
\text { Nurses - } 108\end{array}$ & $\begin{array}{l}\text { Questionnaire } \\
\text { with open ended } \\
\text { questions } \\
\text { Non- } \\
\text { experimental } \\
\text { design with } \\
\text { qualitative } \\
\text { component }\end{array}$ & $\begin{array}{l}\text { Parents' and } \\
\text { nurses' } \\
\text { perceptions of } \\
\text { the concept of } \\
\text { family-centered } \\
\text { care }\end{array}$ & $\begin{array}{l}\text { Although nurses believe they facilitate family-centered } \\
\text { care, parents claim it occurs far less than nurses indicate. } \\
\text { It is apparent that many nurses are only focusing their } \\
\text { attention on the child and the direct involvement that } \\
\text { parents want with the child's care. Little consideration is } \\
\text { given to the other aspects which impact on a family when } \\
\text { a child is hospitalized such as support for and comfort } \\
\text { needs of the parents and assisting parents to attend to } \\
\text { other roles. For those nurses who are including parents in } \\
\text { the care of their child, the parents' involvement is being } \\
\text { assessed on admission but not renegotiated routinely } \\
\text { throughout the hospital stay. } \\
\text { Nurses need to communicate more frequently with } \\
\text { parents. Nurses must actively and objectively assess the } \\
\text { parents' desire for participation on a regular basis, at least } \\
\text { daily. Parents and nurses must become partners in the } \\
\text { care of the child. Each partner needs to articulate their } \\
\text { expectations and understand the expectations of the other } \\
\text { so they can work with each other. Nurses who work } \\
\text { through this process of assessment and negotiation with } \\
\text { families will find that there will be better communication } \\
\text { with all involved, fewer misunderstandings and lost }\end{array}$ \\
\hline
\end{tabular}

Watts et al. Family-centered care for hospitalized children aged 0-12 years: a systematic review of qualitative studies () the authors 2014 doi:10.11124/jbisrir-2014-1683 


\begin{tabular}{|c|c|c|c|c|c|}
\hline & & & & & $\begin{array}{l}\text { opportunities for care and teaching. } \\
\text { The health care system also has to improve facilities } \\
\text { available to children and families. Adequate } \\
\text { accommodation, meal arrangements and phone access } \\
\text { for families are required. Separate rooms for children that } \\
\text { are decorated to make the hospitalization experience less } \\
\text { threatening, the provision of a play area and equipment } \\
\text { are basic requirements when incorporating pediatric beds } \\
\text { in a hospital profile. } \\
\text { Family-centered care needs to be defined in the broadest } \\
\text { possible sense to encompass the whole family of the } \\
\text { child. As health professionals nurses need to see beyond } \\
\text { the child to the parents who are trying to maintain their life } \\
\text { at home as well as support the child in hospital and to } \\
\text { siblings who need to visit the sick child or establish other } \\
\text { lines of communication. Consistent with Knafl et al. } \\
\text { (1988), some nurses have begun to achieve this wider } \\
\text { view of the family, but many still focus their attention only } \\
\text { on the child, and do not provide for the family to assist } \\
\text { them through a stressful time. (p.111) }\end{array}$ \\
\hline $\begin{array}{l}\text { Ygge }^{26} \\
\text { (2007) } \\
\text { Sweden }\end{array}$ & $\begin{array}{l}\text { To examine } \\
\text { registered nurses' } \\
\text { perceptions of } \\
\text { parental } \\
\text { involvement and } \\
\text { communication in } \\
\text { pediatric hospital } \\
\text { care }\end{array}$ & $\begin{array}{l}\text { Registered } \\
\text { Nurses: } \\
\text { Group } 1 \\
\text { experienced } \\
\text { pediatric nurses } \\
\text { ( } \mathrm{n}=7 \text { ) } \\
\text { Group } 2 \text { recent } \\
\text { nursing } \\
\text { graduates }(\mathrm{n}=6)\end{array}$ & $\begin{array}{l}\text { Qualitative } \\
\text { exploratory } \\
\text { study }\end{array}$ & $\begin{array}{l}\text { Registered } \\
\text { nurses' } \\
\text { perceptions of } \\
\text { parental } \\
\text { involvement and } \\
\text { communication } \\
\text { in pediatric } \\
\text { hospital care }\end{array}$ & $\begin{array}{l}\text { Younger and less experienced nurses may have } \\
\text { difficulties in separating role as nurse and friend. More } \\
\text { experienced nurses know parents do not need friends - } \\
\text { need professionals able to perform nursing interventions } \\
\text { with warm, empathic relationship. Need for pediatric } \\
\text { hospital to have nurses who communicate with child and } \\
\text { family, aware of their impact and help with role clarification } \\
\text { for parents of children in hospital.(p.40) }\end{array}$ \\
\hline
\end{tabular}


Appendix VII: Methodological assessment

\begin{tabular}{|c|c|c|c|c|c|c|c|c|c|c|}
\hline Study & Q1 & Q2 & Q3 & Q4 & Q5 & Q6 & Q7 & Q8 & Q9 & Q10 \\
\hline $\begin{array}{l}\text { Aein, et.al } \\
200950\end{array}$ & $\mathrm{~N} / \mathrm{A}$ & $Y$ & $Y$ & $Y$ & Y & $Y$ & $\begin{array}{c}\text { Part } 1 \\
-Y\end{array}$ & $Y$ & $Y$ & $Y$ \\
\hline $\begin{array}{c}\text { Callery \& } \\
\text { Smith } \\
1991^{41}\end{array}$ & $\mathrm{~N} / \mathrm{A}$ & $Y$ & Y & $Y$ & Y & $Y$ & $\mathrm{~N}$ & $Y$ & $Y$ & $Y$ \\
\hline $\begin{array}{c}\text { Darbyshire } \\
1994\end{array}$ & $Y$ & $Y$ & $Y$ & $Y$ & $Y$ & $Y$ & $Y$ & $Y$ & $Y$ & $Y$ \\
\hline $\begin{array}{c}\text { Dicastillo \& } \\
\text { Cheung } \\
2004^{51}\end{array}$ & $\mathrm{~N} / \mathrm{A}$ & $Y$ & $Y$ & $Y$ & $Y$ & $\mathrm{~N}$ & $N$ & $Y$ & $\begin{array}{l}\text { Part } 1 \\
-Y\end{array}$ & $Y$ \\
\hline $\begin{array}{c}\text { Espezel \& } \\
\text { Canam } \\
2003^{49} \\
\end{array}$ & $\mathrm{~N} / \mathrm{A}$ & $Y$ & $Y$ & $Y$ & $Y$ & $\mathrm{~N}$ & $\begin{array}{l}\text { Part } \\
1-Y\end{array}$ & $Y$ & $Y$ & $Y$ \\
\hline $\begin{array}{l}\text { MacKean, } \\
\text { et.al. } \\
2005^{9} \\
\end{array}$ & Y & $Y$ & $Y$ & $Y$ & $Y$ & $\mathrm{~N}$ & $Y$ & $Y$ & $Y$ & $Y$ \\
\hline $\begin{array}{c}\text { Neill } \\
1996^{42 ., 43} \\
\end{array}$ & $\mathrm{~N} / \mathrm{A}$ & $Y$ & $Y$ & $Y$ & $Y$ & $\mathrm{~N}$ & $\mathrm{~N}$ & $Y$ & $Y$ & $Y$ \\
\hline $\begin{array}{l}\text { Paliadelis, } \\
\text { et.al. } \\
2005^{47}\end{array}$ & $\mathrm{~N} / \mathrm{A}$ & $Y$ & $Y$ & $Y$ & $Y$ & $\mathrm{~N}$ & $\mathrm{~N}$ & $Y$ & $Y$ & $Y$ \\
\hline $\begin{array}{l}\text { Roden } \\
2005^{30}\end{array}$ & $Y$ & $Y$ & Y & $Y$ & $Y$ & $\mathrm{~N}$ & $\begin{array}{l}\text { Part } \\
1-Y\end{array}$ & $Y$ & $\begin{array}{l}\text { Part } 1 \\
-Y\end{array}$ & $Y$ \\
\hline $\begin{array}{c}\text { Sheilds \& } \\
\text { King } \\
2001^{44,45}\end{array}$ & $\mathrm{~N} / \mathrm{A}$ & $Y$ & Y & $Y$ & $Y$ & $\mathrm{~N}$ & $\begin{array}{l}\text { Part } \\
1-Y\end{array}$ & $Y$ & $\begin{array}{c}\text { Part } 1 \\
-Y\end{array}$ & $Y$ \\
\hline $\begin{array}{c}\text { Teare \& } \\
\text { Smith } \\
2003^{46}\end{array}$ & $\mathrm{~N} / \mathrm{A}$ & $Y$ & $Y$ & $Y$ & $Y$ & $\mathrm{~N}$ & $\mathrm{~N}$ & $Y$ & $\begin{array}{c}\text { Part } 1 \\
-Y\end{array}$ & $Y$ \\
\hline $\begin{array}{l}\text { Wilson } \\
2004{ }^{48}\end{array}$ & $\mathrm{~N} / \mathrm{A}$ & $Y$ & Y & $Y$ & Y & $\mathrm{N}$ & $N$ & $Y$ & $Y$ & $Y$ \\
\hline $\begin{array}{c}\text { Verwey, } \\
\text { et.al. } \\
2008{ }^{27}\end{array}$ & Y & $Y$ & $Y$ & $Y$ & $Y$ & $Y$ & $Y$ & $Y$ & $Y$ & $Y$ \\
\hline $\begin{array}{c}\text { Ygge } \\
200726\end{array}$ & $N / A$ & $Y$ & $Y$ & $Y$ & Y & $\mathrm{N}$ & $\mathrm{N}$ & $Y$ & $Y$ & Y \\
\hline $\begin{array}{c}\% \text { of Yes } \\
\text { responses }\end{array}$ & $29 \%$ & $100 \%$ & $100 \%$ & $100 \%$ & $100 \%$ & $29 \%$ & $36 \%$ & $100 \%$ & $86 \%$ & $100 \%$ \\
\hline
\end{tabular}




\section{Appendix VIII: Study findings with illustrations}

Findings - Parents

\section{Synthesis 1: Parent engagement}

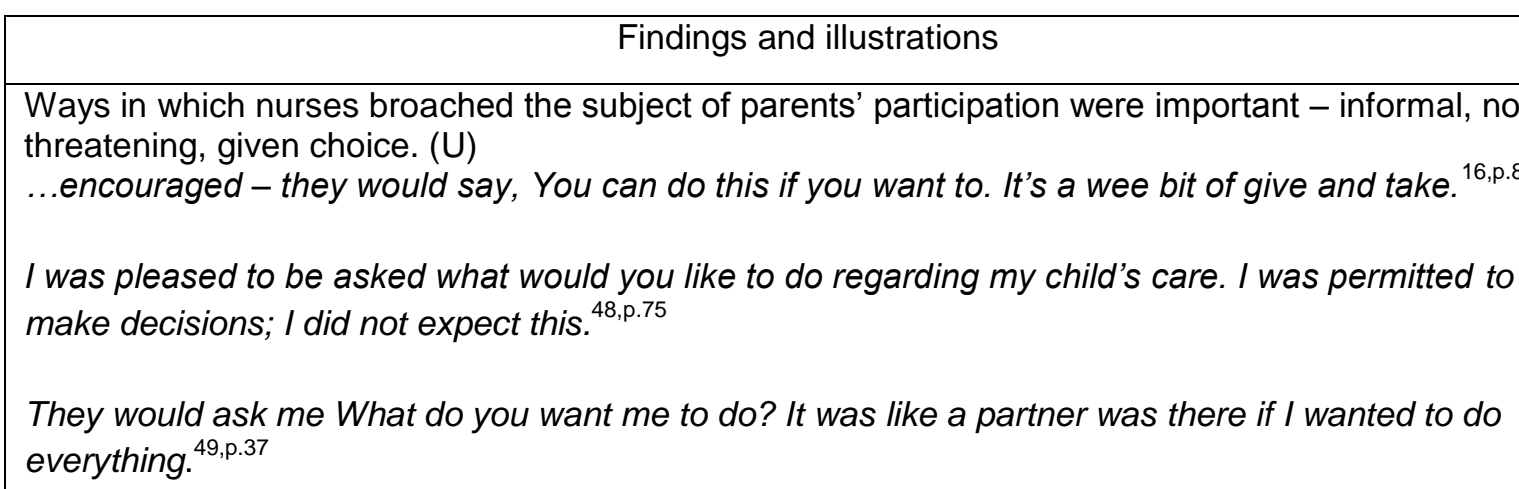

They encouraged me to stay... When (child) was settled after her fit they encouraged me to go home, shower, clean clothes, food etc. (time out) and to then come back and settle for the night. Very happy to look after her. ${ }^{48, p .75}$

As we got more used to it we started to do things like physio and wash her, do her mouthwash and things like that. (Interviewer): How did that feel to you? It made us feel really, really happy. ${ }^{43, p .112}$

...and they always say - well what does mum think, so I feel like they're asking my permission as well. $^{46, p .9}$

Parental lack of knowledge about the nature and possible extent of participation. (U)

I was surprised that they let the mothers do so much... just because I didn't know what to expect... ${ }^{16, p .84}$

Parent participation an unspoken assumption. (U)

You're not told basically, and they don't ask you what you would like. ${ }^{16, p .85}$

I felt like, coz I was there, they didn't bother, sometimes... coz they think Oh well, their mum's there and they go and help somebody else who hasn't got a mum there. ${ }^{43, p .111}$

I think some nurses kind of expected you to do a little more. Like I went in because there's, you know, nursing shortage as it is. I did a lot of procedures with the doctors instead of a nurse coming in sometimes... I went in and kind of assisted because they didn't have any nurses available. ${ }^{49, p .37}$

Most parents willing to do the mothering but reluctant to perform nursing care. (U)

No... I don't have any ideas about what I want to do for B... No, not really I just leave them to do the nursing and I do the mothering. . $^{30,232}$

I do all the direct care... they don't do any of it really, that's my choice..$^{46, p .15}$

We're doing the basic care while she's here. They come to us, you know, and ask us when she's been to the toilet, what she's been drinking, what she's been eating ... ${ }^{30, p .228}$

You care for him by nursing and cuddling him... the mother does this the best... whereas I'd say nursing is more making sure that her blood pressure's OK, that she's breathing OK, making sure that she gets the right amount of Ventolin and stuff like that. ${ }^{30, p .232}$

As one mother said, she was not going to change dressings or touch the intravenous line because if she was at home she would only be changing nappies and giving fluids. ${ }^{30, p .232}$

Watts et al. Family-centered care for hospitalized children aged 0-12 years: a systematic review of qualitative 
I prefer the nurse to take the temperature as she does it better... Nurses must do this job as it is their duty. ${ }^{50, p .224}$

At home if your child's ill you take their temperature... There are times when you could do it, it would make the child feel more comfortable, and you more comfortable, get you more involved in the nursing side of caring for your child. But not if it was really important to be very accurate, if the child was very ill. Then I don't think the parents should do it. ${ }^{43, p .111}$

Nature of participation was determined by severity of child's illness or injury. (U)

There was nothing we could do, he was on a ventilator he was so sick... It's different now (out in ward) , I can do things for him ${ }^{16, p .86}$

Some parents wish to be involved in planning the child's nursing care. (U)

l'd got it all worked out, so she wasn't in any pain at all, so the drugs overlapped so she wouldn't be in any pain. ${ }^{46, p .15}$

Parents want to negotiate and have some control over the extent of their participation. (U) The nurse just said to me Is it all right if I just leave it to you to look after her? And I said Yes, that's fine. ${ }^{43, p .114}$

If I'm there, if she's due her nebuliser or whatever, due her medication, the nurses will say to me Would you like to give $S$ this? Would you mind? Well of course I wouldn't, you know... ${ }^{43, p .114}$

No, they didn't ask me about my wishes, it is what they say themselves, I didn't want it. ${ }^{50, p .225}$

...more open discussion and understanding of the fact that the person they are treating is not their patient, but my child. ${ }^{48, p .74}$

...I think I have been his carer, I've been the one that's done it really but I still think that there should be back up from the nursing staff...16,p.87

Delegation of nursing care to parent can lead to overloading the parent and inconsistency in care. (U) I have become tired. It is almost 2 months [that] we have been here. They have asked me to give [a nebulizer] every $2 \mathrm{~h}$ but I give [it to] him once every $6 \mathrm{~h}$. I am tired and fed up... (Mother of a child with cystic fibrosis) $)^{50, p .225}$ 
Feeling powerless in caring for their child. (U)

They don't ask the parents... I'm only the mother... they don't take any notice of me. ${ }^{30, \mathrm{p} .228}$

I felt that I had lost any control I should have had over my child's health care. I was kept informed of his medical needs but not included in any decisions regarding his care. We were expected to conform to hospital practices. ${ }^{48, p .74}$

I felt that I had lost any control I should have had over my child's health care. I was kept informed of his medical needs but not included in any decisions regarding his care. We were expected to conform to hospital practices. ${ }^{48, p .74}$

There was an instance where my son would not take his medication and while I was downstairs they put a tube down his throat which made him more upset. They should have waited for me to come back. $^{48, p .74}$

As far as her welfare was, I was no longer the one in charge of it all. They were the one in charge. ${ }^{43, p .112}$

There wasn't as much control as I would have liked, or information coming back..$^{43, p .112}$

Because...we felt useless. I mean you could talk to her and we did that as much as we could, but...although she knew we were there, it was more physical contact that we wanted. ${ }^{43, p .112}$

The worst was when they told me I wasn't allowed to go with her when they put the drip in...what mother can leave her child while they hold her down and hurt her? $?^{27, p .34}$

Need for training from staff prior to care delegated to parents

They ask me to take the temperature and urine sample. I'm not very literate and not well informed either. They don't teach me... ${ }^{50, p .224}$

I would like the staff to take the time necessary to teach me how to give certain types of care. I would like them to be certain of my ability before leaving me with the responsibility for providing a given aspect of care. The medical personnel need to be certain that the parents know what they have to do before devolving this to us. $(M 7)^{51, p .90}$

I saw the nurses doing these jobs [taking the temperature]. I also learnt how to do the... ${ }^{50, p .224}$

I can actually get the medication down her - daddy can't... he eventually had to walk up to the front desk and say now look who's going to help me give my child this medication? $?^{46, p .10}$

Now, I know how to take the temperature but many mothers don't know how to do it. There is no one to do it for them either. Mothers teach each other how to. (Mother) ${ }^{50, p .224}$

Need for consistency in instruction. (U)

...We have even been discharged without enough information... Even nurses instruct me differently. One tells me to put [the insulin] injection each time on one hand, another says if one hand is overinjected, use the other hand. Actually, I don't know what to do. ${ }^{50, p . ~ 224}$

The need for assistance with advocacy in a complex, fragmented system for a child with longer term needs. (U)

Our struggle began... When it comes down to advocacy... you can only do that to a point, and I think that is something that hopefully will develop and be explored more in the future. But how much energy can you have left [to advocate] for your child when you are trying to care for this child? You run out of energy to be a wife and a mother and a person. Um, like, you can only do so much. ${ }^{9, p .80}$

Yup, it's basically incumbent on the parents... If I'm not going to have anybody coordinating any of this crap for me... I want something so that I don't feel so

Watts et al. Family-centered care for hospitalized children aged 0-12 years: a systematic review of qualitative studies (C) the authors 2014 doi:10.11124/jbisrir-2014-1683 
responsible..$^{9, p .19}$

If you are a good advocate for your child, and we are all good advocates, let's face it, because that's why we're all here. We're doing great; our kids are doing great; we're getting the best of everything. And we are making sure they do, but we're such a small percentage... ${ }^{9,0.80}$

Everybody was telling us, get ready to fight for speech. We were at a point now, like when our whole family was just about crashed, we were going, (sigh), we gotta fight for something [else] now. Who's going to help me here? Like, whadya mean we gotta fight? ${ }^{9, p .80}$

...you know, you're emotive and attempting to advocate in a system that makes absolutely no sense. You know, even to me [because I work in the system], I just couldn't find a way to navigate through it, and found it very frustrating. (parent) $)^{9, p .80}$

\section{Synthesis 2: Caring for the parent carer}

Advising parent of available facilities. (U)

I suppose I should have asked them about a shower, but I didn't realize there was a shower room. ${ }^{46, p .11}$

Well I've never really asked about a bath or a shower for me. ${ }^{46, p .11}$

I wasn't aware that toast came round in the morning for parents, I'm budgeting so have no spare cash, I came without a purse, came straight from the GP. ${ }^{46, p .11}$

Where must I find transport at that time... and then I had to pay extra, because there are so few taxis. ${ }^{27, p .} 37$

Sources of support - other parents. (U)

We are lucky we have made friends, but the first few days, l've not had friends and once you get to talk it's not bad. ${ }^{46, p .12}$

The unknown (U)

You stress because it's the unknown. Like you go in there with them and you don't after the last hospital. You don't know how fast they're going to get treated or if they're going to get the attention they need. You're worried about them and all you can think about is, are they going to have time for me? ? $^{30, p .229}$

You always worry and you're concerned about your sick child. ${ }^{30, p .23}$

Waiting for admission (U)

Dehydration that can mean all sorts of problems to me. Dehydration. Whether you bundle them off to hospital for dehydration and not look after the others, that is not the biggest worrying thing. How long will you be in there for, how quickly can they get them a bed. The specialist treatment that she needs. Being with the other kids and her mother. ${ }^{44, p .143}(\mathrm{U})$

The surgeon was told about the case at 1630 and at 2000 still hasn't arrived to see my son, nor has he seen my son's $x$-rays. ${ }^{27, p .39}$

Sometimes babies cry with hunger and they are thirsty because they took so long time. ${ }^{46, p .13}$

Their child's distress $(U)$

I didn't like to see... It was hurting her... you don't want something to hurt your child and you don't like to see something that is hurting them, you want to stop it, but she had to have it done 
to get made better. (Interview $8, M)^{43, p .115}$

You wish you could be in her shoes and just take all the pain and make her feel better straight away... It's so hard, it's really hard. ${ }^{30, p .232}$

Synthesis 3: Interpersonal skills and communication

Parents valued staff who:

- $\quad$ were patient and unhurried in their interactions with them and their child. (U)

They tried to coax her for 10 minutes to take this medicine ... They spent time you know, they didn't give you a minute then force it, they gave time... patience. ${ }^{16, p .125}$

- $\quad$ took or found the time to speak to them or do something special for the child. (U)

Sally is awfully good with her. She'll sit and talk to her, get her teddies and play with her... 16,p. 125

...and talk to her and distract her the whole time... and they build good relationships with the child. $^{27, \text { p.39 }}$

- $\quad$ allowed parents to talk about what was of importance to them and express their feelings openly. (U)

...somebody who doesn't mind me talking and mentioning all the things and someone who explains everything to me... they would say Don't be embarrassed, just if you want to cry just sit there and cry... ${ }^{16, p .126}$

- $\quad$ were warm and friendly. (U)

If there's a friendlier approach you appreciate it more. You're a person then, not just this mother, a parent. ${ }^{16, p .126}$

We were welcomed when we came and the nurses and doctors have just been fabulous. ${ }^{46, p .12}$

- $\quad$ showed an interest (compared to going through the motions). (U)

They took an interest... have seen to him, that went over and spoke to him, they actually took time and spoke to him...16.p.127

Even if they see me in the corridor they stop me and say how is she today? ${ }^{46, p .12}$

They do seem genuinely interested to help you; you don't feel you're in the way. ${ }^{46, p .13}$

- $\quad$ supported and coaxed them, fostering hope through encouragement. (U)

There are certain nurses who have cared for him quite often and I feel really care about him... who are really behind him... Basically they keep your spirits up, they've kept mine up... they do jolly me along. ${ }^{16, p .128}$

- $\quad$ caring $(\mathrm{U})$

You need that... whatever that is, caring and humanity or compassion, along with competency. 9, p.78

Some nurses have big levels of empathy with us and others are on a different level.

It's the way they talk to you, like body language and stuff, the way they react to you...

... and you can tell who cares. ${ }^{46, p .12}$

Importance of continuity of staff in building rapport. (U) 
If a nurse keeps coming in they build a bond between themselves...makes the patient happy as well as the parent (referring to the same nurse). ${ }^{46, p .13}$

You definitely need the same ones because you do build a rapport. ${ }^{46, p .13}$

Differences in interpersonal skills between staff. (U)

The nurses are better. The doctors are sometimes gruff, no bedside manner. Very gruff as to what's going to go on, and I think the nurses are better. ${ }^{49, p .} 38$

I guess it's irrelevant what their bedside manner is. I mean, I guess what you're looking for is the best you can get... I mean, I found Dr [name] just horrendous but I said after the fact, in a crisis do you think that doctor will do the best for your child? I guess you just have to swallow whatever else comes along with it. ${ }^{49, p .38}$

They [the nurses] were really good. They were informative and they always answered all my questions and told me everything, or most of them anyway. Probably more so than the doctors because the doctors just kind of speak in their language and you don't really know half of what they're saying. But the nurses will explain exactly what they were saying, which was nice. $^{49, p .38}$

Rudeness of staff. (U)

Need more old fashioned bed side manner and treat people the way you would want to be treated. $^{48, p .77}$

...the person who came and took my son's blood tests was extremely unpleasant, my son had had a fit and was unconscious when she tried to put the needle in his arms (had to try both). My son responded by wriggling and crying - she yelled at him and told him he was being a stupid little boy... ${ }^{48, p .87}$

Judgmental attitudes exhibited by staff. (U)

And, I also found a lot of judgmental behavior towards working mothers, I mean mothers who work outside of the home; like in other words you should devote 24 hours a day to implementing the things we are teaching you [about working with your child at home]... ${ }^{9, p .79}$

My daughter's condition had been happening for 10 days and when I got to hospital several nurses (not all) made me feel like a paranoid mother. ${ }^{48, p .77}$

Failure to acknowledge parents know their child. (U)

I just think they should listen to me when I say I know she is in pain. ${ }^{46, p .9}$

Like you know what's normal for him. It took me 3 weeks to get somebody to listen to me. ${ }^{46, p .9}$

I think it was right he did something with the nurses... they, by taking him for a walk, could see how he reacted, actually being rather floppy. It was [up to] somebody else to actually verify what we were saying, rather than us...ut... as I said to the consultant quite a few times he's very tired and he can't manage to walk very far". I was just told that 5 year-old boys do get tired. Our word against his really. ${ }^{43, p .112}$

Importance of good communication skills. (U)

That's what I liked about them (the nurses,) that they were always very positive. They would always say, you know, Well this is common... that's good. They would share with me their experiences that this is what happens. They would give me something that wasn't really that positive, but they would back it up with something that was a little bit more positive just to try and reassure me and make me feel better. ${ }^{49, p .38}$

Watts et al. Family-centered care for hospitalized children aged 0-12 years: a systematic review of qualitative studies (C) the authors 2014 doi:10.11124/jbisrir-2014-1683 


\begin{abstract}
We always had one person who was actually looking after him, which I thought was very good...if I needed any reassurance, or wanted to know anything or felt he was going downhill or something, then I would know which - rather than knowing that you have to stop another nurse who was busy or something - you knew you'd been allocated to a nurse, knew her name obviously, and they knew the case, and I thought that was very good. ${ }^{43, p .113}$

In terms of the patient, the communication between doctors, and the parents, it is very important that the parents are kept very aware of what is happening and what is likely to happen so they can prepare themselves for the situation. I believe that the child should be kept as comfortable as possible and obviously this is no always possible but where he should be kept basically informed in every sense..$^{4, p .142}$
\end{abstract}

Access to an interpreter. (U)

Well I understand it but my husband he didn't understand, so I need to tell him, so it's good to have an interpreter. ${ }^{46, p .10}$

Importance of both verbal and written information. (U)

They're doing a thing now where they've got a little board up over the bed. You know, my name is $S$ and my doctor is... my nurse is... so if I phoned up... it was much easier to ask for the particular nurse who was looking after $S^{43, p .113}$

Understanding the impact of stress on parents' ability to retain information

With somebody whose child is that sick, your mind is in such a turmoil, you don't know if you're coming or going, and you're yesing one minute, like I mean, I'm sure half the time sister's saying to me, and the eyes... I'd be looking at her, but half the time I wouldn't be listening to her. $^{43, p .113}$

Advised re discharge. (U)

Doctor $x$ told me we can go home tomorrow probably and then he will just continue with the antibiotics at home. ${ }^{27, p .36}$

Effective communication between health care professionals. (U)

Since we came through our GP with a letter, it has just been plain sailing. ${ }^{46, p .10}$

Insufficient or no information provided to parents. (U)

We feel that in that sort of situation you shouldn't really have to [ask]. We should have been informed. ${ }^{43, p .113}$

When you're waiting you don't feel safe you don't know what is happening, they're not explaining to you. ${ }^{46, p .13}$

If I hadn't read my own Kardex, I wouldn't have known anything about that and I don't think that is fair. ${ }^{46, p .9}$

I refused to sign consent and that was an issue because the surgeon wanted to operate and he was scrubbed up and refused to come into the theatre reception area to tell me what he wanted to do, So I said I am taking him to another hospital. ${ }^{27, p .38}$

...and half an hour later they come and it's too late (waiting for a response from a nurse). ${ }^{46, p .14}$

I felt sort of isolated, that they knew what they were doing to my little girl and her condition.

And the one closest to her knew nothing about it.. I felt blocked out. ${ }^{43, p .111}$

That's what's up with you two isn't it, because you're getting no answers. Whereas I know what's wrong with mine but you two don't. ${ }^{46, p .14}$

Watts et al. Family-centered care for hospitalized children aged 0-12 years: a systematic review of qualitative 
They won't come out with it straight and say this is what's wrong with them. ${ }^{46,0.14}$

I just wish there is some evidence you know to say we don't know why this was caused but we'll do tests to see if we can find out what is going on. ${ }^{46, p .14}$

We have never been told the results of those tests, we have no idea. ${ }^{46, p .14}$

Is you at the end of the day as a parent to keep asking questions as to what's wrong and have they got the results. ${ }^{46, p .14}$

He (the doctor) saw me and came and said... he's fine, they definitely won't need to operate. That wasn't explained to me that if he had the infection to his knee joint, they'd have to operate. I was not upset, hut feeling a lot worse because I didn't really know that he could have had an operation. 43, p. 113

I don't have time to go through this [chart], give me the long and short of what she's got... I mean I can't tell that [child] doesn't have the thing [certain vein coming off the heart] he needs, unless he shows me a diagram like they did the third time and say, 'This is what he's missing.' I didn't know that... ${ }^{\text {,p.79 }}$

I was a little bit expecting... It didn't actually happen... think they expected me to come in and say 'Look, I'm the mother... I'm taking over from my husband... 30,p.228

And I expected them to come in with me and sort of... or at least tell me out there about everything that's happened... but that didn't happen... So, I asked them. ${ }^{30, p .228}$

\section{Synthesis 4: Impact on family}

Findings and illustrations

Caring for other members of the family. (U)

It's just hard... especially if you've got other kids at home and you don't get to see them ...

You're sort of stuck between a rock and a hard place... you're stuck in the middle and you can't do anything and you want to make her better so you can get home and look after the other one... I'm sure there are some mothers that aren't here whose children cry constantly for them. They probably have other children but don't have anybody to leave them with. This means they can't visit their sick ones... I feel sorry for people like that because at least I know that if my children are sick, my mum's always there to look after the other ones. ${ }^{30, p .} 232$

It is an extra pressure to have to find someone to care for your children while you are in hospital with the one who is sick. While there are a lot of things happening, you have to juggle the co-ordination of the other children's care along with everything else..$^{51, .89}$

Surely parents feel busy because they have other matters to take care of in addition to taking care of their sick child. I would choose to stay with my sick child and allow my other children to be looked after by family, relatives, or the housemaid, or if necessary even by a good neighbor. In a position such as mine, I would stay with my ... child ... . ${ }^{4, p .143}$

I know mine haven't been to school as I haven't been able to do any washing of their uniforms. 46, p. 11

I have one older son. I've left him in the care of God... I am really concerned about him but I focus all my effort on my ill child. ${ }^{50, p .223}$

...that my child's stay may impact on her sibling... found out in later weeks the distress caused to her sister through reading her school diary. ${ }^{48, p .75}$

Watts et al. Family-centered care for hospitalized children aged 0-12 years: a systematic review of qualitative studies (C) the authors 2014 doi:10.11124/jbisrir-2014-1683 
Impact on employment. (U)

My priority would certainly be to the others, to get them to school, clothing, all the practicalities that would go through my head but the main thing is I would stay, and also work I would have to cancel that, but my main priority would be to be with $Z^{44}$, p.144

\section{Synthesis 5: Barriers to implementation}

\section{Nurses' workload (U)}

Findings and illustrations

I would say that $80 \%$ of them (nurses) you could have a wee conversation with, but you hate to keep them back from their work 'cos they're aye that busy, so you don't like to talk too long 'cos they're always busy. ${ }^{16, p .122-123}$

...they always give the impression they've got no time for you... it looks as though they haven't got time to stop, and unless they're sitting down at the desk you think l'd better not ask because she's busy or l'd better not do that because she's too busy to give me a hand... ${ }^{43, p .112}$ Hospital routines (U)

Hospital is a busy place - jobs need to be done - cleaners/nurses - more important in their day to complete tasks than to consider the needs of individuals. ${ }^{48, p .74}$

Allowed to sleep on bed beside child by night staff but up before day staff arrived. ${ }^{51, \mathrm{p} .89}$

Lack of facilities (U)

A child's (sic) ward would be great; my six year old daughter was in with a 70 year old lady. 48,p. 74

Phones not accessible, this was a great inconvenience. ${ }^{27, p .40}$

It feels like sitting in a corridor (waiting for a child to be assessed) ${ }^{46, p .13}$

It is just the sleeping on the couch, I don't know, they must try something that will make you feel comfortable at night you see and maybe supply food to the parents if they have infants that need $24 / 7$ care. $^{27, \text { p. } 39}$

\section{Synthesis 6: Parental perspectives on the provision of care}

\begin{tabular}{|l|}
\hline \multicolumn{1}{|c|}{ Findings and illustrations } \\
\hline $\begin{array}{l}\text { Immediate, prioritized attention (U) } \\
\text { Immediate care was given rather than form filling, this was brilliant, my child had a chest } \\
\text { infection and the nurses gave her oxygen straight away. }{ }^{46, p .12}\end{array}$ \\
$\begin{array}{l}\text { A feeling of safety (U) } \\
\text { I think the best thing about while you are in hospital is that you are in safe hands. }{ }^{4, p .12} \\
\text { As soon as you get in the room you feel safe when they are around you. }{ }^{46, p .12} \\
\text { I am 100\% satisfied that she is in good hands. }{ }^{27, p .38} \\
\text { I guess, just that he's looked after correctly, that he gets all his medicine and stuff on time, } \\
\text { that, yeah, that's about all. }{ }^{44, p .142}\end{array}$ \\
\hline
\end{tabular}

Watts et al. Family-centered care for hospitalized children aged 0-12 years: a systematic review of qualitative studies (C) the authors 2014 doi:10.11124/jbisrir-2014-1683 
They know what they're doing, they know more than me, so 1 would listen to the doctors. ${ }^{43, p .}$
You put yourself in their hands.
You're.114
there's always somebody there to help you. ${ }^{43, \text { p. }^{114}}$

Time for family (U)

They've been good this time... Y Yeah, a lot better than the last two times ... they're not so busy. ${ }^{30, \text { p.229 }}$

The level of care was superb and exceeded expectations ... looked after us as friends. ${ }^{48, p .77}$

Care environment (U)

Her bed was changed a lot... everything and everyone is very neat here. ${ }^{27, \text { p. } 37}$

Lack of care (U)

Poor child hadn't been bathed... 27,p. 37

Nurses should help maintain child's normal routines $(\mathrm{U})$

The nurses should ask you about the child's daily routine and help you stick to it. ...bed lower to the ground so if your child is potty trained they can hop out themselves and go. ${ }^{48, p .74}$

The nurses' role $(\mathrm{U})$

They're round checking temperatures and taking their pulse rates... bring children their feeds and change them and wash them... and obviously there's times when they go round with the medications too. ${ }^{16, p .121}$

I think their work must be pretty boring (laughs) ... it doesn't seem particularly skilled work. 16, p. 121

Narrative: Benefits of parental presence

Findings and illustrations

Parental presence provides emotional security for the child. (U)

I must stay here. My child would never settle here without me. ${ }^{50, \text { p.223 }}$

Like you say, two to five. That's the age they really miss you... At that age they would really notice if you weren't there. I think you would have to be there really... Her arms were always out for me anyway. ${ }^{43,}$ p.110

Your baby knows you better than the nurses. So if you are with your baby then the baby doesn't have much problems, so to be with your baby I think is a fine thing. ${ }^{27, p .34}$

I think the mother should really be there for the child regardless of the child's age 'cause they fret, they're in a strange place. ${ }^{30,}$ p.232

Parents know their child. (U)

Mum does know best, because mum knows what they are like normally ${ }^{46, \text { p.14 }}$ 


\section{Parents know what is happening with their child - reduces parental anxiety \\ I think it's good because you're there, and at least you're knowing what's happening to them, giving you peace of mind as well... You're watching them and seeing what's going on. ${ }^{43, p .111}$ \\ It's your child and you might have to come home and care for that child at home.... if they are going to be ill a lot of the time, obviously you have got to be involved from that point of view. 43,p. 111 \\ Helping the nurses \\ I know they've got other things they could be doing, and instead of me just sitting there watching, it would save a bit more time if I could do it. ${ }^{43, p .111}$ \\ I dare say it takes the strain away from them as well towards that child... and they can spend more time with another child. ${ }^{16, p .} 87$ \\ I don't think this hospital would run if everyone's mum went home. ${ }^{46, p .15}$ \\ Ensuring the child was not neglected. (U) \\ I don't dare leave my child alone...I cannot be at all confident of the care he will receive if I leave him... Nurses are so busy. They have much...work to do... ${ }^{50,2.223}$ \\ I wouldn't even leave her to go to the toilet, I had to wait until one of the staff were ready, had 10 minutes to sit with her. ${ }^{46, p .11}$}

Since a mother is more compassionate than a nurse, she does a better job and that's why I love to do these tasks. I am more comfortable this way, rather than troubling the nurses. If I ask the nurse to change the serum, it will take a quarter or half an hour to attend [to] my child... ${ }^{50, p .224}$

Well, if I don't do this, then who else would?... nurses would not come to do the job. ${ }^{50, p .224}$

The professionals cannot be here in the room all the time; they have to do other things. So they don't know if the children are eating. They don't know if they are drinking enough fluids. Some things they have to leave to us (the parents) and these are what I have to do myself. 51, p. 90

All morning l've wanted to go out for a fag and a cup of coffee, and l've waited till 10 minutes before we came up here, because I daren't leave her. ${ }^{46, p .11}$

Findings - Healthcare professionals

Synthesis 7: Health care professionals' (HCPs) understanding of the concept of familycentered care (FCC)

Findings and illustrations

Nurses acknowledged the importance of assuming responsibility for care and protection of families, not just individual child. (U)

Some may think you should say to parents you need to do this, but it's not fair when parents are stressed anyway. We need to fulfill our role and look after the child and the parents. ${ }^{47, p .35}$

Watts et al. Family-centered care for hospitalized children aged 0-12 years: a systematic review of qualitative 
Health care practitioners believed the service should be driven by family needs. (U) But we really don't have a client, needs-based system here at all...the interactions that go on between individual patients and providers [may be positive], but the system that surrounds that very important dyad should become the fundamental basis of an integrated system of care for families. ${ }^{9, p .80}$

Importance of knowing the family and involving them. (U)

In this children's hospital we always involve the family in treating their children. So when treating a child, we must have more knowledge of the patient's family so that we can give them guidance and counselling. ${ }^{45, p .} 208$

Nurses felt more support for parents meant more support given to child. (C)

The most important thing in collaboration with parents is to make them feel good as parents. 26,p.39

Some HCPs identified the role parents were able to play would vary between families and working with families was a collaboration process. (U)

...each parent... you know, and couple being so different in how much, and how little, and what kind of information and trying to be sensitive to that to engage them in the process. 9,p.79

Most of the nurses stated that a parental presence meets the needs of the child, reduces the child's emotional stress, increases the child's security and cooperativeness, and decreases behavioral issues. (U)

Taking care of everything in general and altogether. These include physical, mental and social aspects. Nurse Thailand ${ }^{45, \mathrm{p} .208}$

[The] presence of [the] mother is very important from the emotional viewpoint. [The] child experiences a particular sense of comfort in the mother's arms ... ${ }^{50, p .233}$

Parental presence valued as reduced nurses' workload - help with basic care and relieving distress. (U)

They know what their kids eat, they shut them up when they are crying. ${ }^{16, p .109}$

Nurses recognized parents know their child best $(U)$

They tend to notice sooner if their child isn't the normal or if they are not acting normally ... 16,p. 108

A mother is able to understand her child and explain him well. ${ }^{50, p .223}$

Many mothers are well informed. Often, the nurse doesn't see many signs that she needs to report to the doctor but, instead, the mother does this job... Our nurses ask the mothers to be keen to these signs and report them to nurses or [the] doctor. ${ }^{50, p .225}$

Nurse manager viewed parents as informal evaluators of care. (U)

Mothers are there and see what the nurse is doing for the child, which they later report to me ... 50,p. 225

The general consensus among nurses was that basic mothering tasks were the province of parents and more technical tasks that of nurses. (U)

...I mean the normal things that they would do at home - the mothering type things like washing and feeding... nothing like giving medicines or anything like that. ${ }^{16, p .109}$

Skilled nursing jobs should be done by the nursing staff, and the nurturing and comforting and the unskilled jobs, like bathing and changing, left to the parents. ${ }^{47, p .34}$

Parents should not take on 'nursing' responsibilities, as they need to focus on the child, not the nursing tasks. ${ }^{47, p .34}$ 
The clear demarcation between parental and nursing roles was blurred in longer stay and chronic illness. $(\mathrm{U})$

I think probably the length of time they have been in... I mean, you wouldn't instantly expect a child that came in very ill, being tube-fed, for the mum to instantly tube-feed the child, but after they've been in for a week and things are stable the you start expecting the parents to participate in care. ${ }^{16, p .143}$

I don't believe we should involve parents [in nursing duties] unless it's teaching them something for when they go out of the hospital environment. ${ }^{47, p .34}$

[The] first time, when we want to instruct them about [the] nebulizer, they feel that we want to shift our responsibilities to them. But, when they come to [the] ward [the] second time, they saw [sic] that they must perform it at home. Therefore, we had been a trainer for them. Now, if we leave it for them to do, they never complain.$^{50, p .224}$

Nurses felt parents willing to do basic care but some were reluctant to perform nursing care. (U)

They complain, Why should this be the case? They say, Haven't we paid?... These are your duties. $^{50, p .224}$

Nurses stressed importance of nurses performing nursing roles and tasks and retaining their professional role; they expressed concerns regarding role erosion. (U)

Things are being taken away from us and handed over to the parents. ${ }^{47, p .34}$

We cannot expect parents to take on our role as nurses... nurses have to continue to be nurses. ${ }^{47, p .34}$

Nurse the 'knowledge experts' in providing nursing care for sick children. (U)

Nurses just go and do things because sometimes nurses know best and kids are better with nursing staff than they are with parents. ${ }^{47, p .34}$

....as nurses we can't lose the skills we trained for... the parents are there to support the child... I mean they can be involved but not take away our role. ${ }^{47,3.34}$

Nurses' accountability for care an issue. (U)

I wouldn't encourage parents to be giving drugs and things like that... because if anything goes wrong l'm the one who takes the rap. ${ }^{47, p .34}$

Some nurses do not support parental presence during painful procedures as they believe the child and parent will get more distressed. (U)

When [the] mother is present at the time of venipuncture, either the child becomes more restless, as he wants to go to the mother's arm, or shows more reaction... not only [is] the mother ... agitated, but we also feel ... under more stress. ${ }^{50, \text { p. } 223}$

\section{Synthesis 8: Engaging parents in their child's care}

\begin{tabular}{|l|}
\hline \multicolumn{1}{|c|}{ Findings and illustrations } \\
\hline Temporal element and timing important if to be successful. (U) \\
It's the way they react to the initial injury that makes you think, right they've accepted this and \\
this is how they go from here... because if they haven't understood what's happened, you can't \\
teach them something to put an input into what you're trying to do. ${ }^{6, \text { pp. } 105-6}$ \\
The parents seemed to drop the barrier. I felt they both felt guilty and inadequate as the child \\
was in hospital thinking it was their fault.
\end{tabular}

Watts et al. Family-centered care for hospitalized children aged 0-12 years: a systematic review of qualitative studies (C) the authors 2014 doi:10.11124/jbisrir-2014-1683 


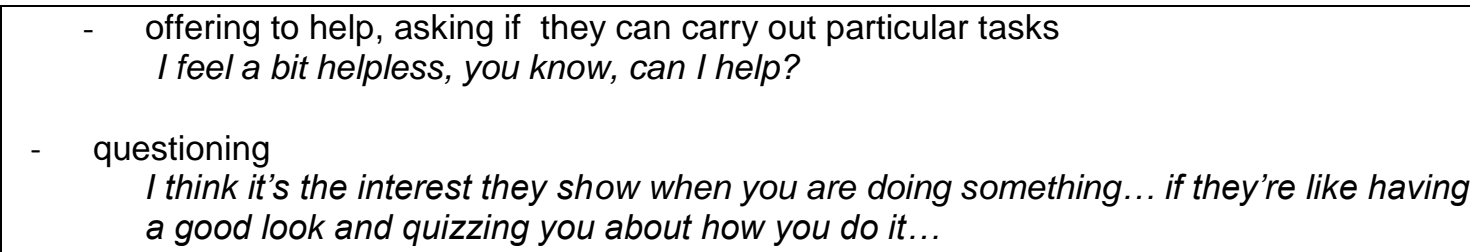

- $\quad$ level and style of interaction with their child

... the way they handle their own child, whether or not they seem very close to it and want to be with it...

- $\quad$ perception of parent competence - give impression of understanding

The ones that understand what you're doing, you know if you are trying to explain something and the parents' don't seem to be taking it in then there's no use in asking them to do a certain procedure. ${ }^{16, p p .106-7}$

Importance of building a relationship (U)

Try and build a relationship with both parents, not talking about medical conditions, but talk on a lighter subject. ${ }^{41, \text { p. }} 779$

Introducing and clarifying the roles (U)

All families and parents are different and some parents want to participate in all the caring for the child and others do not. Some of them are afraid of doing the usual caring for their child when they are in hospital; they think we must do everything while other parents act like they were at home. It is best for the child if the parents are involved in caring for the child. Nurses are responsible for creating a clarity which benefits the collaboration with the child and family. ${ }^{26}$ ,p.39

[I] introduced myself as the nurse who was looking after the child and asked her if she would like to assist me in washing and changing him, as this was necessary. ${ }^{41, \mathrm{p} .779}$

[I]explained the importance and significance of the mother's continued involvement in the child's care in view of the child's age (3 years) and because she has to continue to manage the situation at home in the future. ${ }^{41, p .778}$

I think I would be asking her to stay. Because ultimately she... well she would probably want to anyway. I mean, I would say most mothers want to stay with their children when they are not well. The fact that she has got those other kids that the husband can look after, she doesn't even have to have a husband; her friends can look after them. Any mother would make the priority judgment with it. Putting me in her position rather than Malcolm's position I would want to stay, and I would find that I would go into some crisis-management mode to organize some child care somehow. ${ }^{45, \text { p. } 210}$

We had a girl on our ward that was involved in a road traffic accident. Her mother was very reluctant to be fully involved in her care. The mother was encouraged to participate in her daughter's care by being asked if she would like to change her, but obviously at first with some assistance from the nurse so that mother could see what her daughter could actually do for herself Other members of the rehabilitation team were involved in encouraging mother to assist in lifting techniques. ${ }^{41, p .778}$

Encouraged parents to familiarize themselves with the ward, e.g. kitchen area, linen rooms, and talked to parents, constantly reassuring and encouraging them to try and carry out his care as they would at home. ${ }^{41, p .778}$ 
Progressing the care partnership (U)

Just making sure that parents and support personnel are actually involved in the treatment and management and that they are present. ${ }^{45, p .208}$

After 2 days the mother was obviously more relaxed about her daughter and began to ask about simple nursing duties, how to do them, is it alright for her to do them (mainly in the giving of IV medications). ${ }^{41, p .778}$

Basic hygiene needs required no new skills for mum but it was discussed with her and medical staff and she was supervised and taught how to give IV medications until it was felt she was at a level competent enough to give them at home without supervision. ${ }^{41, p .778}$

Trust in parents' ability to do complex care depended on a nurse's experience. (U) I always ask my colleagues [to] do complex nursing care themselves because, when a mother states that she can do feeding by NG [nasogastric] tube, it should not be taken at face value... But, most [of] our nurses are inexperienced, so they believe [the] mothers' claim. I never let mothers do these kinds of nursing care unless under my supervision. ${ }^{50, p .} 224$

Parents' involvement may be to the exclusion of their own health. (U)

...tactfully encouraged her to try and get some rest, told her there was adequate staff to look after her son whilst in hospital, and reassure her we were happy to care for him and did not think badly of her for going. ${ }^{41, p .778}(\mathrm{U})$

Negotiating care between parents and staff $(\mathrm{U})$

Ward policy was to clean Hickman line with Mediswabs when giving IV drugs. Parents expressed verbally they preferred using Ind Meths $70 \%$ spray as well and seemed uneasy if nurses used Mediswabs. When giving IV drugs parents were asked to spray line as they preferred and to clean the line before nurse gave IV drugs ${ }^{41, p .779}$

Protecting parents from stress $(\mathrm{U})$

I asked "would one of you like to come in"... but by the looks on their faces, they were scared stiff. So I said l'll just bring him back to you when it's over, for a cuddle. ${ }^{47, p .35}$

If a child is going to die I want to protect them (parents) for it, instead of saying yes it may happen. ${ }^{47, p .35}$

Sometimes I ask parents to leave because it is easier for them and the child to cope..$^{47,0.35}$

Importance of keeping parents informed (U)

I think the most important thing for the children in hospital is just to keep everybody, the child and parents or whoever the main carers are as fully informed as possible in every aspect. I think professional judgment is going to play a major part in information that you think the parents are going to want and how you offer them that. I think you have got to establish that. Again, if they want to know everything, tell them everything. I think it is important that you can have time with the parents and particularly when you admit them. That is going to give them the first impression of the ward and if you give them some time then they will think that you have time to stay there and they won't feel badly about asking. ${ }^{45, \mathrm{p} .207}$

The need to inform and explain to the parents the child's condition or procedure to be performed. (U)

You have to inform parents to confirm that they are with you, they know what is going to happen. If you do not have the parents with you, you will not be able to get this blood sample from the child. $26,0.39$

[I] sat down and explained about febrile convulsions; let her read the cooling chart and how to deal with febrile convulsion. Also explained that the child was not seriously ill and could be treated normally. $41, \mathrm{p} .778$

Watts et al. Family-centered care for hospitalized children aged 0-12 years: a systematic review of qualitative studies (C) the authors 2014 doi:10.11124/jbisrir-2014-1683 


\section{We're often under time pressure and understaffed so it isn't always possible to explain procedures. $^{47, p .35}$}

Need to explain to parents the expectations of them in regard to hospital, ward and professional policies. (U)

[I]told the mother that she would need to get special permission from the anesthetist and that she would need to change into theatre clothing. I also explained the procedure in the anesthetic room to check she would be able to cope. ${ }^{41, p .778}$

Acknowledgement that parents do not always absorb the information provided. (U) ... you know, if you are trying to explain something and the parents' don't seem to be taking it in then there's no use in asking them to do a certain procedure. ${ }^{16, p .107}$

Insufficient information can adversely affect care. (U)

Once the child is NPO the 4-5Kg child should have 60-70cc I.V. fluid ... The mother thinks that the more her baby takes of the serum the sooner he will be better. This is because of the shortcomings in our training for parents ... she increased the flow two or three times faster ...well, this would adversely affect the child. ${ }^{50, p .225}$

HCPs spoke more about their role as information-giver and comparatively less about their role as a caring person, collaborator and helper. (C)

I think, again, it's finding the time to really sit down with them and talk about, you know, what they already know about their child. Provide them with information options and help them narrow it down... They are overwhelmed by the information. ${ }^{9, p .78}$

We want to provide enough information for parents so that they feel empowered around making decisions for care for their child. ${ }^{9, p .78}$

Nurses acted as a communication conduit between medical officers and the child and parents e.g. translating medical jargon into laypersons' language and checking parents' understanding of child's condition and care requirement. (U)

It's up to us to keep the parents fully informed... acting as an interpreter between the doctor and the family. ${ }^{47, p .34}$

Cultural considerations were more likely to be taken into account in some countries than others; this may have been influenced by the prevailing culture of dominance of the medical profession in the latter countries. (U)

... the Aboriginal and Islander liaison nurse... seek advice from her... make sure accommodation is provided for them. We had this situation not very long ago and mum was absolutely terrified, would not get in the elevator, had to walk down the stairs, would not eat, would not go and have breaks away from her child so just respect that. You know, if we were... taken out of our place and go to another place well, I would probably be really frightened... so... if she needs four uncles and her, this other lady that they call mum too, to um, you know, be her support network while they're down here well so be it, yeh, familycentered care - it doesn't have to be you know, the nuclear family, whoever they describe as family is their family - try and get somebody in that's got a bit of insight into what's happening. $45, \mathrm{p} .208$

The cultural, different culture which means lots of factors need to be kept, taken into consideration with regard to the family. The staff involved should have an understanding of what the culture of the family is and their wishes should be adhered to according to diet and religious needs and there are issues that are different. Therefore, the aunt may want to stay with him permanently at the bedside which is all right. ${ }^{45, \mathrm{p} .208}$

HCPs spoke of their admiration for the persistence of parents of children with long term conditions in dealing with 'the system'. (U)

Especially when they have very, very difficult children that aren't actually very likeable children some of them, you know... But the parents really make up for that because they are such upbeat, great people, and they have 3 or 4 other wonderful kids. They are just doing so, you're

Watts et al. Family-centered care for hospitalized children aged 0-12 years: a systematic review of qualitative studies (C) the authors 2014 doi:10.11124/jbisrir-2014-1683 
just so amazed at their energy and uh, their ability to keep going to the next teacher, the next government person, the next whatever. ${ }^{9, p .78}$

\title{
Synthesis 9: Barriers to the implementation of FCC
}

\begin{abstract}
Findings and illustrations
Time constraints, staff shortages, heavy workloads impacted on nurses' ability to give sufficient time to each family. (U)

When it's really busy it's hard to be able to spend time with them [parents], teaching them things. ${ }^{47, p .35}$

I would like to have more time to spend with the child and the family, but it is impossible, there are too many other administrative tasks that we have to do. ${ }^{26, p .39}$

In a very busy ward it's easier to do it yourself... it's a time frame thing. ${ }^{47, \mathrm{p} .35}$

Often busy/short staffed in an acute situation therefore don't necessarily have the time. ${ }^{48, p .79}$

Time allocated to care is limited. We do the best to our ability and the length of stay on each admission. Parents are usually very stressed. ${ }^{48, \text { p.79 }}$

Nurses believed they were too busy to assist parents with aspects not directly related to the child's care. (U)

I feel families require more time with staff, more information sessions and a private venue allocated for such times. Time and staff are issues. ${ }^{48, p .78}$
\end{abstract}

The 'unspoken arrangement' - nurses shared parents' perception that participation was rarely discussed at the outset. (U)

We expect then to carry on the daily care... washing, feeding the... and basically you expect them to do it, but it's never said to them. ${ }^{16,111}$

Most of the nurses stated that they left the parents to get on with it and to learn about expectations over time.

It's not [the] mother's duty, but they learn through experience during [the] child's

hospitalization... The moment they come to the hospital, they become self-learners... ${ }^{50, p .224}$

Lack of organizational support and infrastructure. (U)

Little experience in children's care - but huge organizational expectation that children are 'just little adults' and can be nursed in an adult unit - maybe near elderly people. Hospital

managers should be targeted to provide appropriate time for care of children but of course, this does come back to funding so one needs to look at... government funding. ${ }^{48, p .79}$

No area to include parents in the hospital as ward too small, often in way - space issue. ${ }^{48, p .79}$

The night sisters had said mums weren't allowed in the kitchen, even to make toast, but that isn't why I did it (refused permission). ${ }^{16, \text { p.138 }}$

Individual nurses reported a lack of knowledge, education and experience. (U)

Not enough education given to staff to deal with social problems. ${ }^{4, \text { p.79 }}$

Need understanding of parental support related to wellbeing of child. ${ }^{48, p .88}$

...lack of knowledge regarding rights and needs of parents and children. ${ }^{48, p .88}$

There is not enough evaluation of staff practices or ongoing education for staff at any of the last three rural hospitals I have worked in over the last 20 years. I must rely on self-directed learning practices and the occasional agency $R N$ who is updated in pediatric care to give advice and direction for same. ${ }^{48, p .88}$

Watts et al. Family-centered care for hospitalized children aged 0-12 years: a systematic review of qualitative studies (C) the authors 2014 doi:10.11124/jbisrir-2014-1683 
Differences were identified between experienced and less experienced nurses in relating to parents. Role insecurity prevents competent addressing of parent questions, education and anxiety. (U)

I'll hear sometimes nurses say that parents could be demanding; there are no demanding parents. A parent who is worried has always to be taken seriously. If you are a young and inexperienced nurse, parents can appear to be demanding, it can be difficult as a young nurse with emotions between child and parents. ${ }^{26, p .40}$

If I am secure in my role as a nurse, it is easier to concentrate more on the relationship with the family. ${ }^{26, p .40}$

The younger nurses act more like friends to the parents, when the parents like to talk more seriously, they usually come to me. ${ }^{26, p .40}$

Narrative: Impact of family-centered care on nursing

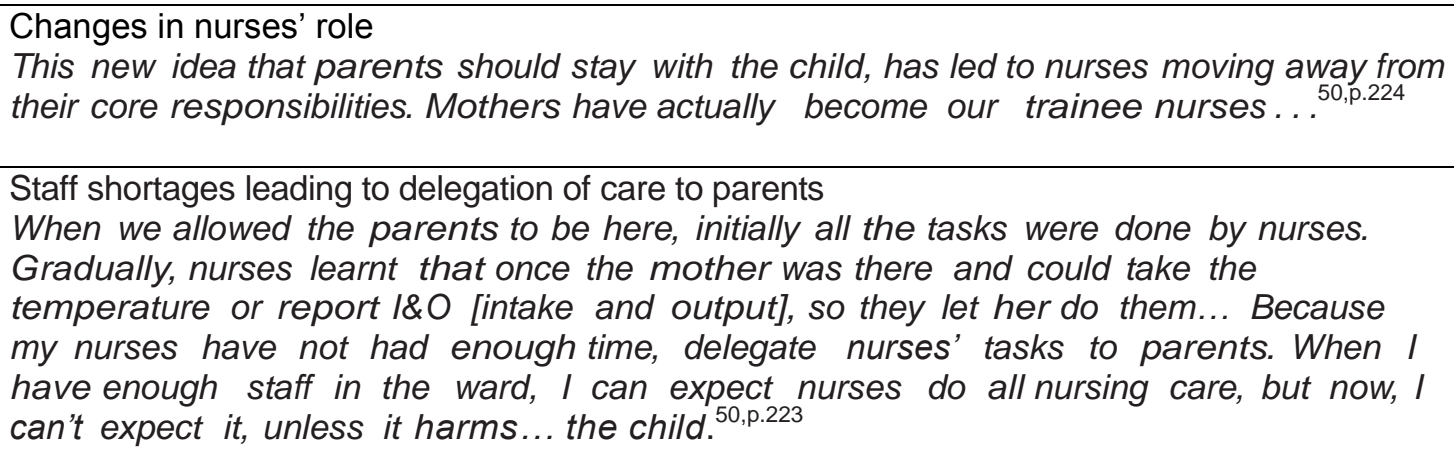

